Efeitos neuroprotetores do canabidiol em modelo experimental de hemorragia da matriz germinativa

\author{
Ribeirão Preto - SP
}




\section{Efeitos neuroprotetores do canabidiol em modelo experimental de hemorragia da matriz germinativa}

\section{TIMÓTEO ABRANTES DE LACERDA ALMEIDA}

Tese apresentada ao Programa de Pós-Graduação em Clínica Cirúrgica da Faculdade de Medicina de Ribeirão Preto da Universidade de São Paulo, para obtenção do título de doutor em Medicina. "Versão corrigida. A versão original encontra-se disponível tanto na Biblioteca da Unidade que aloja o Programa, quanto na Biblioteca Digital de Teses e Dissertações da USP (BDTD)"

Área de concentração: Clínica Cirúrgica

Orientador: Professor Dr. Hélio Rubens Machado

Ribeirão Preto - SP 
Autorizo a reprodução e divulgação total ou parcial deste trabalho, por qualquer meio convencional ou eletrônico, para fins de estudo e pesquisa, desde que citada a fonte.

FICHA CATALOGRÁFICA

Abrantes de Lacerda Almeida, Timóteo

Efeitos neuroprotetores do canabidiol em modelo experimental de hemorragia da matriz germinativa. Ribeirão Preto, 2020. Versão corrigida.

102 p.: il. color; $30 \mathrm{~cm}$

Tese de Doutorado, apresentada à Faculdade de Medicina de Ribeirão Preto, USP. Área de concentração: Clínica Cirúrgica.

Orientador: Professor Dr. Hélio Rubens Machado.

1. Hemorragia da matriz germinativa; 2. hemorragia da prematuridade; 3 . canabidiol; 4 . neuroproteção; 5 . inflamação. 


\section{FOLHA DE APROVAÇÃo}

Timóteo Abrantes de Lacerda Almeida: "Efeitos neuroprotetores do canabidiol em modelo experimental de hemorragia da matriz germinativa"

Tese apresentada ao Programa de Pós-Graduação em Clínica Cirúrgica da Faculdade de Medicina de Ribeirão Preto da Universidade de São Paulo, para obtenção do título de doutor em Medicina.

Área de concentração: Clínica Cirúrgica

Orientador: Professor Dr. Hélio Rubens Machado

Aprovado em: 6 de Dezembro de 2019

\section{Banca examinadora}

Prof. Dr. Instituição:

Julgamento: Assinatura:

Prof. Dr. Instituição:

Julgamento: Assinatura:

Prof. Dr. Instituição:

Julgamento: Assinatura:

Prof. Dr. Instituição:

Julgamento: Assinatura: 


\section{DEDICATÓRIA}

\section{Para minha esposa, Gunjan}

"Te amo sin saber cómo, ni cuándo, ni de dónde, te amo directamente sin problemas ni orgullo: así te amo porque no sé amar de otra manera,

Sino así de este modo en que no soy ni eres, tan cerca que tu mano sobre mi pecho es mía, tan cerca que se cierran tus ojos con mi sueño."

Pablo Neruda 


\section{AGRADECIMENTOS}

Aos meus pais, pelo amor incondicional e incentivo constante durante toda minha trajetória acadêmica. Pelos seus incontáveis conselhos; pela mão firme e ombro amigo.

Ao professor e mentor Dr. Hélio Rúbens Machado que me recebeu como fellow na divisão de neurocirurgia pediátrica e acreditou nesse trabalho. Serei sempre grato por seus ensinamentos.

Ao professor Dr. Marcelo Volpon, pela amizade e pelos conselhos ao longo dos últimos anos. Sua ajuda tornou essa jornada mais fácil.

À professora Dra. Luiza Lopes, pela paciência e cuidado no trabalho junto ao laboratório de neurocirurgia pediátrica.

Aos amigos Stephanya Silva, Pâmella Beggiora, Gustavo Sampaio, Ivair Matias, Ricardo Brandão, Renato Freitas, Priscila Medeiro e Camila Araújo. A alegria e a companhia de vocês fizeram as longas horas de trabalho parecerem mais leves.

Aos técnicos Sandra, George, Maria Cecília e Izilda pela ajuda e ensinamentos quanto as diversas técnicas bioquímicas, histológicas e imuno-histoquímicas. 
"Far better is it to dare mighty things, to win glorious triumphs, even though checkered by failure... than to take rank with those poor spirits who neither enjoy nor suffer much, because they live in the gray twilight that knows neither victory nor defeat."

Theodore Roosevelt 


\section{RESUMO}

Almeida TAL. Efeitos neuroprotetores do canabidiol em modelo experimental de hemorragia da matiz germinativa [tese]. Faculdade de Medicina de Ribeirão Preto, Universidade de São Paulo; 2019.

Introdução. Com o aumento na sobrevida de recém-nascidos prematuros, a hemorragia da matriz germinativa tornou-se um importante problema de saúde pública. No entanto, estratégias para o manejo da lesão neuronal direta, decorrente da hemorragia da matriz germinativa, ainda são escassas. O presente estudo tem por objetivo analizar a atividade neuroprotetora do canabidiol em modelo experimental de hemorragia da matriz germinativa. Métodos. 152 ratos Wistar com 7 dias de vida (P7) foram submetidos a modelo experimental de hemorragia da matriz germinativa com colagenase. Intensidade de resposta inflamatória e morte neuronal foram analisadas na zona perilesional e na região de CA1 do hipocampo ipsilateral. Imuno-histoquímica com marcação de GFAP e caspase 3 foi utilizada. Dosagem de malondialdeído foi utilizada para análise da intensidade do estresse oxidativo após lesão hemorrágica. Análise do conteúdo de água livre por técnica de liofilização foi utilizada para estimação de edema cerebral. Resultados. Evidenciamos redução da astrocitose reacional na zona perilesional, tanto 24 horas como 14 dias após injúria hemorrágica $(\mathrm{p}<0,001)$ nos animais tratados com canabidiol. $\mathrm{O}$ mesmo foi visualizado na região do Stratum oriens do hipocampo ipsilateral 14 dias após indução da hemorragia $(\mathrm{p}<0,05)$. Além disso, percebemos uma diminuição significativa no número de células marcadas com caspase 3 na zona perilesional 24 horas após a hemorragia $(\mathrm{p}<0.001)$. O tratamento com canabidiol foi também acompanhado de aumento significativo do ganho ponderal. Conclusão. O tratamento da hemorragia da matriz germinativa com canabidiol reduziu significativamente o número de células em apoptose e da astrocitose reacional na área perilesional e no hipocampo. Observamos ainda que essa resposta foi sustentada 14 dias após a lesão hemorrágica. Esses resultados corroboram nossa hipótese de que o canabidiol apresenta potencial como agente neuroprotetor na hemorragia da matriz germinativa.

Palavras-chave: 1. Hemorragia da matriz germinativa. 2. Hemorragia da prematuridade. 3. Canabidiol. 4. Neuroproteção. 5. Inflamação. 


\begin{abstract}
Almeida TAL. Neuroprotective effects of cannabidiol in an experimental model of germinal matrix hemorrhage [doctoral thesis]. Faculdade de Medicina de Ribeirão Preto, Universidade de São Paulo; 2019.

Introduction. As the survival of preterm infants has increased significantly, germinal matrix hemorrhage (GMH) has become an important public health issue. Nevertheless, treatment strategies for direct neuronal injury are still scarce. The present study aims to analyze the neuroprotective properties of cannabidiol in the germinal matrix hemorrhage. Methods. 152 Wistar rat pups (P7) were submitted to an experimental collagenase induced model of GMH. Inflammatory response and neuronal death were analyzed both at the perilesional area as at the distant ipsilateral CA1 hippocampal area. Immunohistochemistry for GFAP and caspase 3 was used. Malondialdehyde level was measured for analysis of the oxidative stress after the hemorrhage, and the ipsilateral free water content was assessed for estimation of cerebral edema, and neurodevelopment and neurofunctional tests were conducted. Results. Reduction of reactive astrocytosis was observed both in the perilesional area 24 hours and 14 days after the hemorrhage lesion $(\mathrm{p}<0.001)$ and in the Stratum oriens of the ipsilateral hippocampal CA1 14 days after the hemorrhage lesion $(\mathrm{p}$ $<0.05)$ in the treated groups. Similarly, there was a reduction in the number of Caspase 3-positive astrocytes in the perilesional area in the treated groups 24 hours after the hemorrhage lesion ( $\mathrm{p}<$ 0.001). Finally, we found a significant increase in the weight of the rats treated with cannabidiol. Conclusion. The treatment of GMH with cannabidiol significantly reduced the number of apoptotic cells and reactive astrocytes in the perilesional area and the ipsilateral hippocampus. Also, this response was sustained 14 days after the hemorrhage. These results corroborate our hypothesis that cannabidiol is a potential neuroprotective agent in the treatment of germinal matrix hemorrhage.
\end{abstract}

Key words: 1. Germinal matrix hemorrhage. 2. Prematurity. 3. Cannabidiol. 4. Neuroprotection. 5. Inflammation. 


\section{LISTA DE FIGURAS}

Figura 1 - Esquema da divisão dos animais em grupos e subgrupos

Figura 2 - Posicionamento de rato neonato (P7) em aparelho de estereotaxia, durante procedimento cirúrgico para alização de modelo experimental de HMG.

Figura 3 - Ilustração dos testes neurofuncionais realizados. Canto superior esquerdo, teste de endireitamento; canto supperior direito, teste de reconhecimento de objetos; canto inferior esquerdo, teste de geotaxia negativa; canto inferior direito, open field. 36

Figura 4 - Boxplot do peso (em gramas) dos animais no dia da indução da hemorragia (P7)

Figura 5 - Fotografias de campos peri-hemorrágicos marcados para GFAP (400x); A e B, campos aleatórios de animal do grupo Controle; $\mathrm{C}$ e D, campos aleatórios de aminal do grupo Canabidiol $10 \mathrm{mg}$....

Figura 6 - Boxplot da quantidade de células GFAP+ (por campo de 0,052 $\mathrm{mm}^{2}$ ) na periferia lesional 24 horas após hemorragia .................................................. 44

Figura 7 - Fotografias de campo peri-hemorrágicos marcados para Caspase 3 (400x); A e B, campos aleatórios de animal do grupo Controle (células Caspase 3 positivas identificadas por círculos vermelhos); C e D, campos aleatórios de aminal do grupo Canabidiol $10 \mathrm{mg}$.

Figura 8 - Boxplot da quantidade de células Caspase 3 positivas (por campo de 0,052 $\mathrm{mm}^{2}$ ) na periferia lesional 24 horas após hemorragia.

Figura 9 - Boxplot da quantidade de células GFAP positivas (por campo de 0,052 $\mathrm{mm}^{2}$ ) em topografia dos núcleos da base 14 dias após hemorragia

Figura 10 - Boxplot da quantidade de células Caspase 3 positivas (por campo de 0,052 $\mathrm{mm}^{2}$ ) em topografia dos núcleos da base 14 dias após hemorragia. 48

Figura 11 - Fotografia da região CA1 do hipocampo ipsilateral (A, 100x) e do Stratum oriens de aminal do grupo Canabidiol $10 \mathrm{mg}(\mathrm{B}, 400 \mathrm{x})$ e de animal do grupo Controle (C, 400x) 14 dias após hemorragia. Setas: élulas GFAP positivas. SLM $=$ Stratum lacunosummoleculare; $\mathrm{SO}=$ Stratum oriens; $\mathrm{SP}=$ Stratum pyramidale $; \mathrm{SR}=$ Stratum radiatum .

Figura 12 - Boxplot da quantidade de células GFAP positivas (por campo de 0,052 $\mathrm{mm}^{2}$ ) no Stratum oriens da região de CA1 14 dias após hemorragia

Figura 13 - Boxplot da quantidade de células Caspase 3 positivas (por campo de 0,052 $\mathrm{mm}^{2}$ ) no Stratum oriens da região de CA1 do hipocampo direito 14 dias após hemorragia

Figura 14 - Fotografia da região de corpo caloso na linha média 14 dias após hemorragia em três espécimes diferentes demonstrando o local de mensuração da espessura

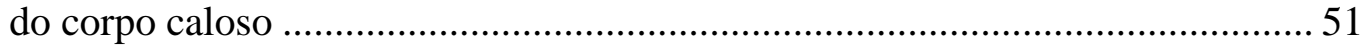

Figura 15 - Boxplot da espessura do corpo caloso (em mm) 14 dias após hemorragia ...... 51

Figura 16 - Boxplot da porcentagem de água livre no hemisfério cerebral ipsilateral 24 horas após hemorragia

Figura 17 - Boxplot da dosagem de MDA (em $\mu \mathrm{M} / \mathrm{mg}$ de proteína) no hemisfério cerebral ipsilateral 24 horas após hemorragia... 
Figura 18 - Curvas de ganho ponderal (em gramas) após indução da hemorragia, por

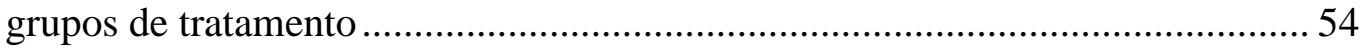

Figura 19 - Boxplot do tempo (em segundos) para realização de teste de endireitamento

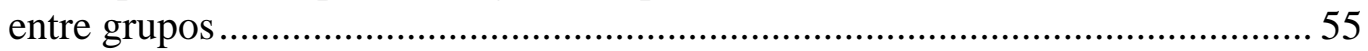

Figura 20 - Boxplot do tempo (em segundos) para realização de teste de geotaxia negativa

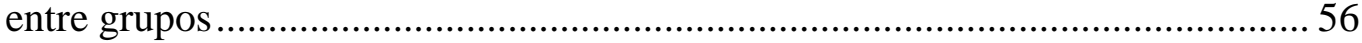

Figura 21 - Porcentagem de tempo gasto na região periférica durante o teste open field... 57

Figura 22 - Frequência de cruzamentos durante o teste open field ..................................... 57

Figura 23 - Frequência de asseio durante o teste open field............................................... 58

Figura 24 - Frequência de soerguimento durante teste open field.................................... 58

Figura 25 - Boxplot do coeficiente de sequências lógicas durante teste em labirinto em Y 59

Figura 26 - Boxplot da porcentagem de tempo gasto na exploração do objeto novo entre os grupos Controle, Canabidiol 10 mg, Pré-tratamento e SHAM ........................... 60 


\section{LISTA DE TABELAS}

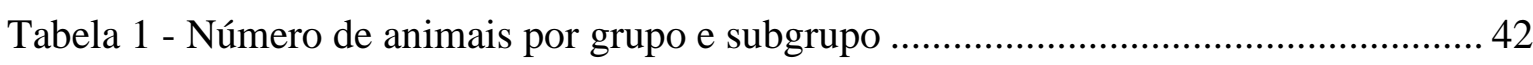


LISTA DE SIGLAS E ABREVIATURAS

\begin{tabular}{l|l}
\hline COX & Ciclo-oxigenase \\
\hline ERK & Quinases mediadas por sinal extracelular \\
\hline FN & Fator nuclear \\
\hline GFAP & Proteína glial fibrilar ácida \\
\hline HMG & Hemorragia da matriz germinativa \\
\hline IL & Interleucina \\
\hline INF & Interferon \\
\hline MCP & Proteína de quimiotaxia monocitária \\
\hline MDA & Malondialdeído \\
\hline MIP & Proteína inflamatória de macrófagos \\
\hline ON & Óxido nítrico \\
\hline PBS & Salina tamponada com fosfato \\
\hline PG & Prostaglandina \\
\hline TGF & Fator de transformação do crescimento \\
\hline TNF & Fator de necrose tumoral \\
\hline USP & Universidade de São Paulo \\
\hline
\end{tabular}




\section{SUMÁRIO}

1 INTRODUÇÃO 17

$\begin{array}{lll}1.1 \text { Hipóteses } & 17\end{array}$

1.2 Objetivos 18

1.2.1 Objetivo geral 18

1.2.2 Objetivos específicos 18

2 REVISÃO DA LITERATURA

2.1 Mecanismos de lesão cerebral secundária 21

2.2 Mediadores da neuroinflamação $\quad 22$

2.3 Propriedades farmacológicas do canabidiol 23

2.4 Canabinóides em modelos de hemorragia da matriz germinativa 26

2.5 Modelos experimentais de hemorragia da matriz germinativa 26

3 METODOLOGIA 29

3.1 Delineamento geral do estudo 29

3.2 Local do estudo 29

3.3 Considerações éticas 29

3.4 População do estudo 30

3.5 Anestesia e preparo dos animais

3.6 Canabidiol 33

3.7 Método de eutanásia dos animais 33

3.8 Avaliação neurofuncional 34

3.8.1 Reflexo de endireitamento 34

3.8.2 Geotaxia negativa $\quad 34$

3.8.3 Teste das funções sensoriais e motoras $\quad 34$

3.8.4 Teste de retenção de memória e aprendizado 35

3.9 Análise histológica e do estresse oxidativo 36

3.10 Análise do conteúdo de água livre 38

3.11 Documentação de imagens 38

3.12 Análise de dados 37

4 RESULTADOS

4.1 Animais operados 41

4.2 Avaliação histológica 43

4.2.1 Análise quantitativa de astrócitos GFAP 24 horas após hemorragia 43

4.2.2 Análise quantitativa de astrócitos caspase $3^{+} 24$ horas após hemorragia 45

4.2.3 Análise quantitativa de astrócitos GFAP $^{+}$na região dos núcleos da base 14 dias após hemorragia $\quad 47$

4.2.4 Análise quantitativa de astrócitos caspase $3^{+}$na região dos núcleos da base 14 dias após hemorragia 
4.2.5 Análise quantitativa de astrócitos $G F A P^{+}$no Stratum oriens da região de CA1 do hipocampo direito 14 dias após hemorragia

4.2.6 Análise quantitativa de astrócitos caspase $3^{+}$no Stratum oriens da região de CA1 do hipocampo direito 14 dias após hemorragia

4.2.7 Análise da espessura do corpo caloso na linha média 14 dias após hemorragia $\quad 50$

4.3 Análise da porcentagem de água livre cerebral 52

4.4 Análise de estresse oxidativo por expressão de MDA 53

4.5 Avaliação neurofuncional 54

4.5.1 Ganho ponderal 54

4.5.2 Desenvolvimento neuropsicomotor 55

4.5.3 Open field 57

4.5.4 Labirinto em $Y \quad 59$

4.5.5 Teste de reconhecimento de objetos 60

5 DISCUSSÃO

6 CONCLUSÃO

REFERÊNCIAS

ANEXOS

Anexo A. $\quad$ Certificado de aprovação da Comissão de Ética no Uso de Animais

80

APÊNDICES

Apêndice A. Resultados dos testes estatísticos realizados 83

Apêndice B. Artigo publicado na revista Neurological Research 100 
1. INTRODUÇÃO 


\section{INTRODUÇÃO}

Temos presenciado um aumento significativo da incidência e da sobrevida de recém-nascidos prematuros em todo o mundo nos últimos anos (LANGHOFF-ROOS et al., 2006), aumentando, por consequência, a incidência de problemas associados à prematuridade, como leucoencefalopatia e hemorragia da matriz germinativa (HMG). A prematuridade acomete aproximadamente $15 \%$ dos nascidos vivos, sendo responsável por 75\% das mortes neonatais, com grande impacto no desenvolvimento cognitivo e motor (SLATTERY; MORRISON, 2002).

Devido ao aumento na sobrevida dos recém-nascidos prematuros, a HMG tem se apresentado como um problema de saúde pública nos últimos 20 anos, com aumento da incidência de déficit cognitivo e motor, de hidrocefalia pós-hemorragia, de paralisia cerebral e de necessidades educativas especiais (SHENNAN; BEWLEY, 2006). Além disso, estratégias voltadas para o tratamento da lesão neuronal direta ainda são escassas, tendo sido estudadas diversas classes de medicações em busca de propriedades neuroprotetoras para o tratamento desses pacientes, porém somente a indometacina demonstrou pequeno efeito benéfico (FOWLIE; DAVIS, 2003).

Devido a descrição recente dos receptores canabinóides e das ações biológicas do canabidiol, os últimos anos foram marcados por um interesse progressivamente maior pelo estudo desse canabinóide e dos seus derivados sintéticos, tendo sido descritas em detalhes suas propriedades anti-inflamatórias, antioxidantes e neuroprotetoras, o que pode ser aplicado no cenário da HMG. A Faculdade de Medicina de Ribeirão Preto tem sido referência no estudo do canabidiol, com importantes contribuições para o conhecimento científico, principalmente no contexto de patologias psiquiátricas (ZUARDI, 2008).

Além disso, no melhor do nosso conhecimento, ainda não há estudos com canabidiol em modelos de HMG. Assim, com base nas propriedades acima descritas, justifica-se o estudo de possíveis efeitos neuroprotetores do canabidiol na HMG.

\subsection{Hipóteses}

O canabidiol apresenta propriedades neuroprotetoras, anti-inflamatórias e antioxidantes, capazes de reduzir a lesão tecidual perilesional secundária à HMG experimental em ratos. 
A redução da lesão tecidual secundária ao tratamento com canabidiol possibilitará uma melhor resposta neurológica em avaliação tardia, através de marcos do desenvolvimento neuropsicomotor e de memória.

\subsection{Objetivos}

\subsubsection{Objetivo geral}

Verificar a ação do canabidiol como potencial neuroprotetor em modelo experimental de HMG.

\subsubsection{Objetivos específicos}

Verificar a ação do canabidiol na viabilidade neuronal na zona perilesional em modelo de HMG, através de estudos histológicos e imuno-histoquímicos.

Avaliar o efeito dose dependente do canabidiol em modelo de HMG, através da comparação do efeito do canabidiol nas doses de 1 e $10 \mathrm{mg} / \mathrm{Kg}$.

Verificar o efeito do canabidiol no edema secundário ao modelo de HMG, através da diferença do peso seco e molhado do tecido cerebral.

Analisar a influência do tratamento com canabidiol no estado neurofuncional em ratos jovens após modelo de HMG, através da avaliação de marcos do desenvolvimento neuropsicomotor e de testes neurofuncionais.

Avaliar a ação antioxidante do canabidiol em modelo de HMG, através da dosagem de malondialdeído (MDA) no parênquima cerebral.

Verificar o efeito do canabidiol na espessura do corpo caloso tardiamente à lesão hemorrágica em modelo de HMG, através de análise histológica. 
2. REVISÃO DA LITERATURA 


\section{REVISÃO DA LITERATURA}

A incidência de HMG é de aproximadamente 3,5 para 1.000 nascidos vivos, tendo se mantido estável nos últimos 20 anos, após uma redução de aproximadamente $50 \%$ na década de 80 (JAIN et al., 2009). Em prematuros com peso entre 500 e 700 g, por exemplo, HMG ocorre em aproximadamente $45 \%$ dos casos (WILSON-COSTELLO et al., 2005). A patogênese da hemorragia da matriz germinativa está intrinsicamente relacionada à prematuridade e à imaturidade da vascularização da região subependimária na região da cabeça do núcleo caudado, a distúrbios do fluxo sanguíneo local e a alterações na cascata de coagulação e na atividade plaquetária (BALLABH, 2010).

Os casos de HMG são classicamente divididos segundo a classificação de Papile (PAPILE et al., 1978), conforme a morfologia da hemorragia e o comprometimento ventricular, em quatro graus: grau 1 correspondendo à hemorragia subependimária, grau 2 à hemorragia comprometendo até $50 \%$ do sistema ventricular, grau 3 à hemorragia comprometendo mais de $50 \%$ do sistema ventricular, e grau 4 aquele com hemorragia intraparenquimatosa associada, sendo também denominada infarto hemorrágico periventricular ou infarto venoso (BROUWER et al., 2014). Conjuntamente, os graus de hemorragia 3 (associado à hidrocefalia) e 4 apresentam o pior resultado neurológico a longo prazo (ADAMS-CHAPMAN et al., 2008), sendo a proporção de casos graves (graus 3 e 4 de Papile) maior quanto menor a idade gestacional e o peso do recém-nascido (BROUWER et al., 2014).

As consequências deletérias da HMG envolve a destruição tecidual periventricular, da substância branca adjacente e o desenvolvimento de hidrocefalia, consequência mais séria e que acomete até $50 \%$ dos recém-nascidos com hemorragia graus 3 e 4 de Papile (DEL BIGIO, 2011; MURPHY et al., 2002). O desenvolvimento de hidrocefalia está associado a atraso do desenvolvimento neuropsicomotor nesses pacientes, sendo o prognóstico pior nos casos com necessidade de intervenção neurocirúrgica (SRINIVASAKUMAR et al., 2013). Uma hipótese para o desenvolvimento da hidrocefalia é que a produção e liberação de fator de transformação do crescimento beta-1 (TGF- $\beta 1$ ) no espaço liquórico após o evento hemorrágico proporcione a deposição desse material no neuropilo e nos espaços perivasculares, obstruindo o sistema de reabsorção liquórica (DOUGLAS-ESCOBAR; WEISS, 2012). O comprometimento parenquimatoso também se 
mostrou fator prognóstico importante associado ao desenvolvimento de paralisia cerebral e de espasticidade (MAITRE et al., 2009).

O prejuízo no desenvolvimento neuropsicomotor desses pacientes é percebido em até $85 \%$ dos casos de hemorragia graus 3 e 4 que evoluem com déficit cognitivo, com aproximadamente $75 \%$ necessitando atendimento especial para sua educação, além de maior incidência de hidrocefalia, paralisia cerebral e retardo mental (VOHR et al., 2003). Os casos mais brandos, menos estudados e, talvez, ainda subdiagnosticados, também são susceptíveis a atraso do desenvolvimento neurológico (PINTO-MARTIN et al., 1999).

\subsection{MECANISMOS DE LESÃO CEREBRAL SECUNDÁRIA}

Após a injúria tecidual inicial, o tecido cerebral perilesional é exposto a uma série de eventos que pode levar a mais morte neuronal. Edema cerebral ocorre quase que imediatamente após o evento hemorrágico, aumenta nos dias subsequentes e apresenta, classicamente, 3 fases evolutivas. Inicialmente, o edema cerebral resulta do processo de retração do coágulo e eliminação de líquido para o tecido adjacente. Após esse momento inicial, a ativação da cascata de coagulação, e consequente formação de trombina, leva ao aumento do edema perilesional. Além de um efeito pró-inflamatório, a formação de trombina favorece a quebra da barreira hematoencefálica resultando em edema vasogênico. Em um terceiro momento, a lise celular, e consequente liberação de produtos do metabolismo eritrocitário, resultam em dano tecidual por estresse oxidativo e intoxicação por ferro, aumentando o edema perilesional (LEE et al., 1996, 1997; XI; KEEP; HOFF, 2006; YANG et al., 1994).

A importância desses mecanismos de injúria tecidual secundária é demonstrada através de estudos do efeito de massa da hemorragia cerebral em animais, nos quais um grupo submetido a modelo de hemorragia cerebral experimental foi comparado com um grupo onde o sangue autólogo era substituído por material oleaginoso, demonstrando formação de edema maior no modelo de hemorragia cerebral (SUZUKI; EBINA, 1980).

Precocemente, após o evento hemorrágico, inicia-se um processo inflamatório pela ativação microglial e astrocitária perilesional, além do afluente de complementos circulantes, resultando em infiltrado neutrofílico e ativação do sistema complemento, formação de complexo de ataque à membrana e consequente lise celular (GONG; HOFF; KEEP, 2000; JENKINS; MAXWELL; GRAHAN, 1989; XI; KEEP; HOFF, 2006). Essa 
resposta inflamatória pode ser co-responsável pelo aumento do edema nas primeiras horas e pela liberação de componentes do metabolismo do heme, através de lise de eritrócitos do hematoma.

A lise eritrocitária resulta na liberação de ferro no tecido cerebral adjacente. Apesar de classicamente ser apontado como desencadeador do edema cerebral tardio, hemoglobina e heme são encontrados no tecido perilesional e no líquor antes de 48 horas após o evento hemorrágico (MARLET; BARRETO FONSECA, 1982; WU et al., 2003). Da degradação do heme, são liberados ferro, monóxido de carbono e biliverdina no tecido perilesional (KUTTY; MAINES, 1981), desencadeando uma série de reações que culminarão na morte celular. O ferro liberado é um possível agente lesivo, através de mecanismos de interação celular direta, ou da geração de radicais livres (HALLIWELL, 1992, 1996). Além disso, o ferro livre pode causar lesão celular através da interação direta com o DNA ou através da inibição de mecanismos de reparo proteico (LI; SWIERCZ; ENGLANDER, 2009).

A geração de espécies de oxigênio reativos é o principal mecanismo pelo qual o ferro livre causa lesão celular. Como consequência, reações de oxirredução, oxidação proteica e peroxidação lipídica marcam o quadro de estresse oxidativo que, sem uma ação antioxidante efetiva, resultarão em morte celular por necrose ou apoptose (HICKENBOTTOM et al., 1999; SALVADOR, 2010), podendo causar ainda disfunção do fator nuclear kappa B $(\mathrm{FN}-\kappa \mathrm{B})$, importante na sinalização para sobrevivência celular, levando a célula a um processo de apoptose (MATTSON; MEFFERT, 2006).

\subsection{MEDIADORES DA NEUROINFLAMAÇÃO}

Células microgliais espressam mediadores inflamatórios nas injúrias cerebrais (ACARIN; GONZÁLEZ; CASTELLANO, 2000). É descrita a liberação do fator de necrose tumoral alfa (TNF- $\alpha$ ), interleucina (IL)-6, IL-8, IL-10, IL-12, IL-15, proteína de quimiotaxia monocitária 1 (MCP-1), proteína inflamatória de macrófagos (MIP)-1 $\alpha$, e MIP-1 $\beta$ por células microgliais após exposição a agentes tóxicos (LEE; NAGAI; KIM, 2002).

TNF- $\alpha$ atua como modulador inflamatório através da indução da ativação autócrina de células microgliais, estimulando a produção de TNF- $\alpha$ e outras citocinas próinflamatórias, e da formação do edema tecidual na fase de injúria aguda (HOLMIN; MATHIESEN, 2000). Em modelo de isquemia cerebral, evidenciou-se também que o 
TNF- $\alpha$ atua na facilitação da recuperação tecidual após a injúria tecidual inicial ao menos em alguns locais do sistema nervoso central (GALASSO et al., 2000). Ativação microglial ocorre de forma mais importante através da estimulação pelas IL-1 $\alpha$ e IL-1 $\beta$, o que também foi demonstrado em modelo de isquemia cerebral (CAI et al., 2004). Além disso, essas moléculas estimulam a produção de outras citocinas, de moléculas de adesão e de óxido nítrico (YANG et al., 1998). Estudos experimentais de injúria cerebral aguda apontaram a existência de citocinas que agem como neuroprotetores (como as IL-6 e IL10) através da redução da resposta inflamatória (BRAIDA et al., 2004; GRILLI et al., 2000). O efeito anti-inflamatório dessas moléculas provavelmente é secundário a inibição da IL-1ß (TILG et al., 1994).

Em estudos sobre HMG, foram descritos níveis elevados de IL-1 $\beta$, IL-6 e IL-8 (DUGGAN et al., 2001; HEEP et al., 2003; MARTINEZ et al., 1998; TAUSCHER et al., 2003). Além disso, polimorfismos na posição -308 da região promotora do $\mathrm{TNF} \alpha$ foram associados a maior risco de HMG (ADCOCK et al., 2003), o mesmo ocorrendo com polimorfismos nos genes da IL-1 $\beta$ e IL-6 (BAIER, 2006).

Enquanto é improvável que algum agente terapêutico reverta o dano neuronal inicial resultante do trauma tecidual direto pelo hematoma, diversos alvos potenciais existem na tentativa de diminuir o dano tecidual secundário e de preservar o tecido cerebral perilesional.

\subsection{PROPRIEDADES FARMACOLÓGICAS DO CANABIDIOL}

O uso medicinal da Cannabis sativa já é conhecido da humanidade desde o Império Chinês 5.000 anos A.C., sendo, provavelmente, a primeira planta domesticada pelo homem (APPENDINO; CHIANESE; TAGLIALATELA-SCAFATI, 2011). Os dois principais canabinóides presentes na Cannabis sativa são o delta9-tetrahidrocanabidiol e o canabidiol, sendo o primeiro o principal responsável pelos efeitos psicomiméticos e tendo sido bastante estudado na literatura médica, enquanto o canabidiol, considerado um agente inativo pelos testes iniciais em animais e humanos, apenas recentemente foi novamente objeto de estudo devido suas atividades biológicas (ZUARDI, 2008).

Devido a descrição recente dos receptores canabinóides e das ações biológicas do canabidiol nos últimos anos houve um interesse progressivamente maior pelo estudo desse canabinóide e dos seus derivados sintéticos (ZUARDI, 2008). Estudos experimentais 
demonstraram o potencial de redução da toxicidade glutamatérgica e a capacidade de redução do estresse oxidativo mediado pelo peróxido de hidrogênio, o que pode ser explicado pela presença do radical resorcinol na sua estrutura (APPENDINO; CHIANESE; TAGLIALATELA-SCAFATI, 2011; HAMPSON et al., 1998a).

Receptores canabinóides e de adenosina foram implicados no mecanismo de ação do canabidiol. Estudos em isquemia cerebral demonstraram atividade antiinflamatória e antioxidante, além de redução na morte neuronal, as quais foram revertidas com antagonistas de receptores CB2 e A2 (CASTILLO et al., 2010). Além de antagonistas de receptores $\mathrm{CB} 2$, antagonista de receptores $5 \mathrm{HT}_{1 \mathrm{~A}}$ também suprimiu a atividade neuroprotetora do canabidiol após injúria isquêmica (PAZOS et al., 2013).

Em estudos de neurotoxicidade secundária a receptores NMDA e AMPA/Kainato, canabidiol demonstrou atividade neuroprotetora independente de receptores canabinóides (HAMPSON et al., 1998b). A nível intracelular, canabidiol demonstrou capacidade de inibição da expressão de genes proinflamatórios e de receptores de quimiocina CX3CR1 (JUKNAT et al., 2012). Também foi demonstrada a capacidade do canabidiol de interagir na via GSK-3 $\beta$ e de ativar receptores nucleares PPAR (VALVASSORI et al., 2013).

Estudos prévios do efeito neuroprotetor em modelos de isquemia cerebral, neurotoxicidade e doenças neurodegenerativas demonstraram efeitos antiinflamatórios e antioxidantes, além da diminuição de morte neuronal após utilização do canabidiol com doses entre 1 e 10 mg/Kg (DA SILVA et al., 2014; EL-REMESSY et al., 2003; ESPOSITO et al., 2011; GARCÍA-ARENCIBIA et al., 2007a; HAYAKAWA et al., 2007; MECHA et al., 2013; PAZOS et al., 2012, 2013; SAGREDO et al., 2007).

$\mathrm{O}$ efeito neuroprotetor do canabidiol foi demonstrado em neurônios nigroestriatais em modelo de doença de Parkinson, e pela redução da atrofia estriatal secundária a toxicidade pelo ácido 3-nitropropiônico (GARCÍA-ARENCIBIA et al., 2007b; SAGREDO et al., 2007). Além disso, maior sobrevida foi observada em células pré-tratadas com canabidiol após exposição ao peptídeo $\beta$-amilóide, provavelmente através de mecanismos antioxidantes e antiapoptóticos (IUVONE et al., 2004).

A atividade anti-inflamatória do canabidiol também foi descrita em modelo de artrite reumatóide, demonstrando-se uma redução dose dependente na produção do TNF- $\alpha$ após tratamento com canabidiol, além de efeito na redução do edema e da hiperalgesia (COSTA et al., 2004; MALFAIT et al., 2000). O mecanismo proposto envolve a redução da produção de prostaglandina E2 (PGE2), da atividade da ciclo-oxigenase (COX) e da 
produção de óxido nítrico (COSTA et al., 2007). Evidência da capacidade neuroprotetora do canabidiol como anti-inflamatório e antioxidante foi demonstrado em modelo de isquemia cerebral em ratos, com maior sobrevida de neurônios hipocampais nos animais tratados, o que se mostrou independente do receptor $\mathrm{CB}_{1}$, podendo esse efeito estar relacionado ao receptor de serotonina 5-HT 1 A (BRAIDA et al., 2003; HAYAKAWA et al., 2004; RUSSO et al., 2005). Agonismo do receptor $5 \mathrm{HT}_{1 \mathrm{~A}}$ também foi demonstrado em modelo experimental em que se evidenciou aumento do fluxo sanguíneo cerebral associado ao seu efeito neuroprotetor (MISHIMA et al., 2005).

No nível molecular, o canabidiol exerce sua atividade anti-inflamatória, antioxidante e imunossupressora através da estimulação de receptores vanilóides VR1, serotoninérgicos $5 \mathrm{HT}_{1 \mathrm{~A}}$, e da inibição do receptor GPR55, além da redução da recaptação de [3H]-adenosina (ZUARDI, 2008). O canabidiol apresenta, porém, baixa afinidade pelos receptores CB1 e CB2. Recentemente, canabidiol foi descrito como agonista inverso desses receptores e indicado como provável responsável pelo mecanismo imunomodulatório, através da redução do recrutamento leucocitário (LUNN et al., 2006; THOMAS et al., 2009). A localização desses receptores também auxilia no entendimento de suas funções biológicas, bem como na elaboração de estratégias para o uso medicamentoso das substâncias canabinóides, sendo o receptor CB1 localizado predominantemente no sistema nervoso central, o receptor CB2 nas células do sistema imunológico, e o receptor GPR55 em osteoclastos e osteoblastos (APPENDINO; CHIANESE; TAGLIALATELASCAFATI, 2011).

Mais recentemente, foi sugerido que o canabidiol promoveria regulação negativa na ativação e migração de leucócitos reativos, além da redução da produção de citocinas inflamatórias e inibição da COX-2, através da interação com receptores de adenosina A2A, agindo, assim, como potente agente anti-inflamatório (CARRIER; AUCHAMPACH; HILLARD, 2006; RIBEIRO et al., 2012). O mesmo foi demonstrado em modelo de esclerose múltipla que evidenciou redução da infiltração leucocitária e da ativação microglial, além da redução do nível sérico do TNF- $\alpha$ e da IL-1 $\beta$, parcialmente mediado pelos receptores de adenosina A2A (MECHA et al., 2013). 


\subsection{CANABINÓIDES EM MODELOS DE HEMORRAGIA DA MATRIZ GERMINATIVA}

O uso de canabinóides como neuroprotetor em modelo de HMG foi recentemente investigado através de estudos utilizando agonistas seletivos do receptor CB2. O uso, por exemplo, do agonistas seletivos do receptor CB2 JWH133 foi capaz de reduzir a injúria tecidual perilesional, além de apresentar menor atrofia cortical e dilatação ventricular em fase tardia e melhor resultado nos testes neurofuncionais (TAO et al., 2015). Ao nível molecular, foi demonstrada redução da produção do TNF- $\alpha$ e da ativação microglial. $\mathrm{O}$ JWH133 é capaz de reduzir, ainda, o edema perilesional 24 horas após modelo de HMG, provavelmente pela redução do acúmulo microglial no tecido peri-hemorrágico mediado pela desfoforilação de quinases mediadas por sinal extracelular (ERK) (TANG et al., 2015). Foi demonstrado ainda redução da lesão da barreira hematoencefálica mediada por trombina em ratos tratados com JWH133, associado à redução do edema perilesional, o que foi revertido com a associação de antagonista do receptor CB2 (LI et al., 2015).

Resultados semelhantes foram demonstrados com o uso da minociclina, também um agonista seletivo CB2, em modelo de HMG em ratos (TANG et al., 2016). Nesse estudo, os autores demonstraram redução no conteúdo de água no parênquima cerebral 24 horas após a hemorragia, além da redução da atividade microglial, e diminuição da atrofia cortical e do volume ventricular 28 dias após a hemorragia. Esses efeitos foram revertidos com a associação de antagonista CB2.

Não apenas o canabidiol apresentou capacidade de redução da atividade microglial de forma geral, mas também foi demonstrado que o mesmo estimula a ativação de microglia CX3CR1 positiva, responsável por secretar fatores neurotróficos e restaurar danos aos circuitos neuronais (TANG et al., 2017). Esse grupo demonstrou a estimulação do fenótipo microglial CX3CR1 positivo em modelo experimental de HMG em ratos, resultando em restauração neuronal.

\subsection{MODELOS EXPERIMENTAIS DE HEMORRAGIA DA MATRIZ GERMINATIVA}

Vários modelos experimentais foram propostos para o estudo da HMG utilizando diferentes espécies animais e métodos para a indução da hemorragia, como pela injeção de sangue autólogo ou através do estabelecimento de estado hiperdinâmico (LEKIC et al., 
2012). Esses métodos, no entanto, apresentam limitações importantes, como o uso de animais de médio e grande porte, além de não simularem adequadamente a HMG encontrada nos pacientes prematuros.

Nesse contexto, Lekic et. al. (LEKIC et al., 2011) propuseram um modelo experimental em ratos Wistar jovens, com 7 dias de vida, através da injeção de colagenase VII na eminência gangliônica unilateral, com o auxílio de aparelho de estereotaxia para pequenos roedores. Esse mesmo grupo descreveu, posteriormente, a replicação dessa técnica em 153 ratos Wistar jovens, demonstrando a uniformidade da hemorragia gerada, simulando uma hemorragia grau 4 de Papile, bem como as alterações histológicas, o atraso do desenvolvimento neuropsicomotor, e o desenvolvimento de hidrocefalia após 30 dias (LEKIC et al., 2012).

Além desses trabalhos, essa técnica tem sido amplamente utilizada para estudos de neuroproteção em modelo de HMG (TANG et al., 2015, 2016; TAO et al., 2015). Também foi descrita uma variação dessa técnica de HMG com colagenase sem a utilização de aparelho de estereotaxia (ALLES; COSTA, 2009). 
3. METODOLOGIA 


\section{METODOLOGIA}

\subsection{DELINEAMENTO GERAL DO ESTUDO}

Estudo controlado experimental em ratos.

\subsection{LOCAL DO ESTUDO}

Os experimentos foram realizados no Laboratório de Neurocirurgia Pediátrica e Neuropatologia Experimental do Departamento de Cirurgia e Anatomia da Faculdade de Medicina de Ribeirão Preto.

\subsection{CONSIDERAÇÕES ÉTICAS}

O presente estudo observou as leis internacionais (Declaração Universal dos Direitos dos Animais, UNESCO) e nacionais (Lei 6638 de 08 de maio de 1979) no que diz respeito à utilização de animais em pesquisas científicas. O projeto foi encaminhado a Comissão de Ética no Uso de Animais da Faculdade de Medicina de Ribeirão Preto - USP e aprovado sob número de protocolo 149/2016.

A metodologia do trabalho foi desenvolvida de modo que a dor ou o sofrimento dos animais fossem reduzidos ao máximo, e que o transporte, a acomodação e os tratos com os animais fossem feitos com o mínimo estresse possível, obedecendo às normas prescritas pelo Colégio Brasileiro de Experimentação Animal. $O$ estudo foi conduzido por pesquisadores capacitados para a aplicação das técnicas experimentais nos animais.

Sedação e analgesia foram empregadas em todos os procedimentos aos quais os animais foram submetidos, para evitar seu sofrimento. $\mathrm{O}$ experimento com animais foi escolhido devido à relevância científica, pela possibilidade de disseminação do conhecimento adquirido e devido à inexistência de recursos alternativos para atender aos objetivos propostos. 


\subsection{POPULAÇÃO DO ESTUDO}

Foram utilizadas ninhadas de ratos machos da linhagem Wistar, com sete dias de vida, oriundas do Serviço de Biotério da Prefeitura do Campus Administrativo de Ribeirão Preto, em número suficiente para composição dos grupos experimentais. Cada ninhada era constituída pela rata-mãe e 8 filhotes, transportados em uma única caixa alojamento, no dia do nascimento, para o Biotério da Cirurgia Experimental do Departamento de Cirurgia e Anatomia da Faculdade de Medicina de Ribeirão Preto. Durante a permanência no Biotério, os animais foram mantidos em ambiente climatizado, com temperatura controlada em $21^{\circ} \mathrm{C}(+/-1)$, com ciclo claro-escuro de 12 horas, com água e ração ad libitum. Os filhotes em fase de desmame também tinham acesso livre a dieta e água. No período pósoperatório os filhotes operados foram mantidos com a mãe em ambiente climatizado, com temperatura controlada em $21^{\circ} \mathrm{C}(+/-1)$, com ciclo claro-escuro de 12 horas, com água e ração ad libitum.

Para o estudo, dividimos os animais em 4 grupos de 32 animais e 1 grupo de 24 animais, totalizando 152 animais. O tamanho da amostra foi estimado utilizando-se o aplicativo WinPepi (PEPI-for-Windows) e tendo por base estudos prévios com realização de cálculo amostral das médias apresentadas (LI et al., 2015; TANG et al., 2015, 2016; TAO et al., 2015). Os cinco grupos foram distribuídos da seguinte forma: (1) Grupo Controle, no qual os animais foram submetidos à indução de HMG e posteriormente administrado apenas Tween 2\% (veículo) sem canabidiol; (2) Grupo Canabidiol $1 \mathrm{mg}$, no qual os animais foram submetidos à indução de HMG e posteriormente submetidos a tratamento com canabidiol intraperitoneal na dose de $1 \mathrm{mg} / \mathrm{Kg}, 1$ hora após a indução da hemorragia, e repetido 1 vez ao dia até o abate ou até o máximo de 7 dias pós hemorragia; (3) Grupo Canabidiol $10 \mathrm{mg}$, no qual os animais foram submetidos à indução de HMG e posteriormente submetidos a tratamento com canabidiol intraperitoneal na dose de 10 $\mathrm{mg} / \mathrm{Kg}, 1$ hora após a indução da hemorragia, e repetido 1 vez ao dia até o abate ou até o máximo de 7 dias pós hemorragia; (4) Grupo Canabidiol Pré-tratamento, no qual os animais foram tratados com canabidiol intraperitoneal na dose diária de $10 \mathrm{mg} / \mathrm{Kg}$ a partir do P5 e 1 hora antes da indução da HMG, seguido de aplicação de canabidiol intraperitoneal na dose diária de $10 \mathrm{mg} / \mathrm{Kg} 1 \mathrm{vez}$ ao dia até o abate ou até o máximo de 7 dias pós hemorragia; (5) Grupo SHAM, no qual os animais foram submetidos apenas a 
agulhameto com técnica semelhante àquela para indução da hemorragia, porém sem a injeção da colagenase. As medicações foram diluídas em solução de Tween 2\%.

Cada grupo foi ainda subdividido em 4 subgrupos conforme procedimento para análise tecidual sendo: (1) eutanásia após 24 horas da indução hemorrágica para coleta de tecido cerebral para análise histológica e imuno-histoquímica, e coleta de sangue e líquor; (2) eutanásia após 24 horas da indução hemorrágica para coleta de tecido cerebral para análise do conteúdo de água cerebral, e coleta de sangue e líquor; (3) eutanásia após 24 horas da indução hemorrágica para coleta de tecido cerebral para análise do estresse oxidativo, e coleta de sangue e líquor; (4) eutanásia 14 dias após a indução hemorrágica para coleta de tecido cerebral para análise histológica e imuno-histoquímica, e para realização dos testes neurofuncionais (Figura 1).

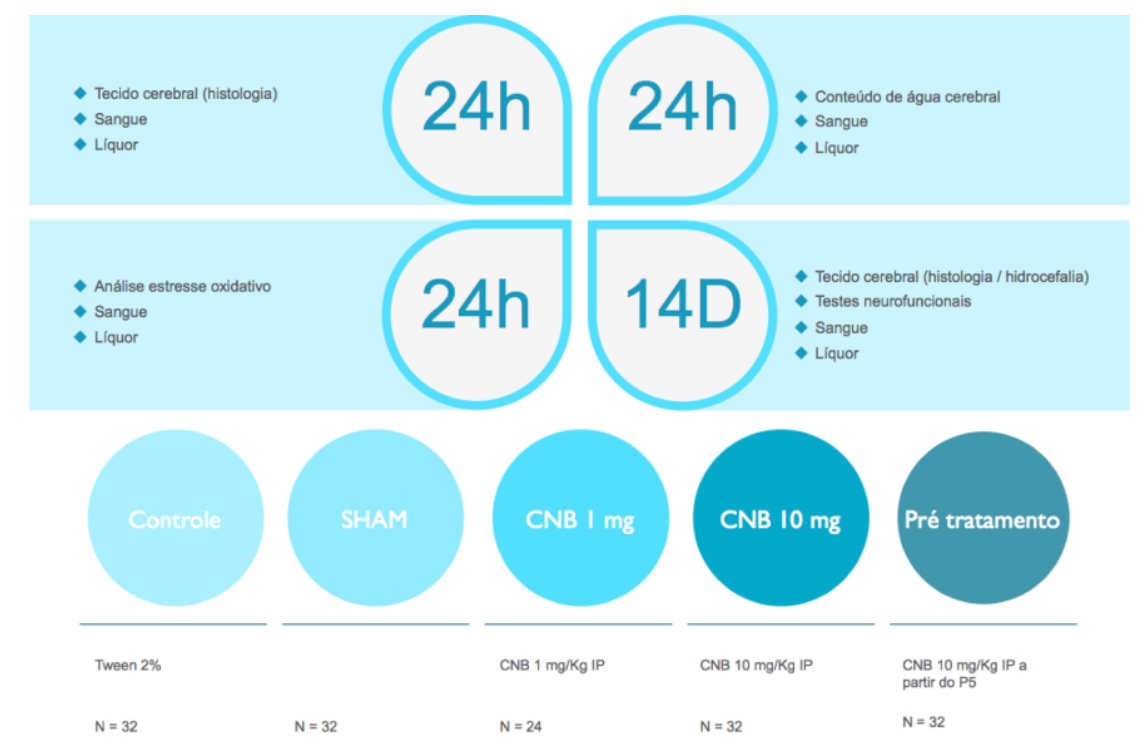

Figura 1 - Esquema da divisão dos animais em grupos e subgrupos

\subsection{ANESTESIA E PREPARO DOS ANIMAIS}

Os ratos Wistar com 7 dias de vida foram anestesiados com isoflurano $4 \%$ durante indução e 1,5 a $2 \%$ durante a manutenção. Oxigenação suplementar foi mantida a $9 \mathrm{~L} / \mathrm{min}$. Após a anestesia, os animais foram posicionados no aparelho de estereotaxia e anti-sepsia do couro cabeludo realizada com clorexidina degermante.

Modelo de HMG foi realizada conforme descrito na literatura (LEKIC et al., 2012). Com o animal anestesiado e colocado em decúbito ventral no aparelho de estereotaxia, 
uma incisão era feita na linha média com bisturi lâmina 15, envolvendo a pele, o subcutâneo e o periósteo, iniciando $2 \mathrm{~mm}$ à frente da sutura coronal até $1 \mathrm{~mm}$ posterior à sutura lambdóide, sendo o pericrâneo delicadamente descolado. Com auxílio de um motor elétrico com broca de ponta esférica, diamantada e delicada, trepanação de aproximadamente $1 \mathrm{~mm}$ era realizada $1,8 \mathrm{~mm}$ anterior e $1,5 \mathrm{~mm}$ à direita do bregma (Figura 2).

Através da trepanação realizada foi introduzida uma agulha de 27 gauge (Hamilton ${ }^{\circledR}$ 700 series) a uma velocidade de $1 \mathrm{~mm}$ por minuto até uma profundidade de 2,8 $\mathrm{mm}$ para posterior injeção de 0,3 U de colagenase VII (Sigma Chemical ${ }^{\circledR}$, USA) diluída em $2 \mu \mathrm{L}$ de solução salina a $0,9 \%$. Após a injeção da solução, a agulha foi mantida no local por 10 minutos para evitar extravasamento da solução.

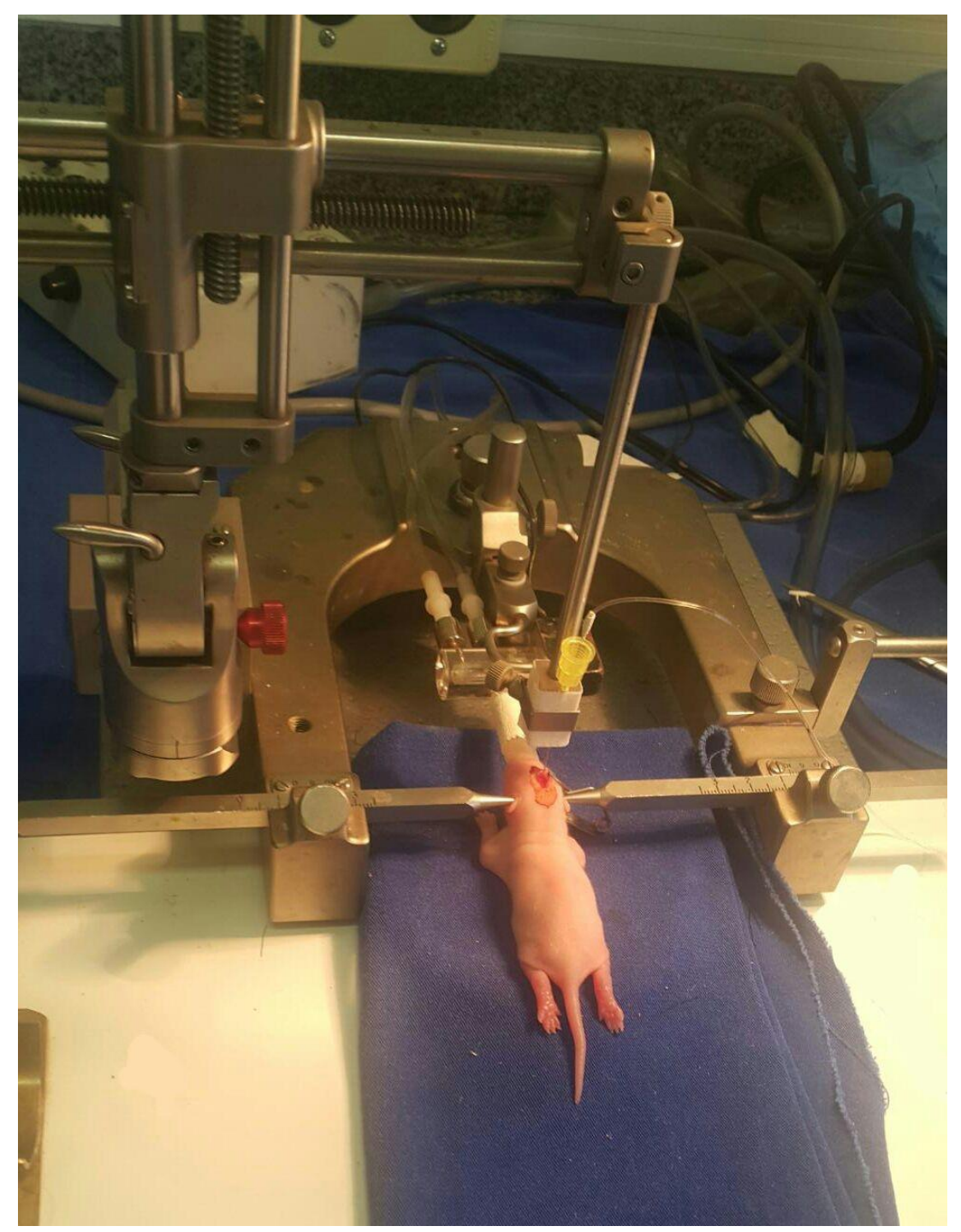

Figura 2 - Posicionamento de rato neonato (P7) em aparelho de estereotaxia durante procedimento cirúrgico para alização de modelo experimental de HMG. 


\subsection{CANABIDIOL}

Canabidiol em pó com pureza de 99,6\% (BSPG-Pharm, Sandwich, UK) foi dissolvido em solução Tween $2 \%$ na dose de $100 \mathrm{mg} / \mathrm{mL}$. O armazenamento, fornecimento e manipulação foram realizados junto ao programa de farmacologia da Universidade de São Paulo em Ribeirão Preto.

\subsection{MÉTODO DE EUTANÁSIA DOS ANIMAIS}

Ao final dos tempos experimentais, os animais de cada grupo foram profundamente anestesiados com injeção intraperitoneal de quetamina 10\% e xilasina 10\% (nas doses de 0,1 e 0,05 mg/100g de peso corporal). Após posicionamento na mesa cirúrgica, em decúbito dorsal, foi realizada uma ampla incisão em "Y" em cada animal, no tórax, das duas clavículas até o apêndice xifoide, e, no abdome, incisão mediana, xifopúbica. Com uma agulha 20 gauge $\left(\mathrm{BD}^{\circledR}\right)$, foi puncionada a ponta do ventrículo cardíaco esquerdo, introduzindo-se a agulha até a raiz da aorta e aspirado 0,1 $\mathrm{ml}$ de sangue total. Após uma pequena incisão na aurícula direita, foi iniciada a perfusão cardíaca com PBS, usando os mesmos parâmetros da retirada do sangue, agora com uma agulha 21 gauge $\left(\mathrm{BD}^{\circledR}\right)$, até o clareamento do líquido de saída (cerca de $1 \mathrm{ml} / \mathrm{g}$ de peso do animal), com auxílio de uma bomba de perfusão peristáltica (Fisher Scientific ${ }^{\circledR}$ ). Para os animais cujos tecidos foram enviados para realização de imuno-histoquímica, após a perfusão com salina tamponada com fosfato (PBS) foi realizada perfusão com solução de paraformaldeido a 3\%. A seguir, os animais foram decapitados e seus encéfalos retirados em bloco através de uma craniectomia de vértex. Para coleta de líquor, procedemos à punção suboccipital, conforme descrito na literatura (RODRÍGUEZ FANJUL; FERNÁNDEZ-FEIJOO; CAMPRUBÍ, 2015). Após retirado o material para análise, os corpos foram encaminhados para incineração em local apropriado junto à Faculdade de Medicina de Ribeirão Preto - US. A rata mãe foi sacrificada após o experimento, conforme protocolo, e também encaminhada para incineração. 


\subsection{AVALIAÇÃO NEUROFUNCIONAL}

Os ratos mantidos vivos por 14 dias após indução da hemorragia foram submetidos a avaliações neurofuncionais (ALLES; COSTA, 2009; VORHEES; WILLIAMS, 2006). Todos os animais foram pesados diariamente e observados quanto a possíveis alterações clínicas (perda de peso e desidratação, alterações da marcha e da consciência, negligência com a higiene). Todos os animais foram avaliados diariamente quanto ao aparecimenrio de abertura ocular, sendo a idade (em dias) anotada. A Figura 3 ilustra os testes realizados.

\subsubsection{Reflexo de endireitamento}

O reflexo de endireitamento consiste no posicionamento do filhote virado de costas sobre uma superfície plana. O tempo para retornar à posição de pé é registrado, tendo a duração do tempo limitada a 1 minuto. Esse teste foi realizado duas vezes para cada animal e após calculada a média entre o P8, P9 e P11.

\subsubsection{Geotaxia negativa}

A geotaxia negativa reflete a preferência dos filhotes de ficar olhando para cima numa superfície inclinada. Os filhotes foram colocados com a cabeça para baixo numa superfície inclinada a $25^{\circ}$ e mantidos nessa posição com cuidado por aproximadamente 5 segundos antes de serem soltos. O tempo para a posição de face foi registrado, tendo a duração do tempo limitada a 1 minuto. Esse teste foi realizado duas vezes para cada animal e após calculada a média entre o P8, P9 e P11.

\subsubsection{Teste das funções sensoriais e motoras}

Para estudo do desenvolvimento sensoriomotor, o comportamento deambulatório foi avaliado pelo teste do "Open Field" no P17. Cada animal foi observado individualmente em uma arena de acrílico transparente de $60 \mathrm{~cm}$ de lado e $45 \mathrm{~cm}$ de altura, por 2 minutos (iniciado após a colocação do animal na arena), sendo avaliados cuidados de higiene, exploração do ambiente e marcha. Para a realização deste teste, foram utilizados cronômetros a partir do início dos movimentos. As arenas foram limpas com solução de 
sabão neutro entre as observações de diferentes ninhadas de animais. Todos os testes foram gravados com câmera digital de alta resolução. Os vídeos foram posteriormente analisados com auxílio do aplicativo X-PloRat. As seguintes variáveis foram analisadas: tempo de permanência na região central, tempo de permanência na região periférica, frequência de cruzamentos, frequência de asseio e frequência de levantamento.

\subsubsection{Teste de retenção de memória e aprendizado}

Para estudo da memória e aprendizagem espacial, os ratos foram submetidos ao Labirinto em Y (realizado no P17) e teste de paradigma de reconhecimento de objetos (realizado nos P18 e P19). O Teste do Labirinto em Y consiste em avaliar a capacidade de memória espacial de roedores. Este teste verifica se o roedor mantém na memória o espaço que acabou de explorar. Os experimentos são conduzidos em um ambiente com atenuação de sons e luz de baixa intensidade. Cada rato foi posicionado no centro do labirinto em Y e ficou livre para explorar os 3 braços por 5 minutos, sendo calculado a porcentagem de movimentos corretos (circulares) realizados pelo animal.

No teste do paradigma de reconhecimento de objetos a tarefa consistiu em um treino no qual foram apresentados dois objetos, seguido de um teste em que um dos objetos introduzidos durante o treino é substituído por um objeto novo. Para este teste, os animais foram expostos a um campo aberto de 60 × 40 × $50 \mathrm{~cm}$, feito de plástico, por 1 hora, 1 dia antes do teste de retenção, para habituação, na ausência de objetos. No dia seguinte, foram dispostos no campo aberto dois objetos, sendo o animal exposto por 5 minutos para retenção. Após 1 hora, um dos objetos foi trocado por outro que diferia quanto à sua cor, altura, formato e textura, sendo os animais expostos a eles por mais 5 minutos. Os objetos e o campo aberto foram limpos com etanol $70 \%$ após cada treino para remover pistas olfativas. Foram consideradas atividades exploratórias do animal: farejar o objeto ou tocálo com as patas anteriores ou focinho, mas não virar o objeto ou sentar-se nele, nem ficar com as quatro patas sobre o objeto. O tempo percentual gasto explorando cada objeto foi calculado e expresso como percentual do tempo total de exploração em segundos. 

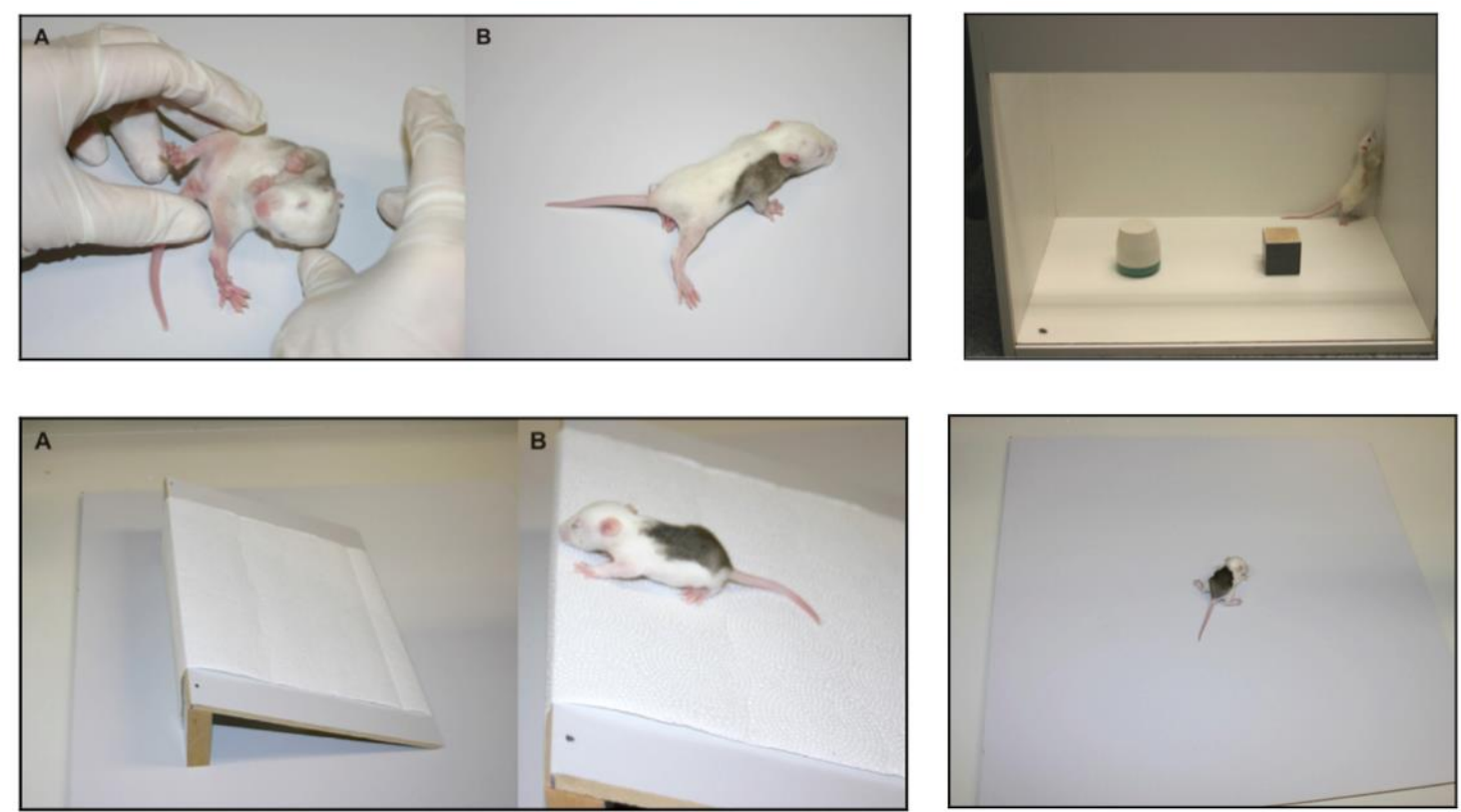

Figura 3 - Ilustração dos testes neurofuncionais realizados. Canto superior esquerdo, teste de endireitamento; canto supperior direito, teste de reconhecimento de objetos; canto inferior esquerdo, teste de geotaxia negativa; canto inferior direito, open field.

Retirado de Ales e Costa, 2009.

\subsection{ANÁLISE HISTOLÓGICA E ANÁLISE DO ESTRESSE OXIDATIVO}

Os animais submetidos à análise histológica tiveram o tecido cerebral imerso em solução fixadora de paraformaldeído diluído a 3\% em tampão fosfato 0,1 M (pH 7,3 - 7,4) por 24 horas à temperatura de $4^{\circ} \mathrm{C}$, subdividas no plano coronal, em cortes de $0,5 \mathrm{~mm}$ de distância utilizando matriz metálica de cérebro de ratos, sendo posteriormente mantidas em uma nova solução de paraformaldeído 3\% fresca, permanecendo nesta solução fixadora por mais 3 dias à mesma temperatura. As amostras foram desidratadas em soluções crescentes de álcool (70\% a 100\%), diafanizadas em xilol e emblocadas em parafina. Foram, então, cortadas coronalmente em micrótomo rotativo em secções de $5 \mu \mathrm{m}$ de espessura e os cortes estendidos em lâminas histológicas.

Para análise histológica, as lâminas foram mantidas em estufa $\left(60^{\circ} \mathrm{C}\right)$ por uma hora para derretimento da parafina. A seguir, os cortes foram submetidos ao processo de desparafinização, seguidos de banhos sequenciais de xilol, álcool em concentrações decrescentes e água; posteriormente, foram corados com hematoxilina e eosina. Serão observadas (hematoxilina e eosina) a citoarquitetura geral, distribuição das estruturas e 
densidade celular. Para imuno-histoquímica, as lâminas foram mantidas em estufa a $60{ }^{\circ} \mathrm{C}$, por 30 minutos, e desparafinizadas em banhos sequenciais de xilol e álcool. Foram realizados estudos por imuno-histoquímica para GFAP (glial fibrillary acidic protein) [de coelho anti-GFAP (DAKO Z0334, Dinamarca)], para avaliação da distribuição e aspecto morfológico astroglial, e Caspase 3 (anticorpo policlonal de coelho, anti-caspase 3, Biorbyt orb 382909), para avaliação de apoptose neuronal. O bloqueio da peroxidase endógena foi feito com peróxido de hidrogênio a 3\% em Metanol. Posteriormente foi feito o bloqueio com soro de cabra 10\% em PBS, por 30 minutos em câmara úmida. Logo após, os cortes foram incubados de um dia para o outro à temperatura de $4{ }^{\circ} \mathrm{C}$ com o anticorpo primário, diluído 1:6000 em BSA. Retirado o anticorpo primário, foi adicionado o anticorpo secundário apropriado (anticorpo biotinilado de cabra anticoelho - Santa Cruz Biotechnology SC-2040, ou anticamundongo - Santa Cruz Biotechnology SC-2039) diluído 1:300 em BSA. Após, os tecidos foram incubados com o anticorpo terciário estreptavidina conjugada com HRP (Thermo Scientific JG 122591) diluído 1:400 em PBS. A seguir, foram revelados com DAB (3,3’- diaminobenzidina - Sigma). Por fim, as lâminas foram submetidas à contracoloração com hematoxilina, lavadas em água corrente, desidratadas por uma série sequencial de banhos crescentes de álcoois e xilol, e recobertas por lamínulas montadas com Permount ${ }^{\circledR}$. Observação: para a imuno-histoquímica, os cortes foram estendidos em lâminas histológicas gelatinizadas.

Os animais submetidos à análise de estresse oxidativo tiveram os encéfalos divididos na linha média e as metades direita e esquerda imediatamente congeladas e mantidas em freezer a $-80^{\circ} \mathrm{C}$ para posteriores dosagens das enzimas antioxidantes.

Para dosagem do MDA, produto final da peroxidação lipídica, foi realizada através da técnica de dosagem de proteína pela reação com solução de Bradford. O tecido cerebral previamente homogeneizado foi descongelado e centrifugado a $1.600 \mathrm{x}$ por g, a $4{ }^{\circ} \mathrm{C}$ por 10 min. As amostras (sobrenadante) e as diluições do padrão foram distribuídos em duplicatas em uma placa de 96 poços e acrescentados os demais reagentes. Após o tempo de pausa para as reações químicas, a placa foi lida em leitora com absorvância de 530-540 $\mathrm{nm}$. 


\subsection{ANÁLISE DO CONTEÚDO DE ÁGUA LIVRE}

Os cérebros foram coletados 24 horas após a indução hemorrágica e divididos em hemisférios direito, esquerdo e cerebelo, sendo seu peso molhado mensurado para posterior desidratação através de técnica de liofilização por 12 horas. Após a mensuração do peso seco com auxílio de balança de precisão, o conteúdo de água foi calculado como a diferença entre o peso molhado pelo peso seco, dividido pelo seu peso molhado e apresentado na forma de coeficiente de água livre.

\subsection{DOCUMENTAÇÃO DE IMAGENS}

A documentação fotográfica das lâminas histológicas foi realizada no laboratório de Neurologia Aplicada e Experimental do Departamento de Neurociências e Ciências do Comportamento da Faculdade de Medicina de Ribeirão Preto - USP, através de um microscópio de luz AxiosKop2 plus (Carl Zeiss ${ }^{\circledR}$ ) e uma câmera digital AxioCam Hrc $\left(\right.$ Carl Zeiss $\left.{ }^{\circledR}\right)$ acoplados à um computador equipado com o software Axio Vision 3.1, utilizando a objetiva de 40x. Nas lâminas marcadas por GFAP foram fotografados 4 campos de 400x nos 4 quadrantes peri-hemorrágicos nos animais sacrificados 24 horas após a hemorragia, e, nos animais sacrificados no P21, foram fotografados 5 campos sequenciais e aleatórios na região dos núcleos da base, e 1 campo de 400x no Stratum oriens de CA1 do hipocampo direito, sendo feita a contagem dos astrócitos reativos.

Todos os testes neurofuncionais foram gravados para documentação utilizando câmera digital de alta qualidade (GoPro Hero $4^{\circledR}$ ).

\subsection{ANÁLISE DE DADOS}

Os dados foram apresentados como média, mediana e intervalos interquartis (percentil 25\% - percentil 75\%) e através de apresentação gráfica com Boxplots. Os dados quantitativos de amostras dependentes (os mesmos ratos, em momentos diferentes) foram analisados com teste $t$ pareado, com correção de Bonferroni para múltiplas comparações. Para a comparação de dados quantitativos entre os grupos utilizamos o teste one way ANOVA (seguido pelo pós-teste de Tukey). Utilizamos o aplicativo Statistical Package for 
the Social Sciences (SPSS v. 24, IBM ${ }^{\circledR}$ ) para análise dos dados, e R para construção dos gráficos. O valor de $\mathrm{p}$ indicado como significante foi de $<0,05$, bi-caudal. 
4. RESULTADOS 


\section{RESULTADOS}

\subsection{ANIMAIS OPERADOS}

Foram operados 152 ratos Wistar com 7 dias de vida, tendo sido considerados para análise estatística 147 destes devido 5 óbitos resultantes de complicações anestésicas durante procedimento de indução da hemorragia (Tabela 1). O peso dos animais no dia da cirurgia apresentou média de 21,17 g (DP 3,19), não apresentando diferença significante entre os grupos (Figura 4).

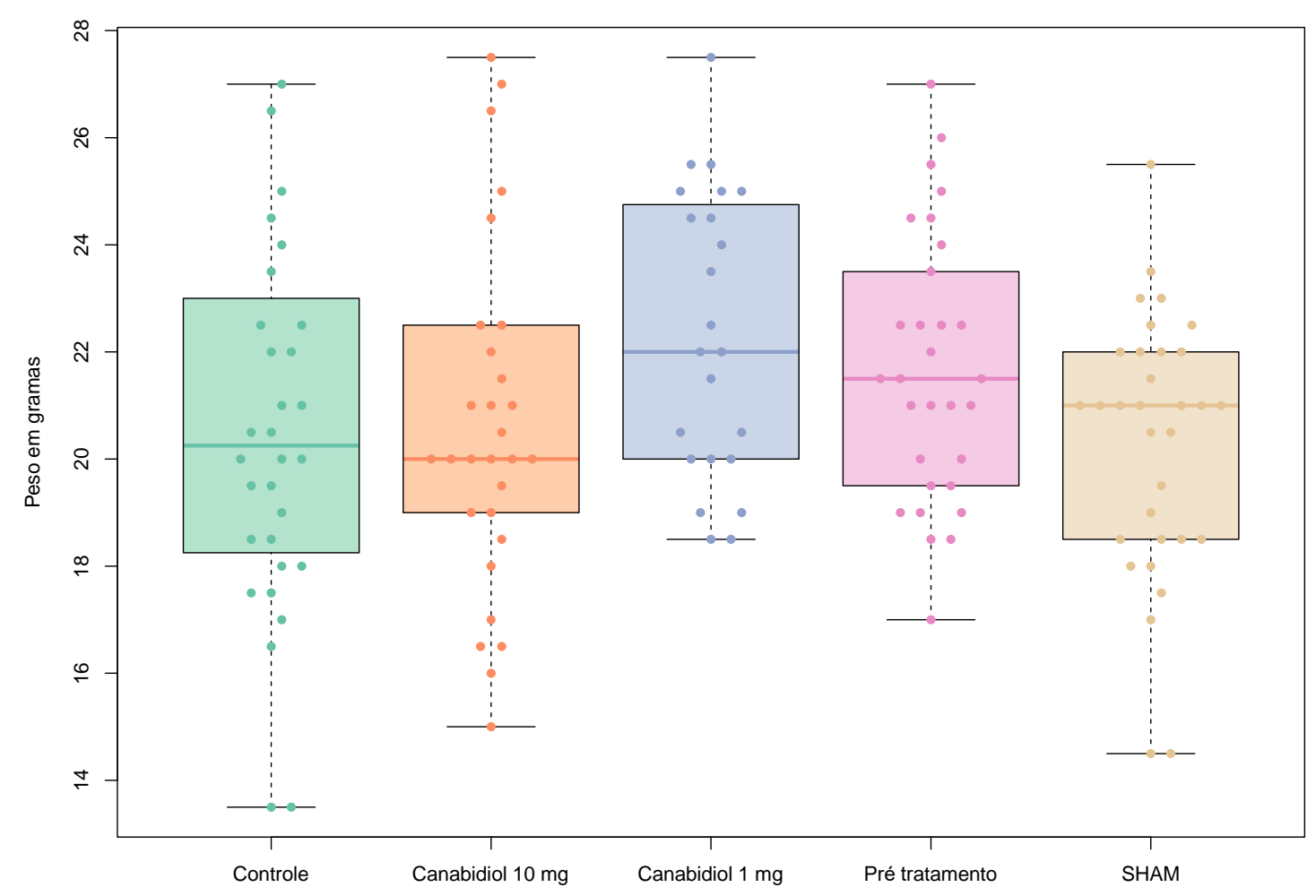

Figura 4 - Boxplot do peso (em gramas) dos animais no dia da indução da hemorragia (P7) 
Tabela 1 - Número de animais por grupo e subgrupo

\begin{tabular}{llc}
\hline \multicolumn{1}{c}{ Grupo } & \multicolumn{1}{c}{ Subgrupo } & Número de casos \\
\hline \multirow{2}{*}{ Controle } & Histologia & 8 \\
& Edema & 8 \\
& Estresse oxidativo & 8 \\
& Neurofuncional & 8 \\
Canabidiol 10 mg & Histologia & 8 \\
& Edema & 8 \\
Estresse oxidativo & 7 \\
Canabidiol 1 mg & Neurofuncional & 7 \\
& Histologia & 8 \\
& Edema & 8 \\
Pré-tratamento & Estresse oxidativo & 7 \\
& Histologia & 8 \\
& Edema & 8 \\
& Estresse oxidativo & 8 \\
SHAM & Neurofuncional & 6 \\
& Histologia & 8 \\
& Edema & 8 \\
& Estresse oxidativo & 8 \\
& Neurofuncional & 8 \\
\hline
\end{tabular}




\subsection{AVALIAÇÃ̃ HISTOLÓGICA}

\subsubsection{Análise quantitativa de astrócitos GFAP+ 24 horas após hemorragia}

Foi observado um aumento na concentração de astrócitos reativos marcados para GFAP (Figura 5) nos campos peri-hemorrágicos no grupo Controle $\left(10,2\right.$ / 0,052 $\left.\mathrm{mm}^{2}\right)$ em relação aos demais grupos (Canabidiol $10 \mathrm{mg}=1,8 / 0,052 \mathrm{~mm}^{2}$; Canabidiol $1 \mathrm{mg}=2,1$ / $0,052 \mathrm{~mm}^{2}$; Pré-tratamento $=0,9 / 0,052 \mathrm{~mm}^{2} ;$ SHAM $=0,7 / 0,052 \mathrm{~mm}^{2}$ ) sendo essa diferença estatisticamente significante ( $p<0,001$; Figura 6).
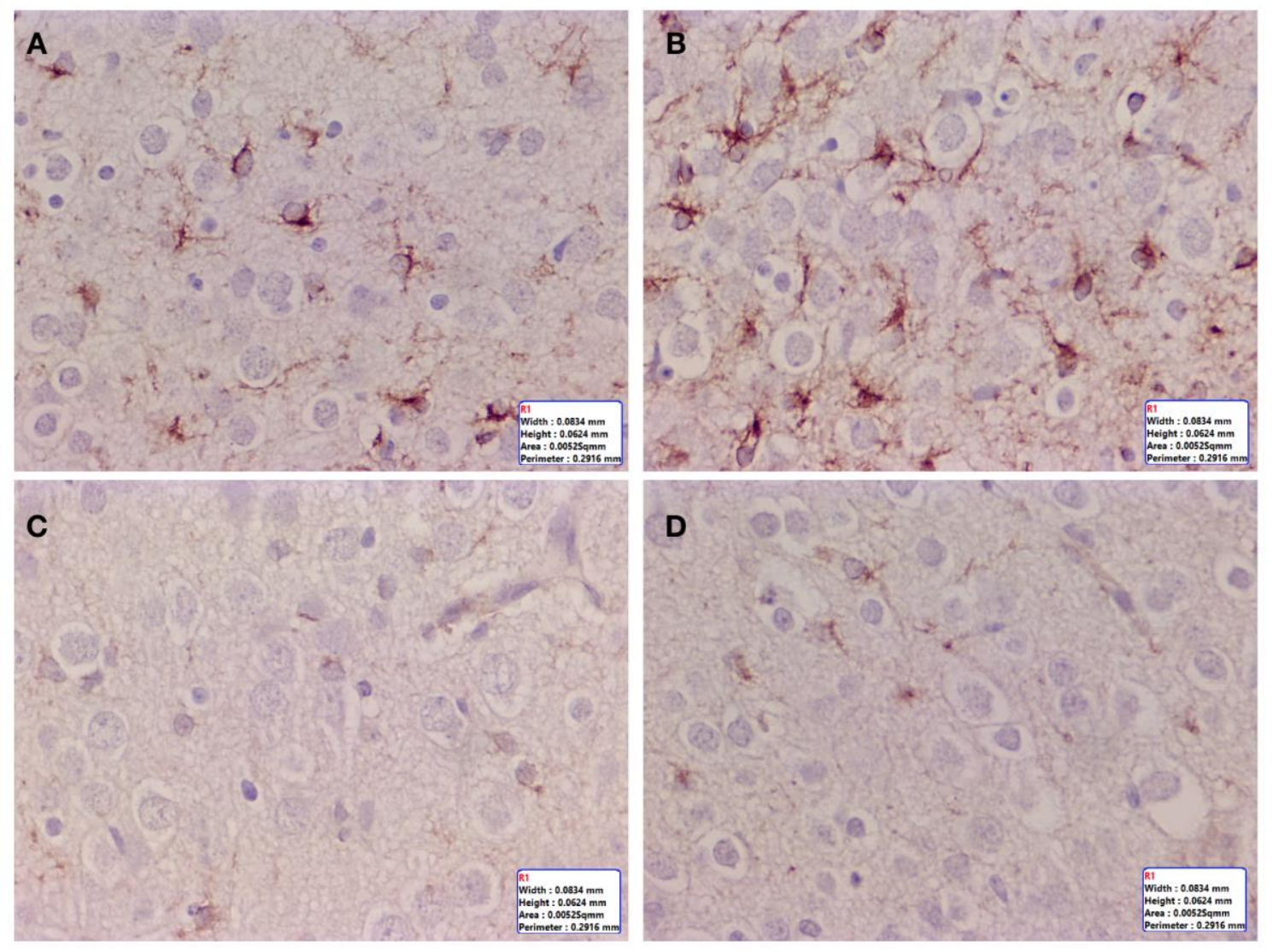

Figura 5 - Fotografias de campos peri-hemorrágicos marcados para GFAP (400x); A e $\mathrm{B}$, campos aleatórios de animal do grupo Controle; C e D, campos aleatórios de aminal do grupo Canabidiol $10 \mathrm{mg}$. 


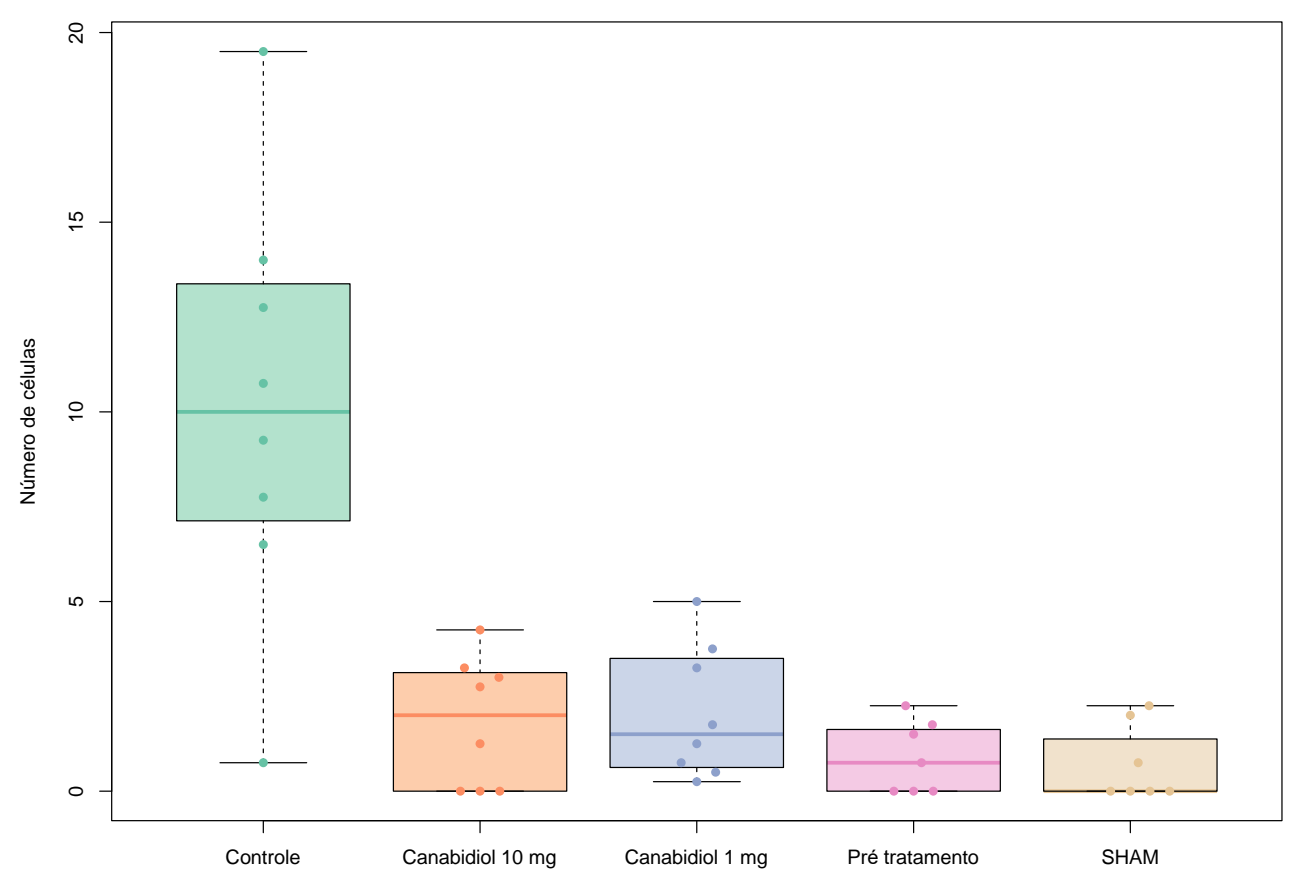

Figura 6 - Boxplot da quantidade de células GFAP+ (por campo de 0,052 $\mathrm{mm}^{2}$ ) na periferia lesional 24 horas após hemorragia 


\subsubsection{Análise quantitativa de astrócitos caspase 3+ $\mathbf{2 4}$ horas após hemorragia}

Foi observado um aumento na concentração de astrócitos marcados para Caspase 3 (Figuras 7 e 8) nos campos peri-hemorrágicos no grupo Controle $\left(11,3 / 0,052 \mathrm{~mm}^{2}\right)$ em relação aos grupos Canabidiol $10 \mathrm{mg}$ (1,5/ 0,052 $\mathrm{mm}^{2} ; \mathrm{p}=$ 0,001), Canabidiol $1 \mathrm{mg}$ (4,6 / $\left.0,052 \mathrm{~mm}^{2} ; \mathrm{p}<0,05\right)$, Pré-tratamento $\left(0,06 / 0,052 \mathrm{~mm}^{2} ; \mathrm{p}<0,001\right)$ e $\operatorname{SHAM}(0,03 / 0,052$ $\left.\mathrm{mm}^{2} ; \mathrm{p}<0,001\right)$.
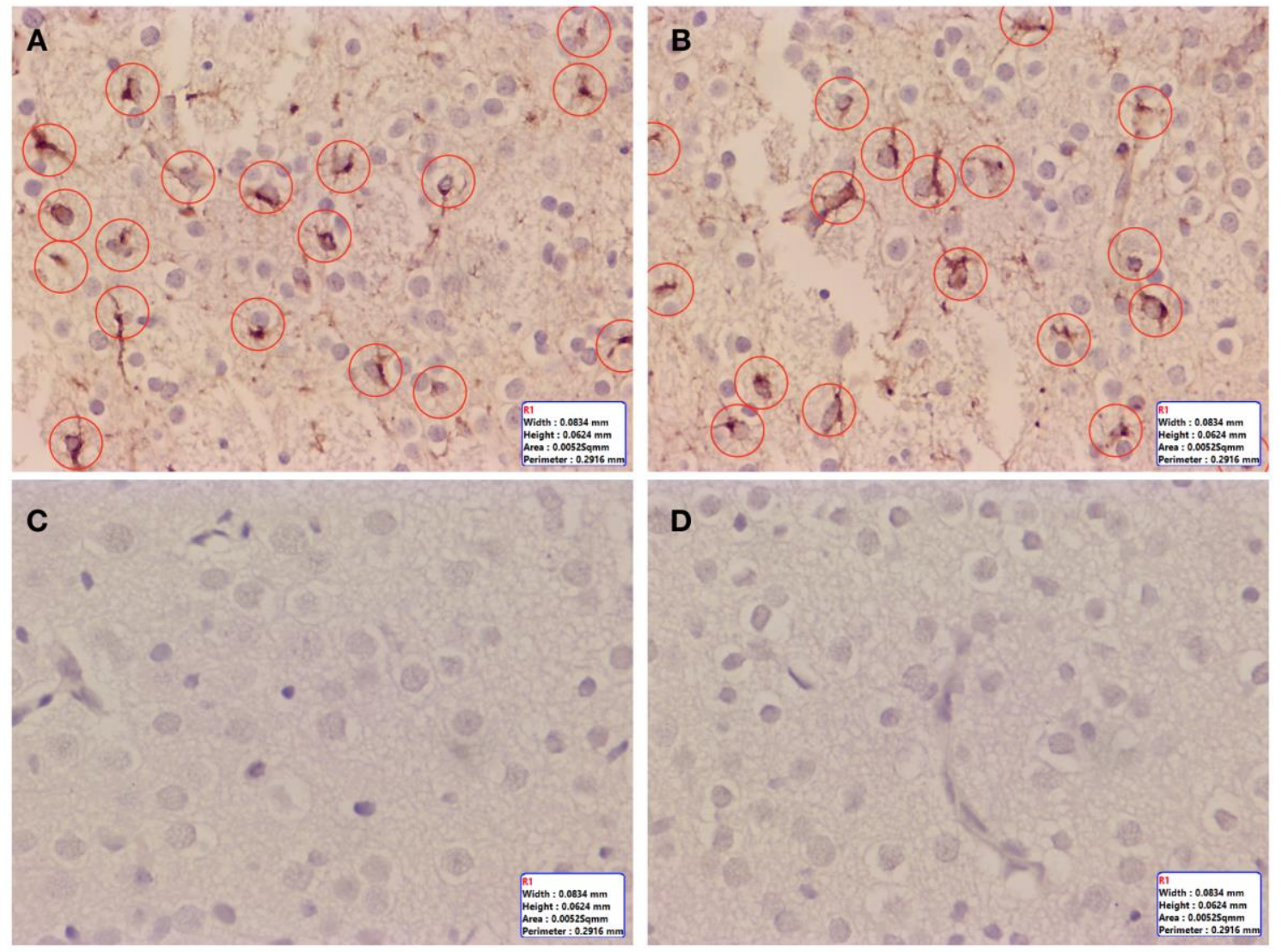

Figura 7 - Fotografias de campo peri-hemorrágicos marcados para Caspase 3 (400x); A e $\mathrm{B}$, campos aleatórios de animal do grupo Controle (células Caspase 3 positivas identificadas por círculos vermelhos); $\mathrm{C}$ e D, campos aleatórios de aminal do grupo Canabidiol $10 \mathrm{mg}$. 


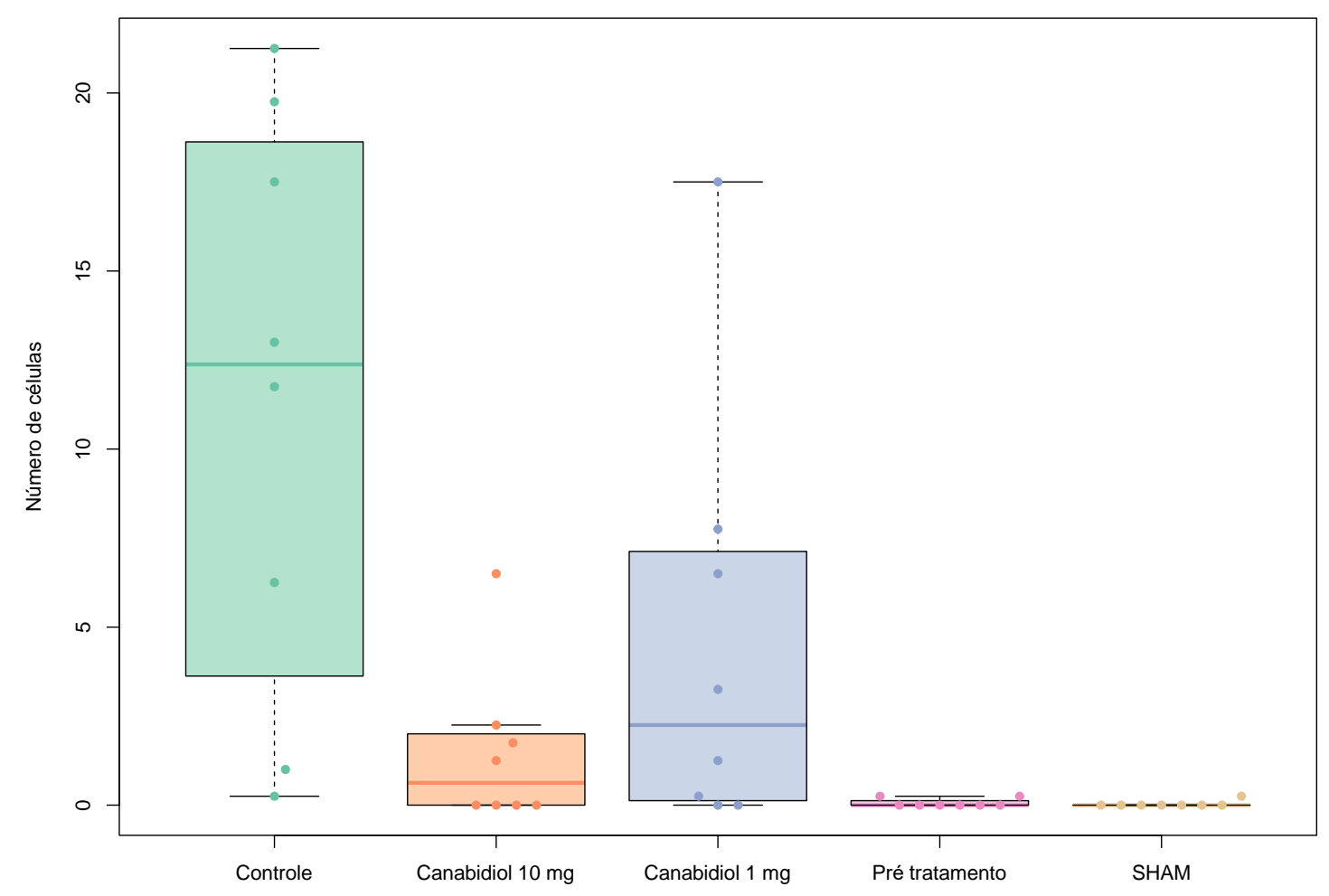

Figura 8 - Boxplot da quantidade de células Caspase 3 positivas (por campo de 0,052 $\mathrm{mm}^{2}$ ) na periferia lesional 24 horas após hemorragia 


\subsubsection{Análise quantitativa de astrócitos GFAP+ na região dos núcleos da base 14 dias após hemorragia}

Foi encontrado um aumento na concentração de astrócitos reativos marcados com GFAP na região dos núcleos da base no grupo Controle $\left(9,8 / 0,052 \mathrm{~mm}^{2}\right)$ em relação aos grupos Canabidiol $10 \mathrm{mg}\left(2,9 / 0,052 \mathrm{~mm}^{2} ; p=0.022\right)$ e grupo SHAM $\left(2,9 / 0,052 \mathrm{~mm}^{2} ; p\right.$ $=0,027)$. O grupo Pré-tratamento apresentou média de 5,1/0,052 $\mathrm{mm}^{2}$, sem diferença estatisticamente significativa em relação ao grupo Controle (Figura 9).

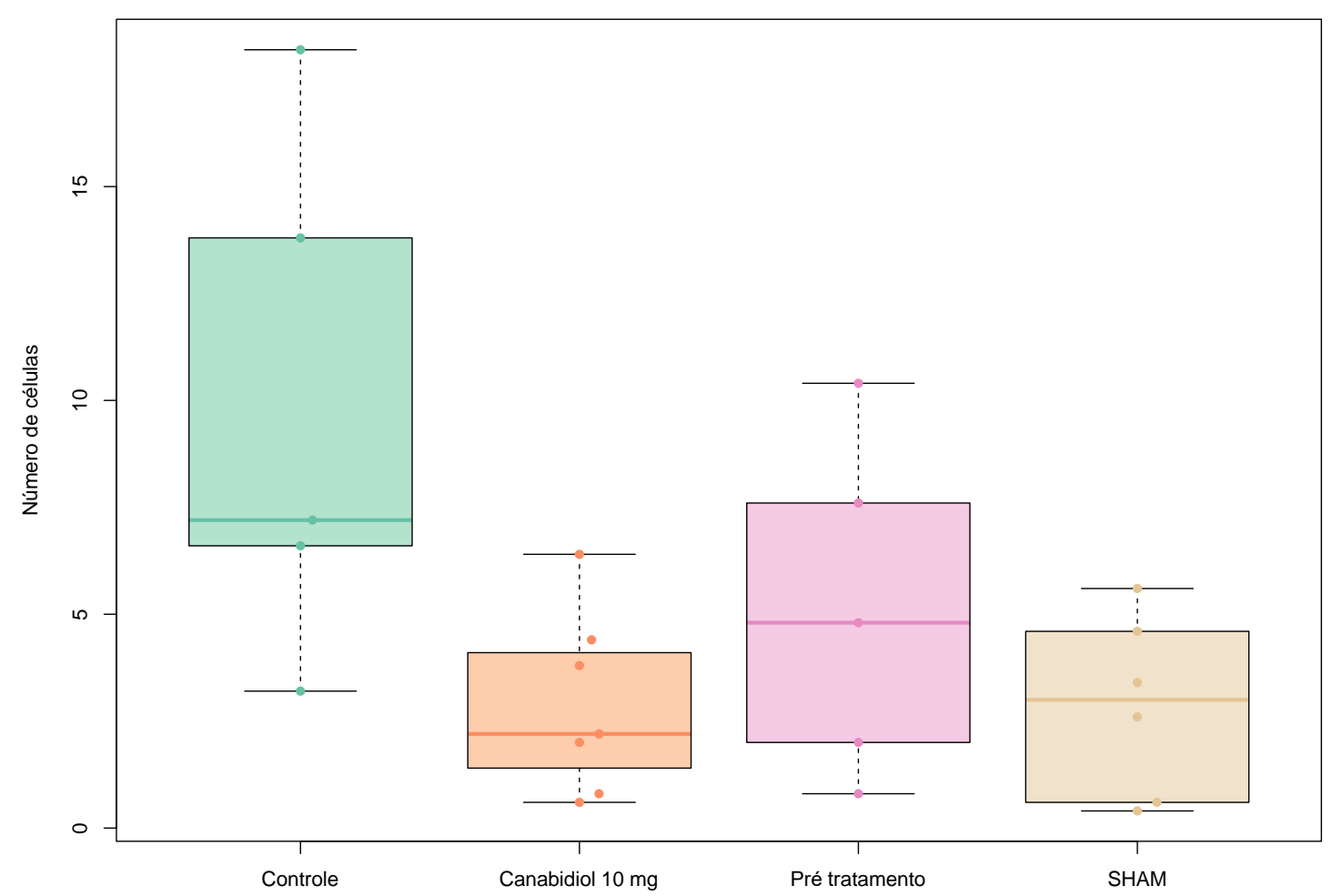

Figura 9 - Boxplot da quantidade de células GFAP positivas (por campo de 0,052 $\mathrm{mm}^{2}$ ) em topografia dos núcleos da base 14 dias após hemorragia 


\subsubsection{Análise quantitativa de astrócitos caspase 3+ na região dos núcleos da base $\mathbf{1 4}$ dias após hemorragia}

Foi encontrado um discreto aumento na concentração de astrócitos reativos marcados com Caspase 3 na região dos núcleos da base no grupo Controle $(0.95$ / 0,052 $\left.\mathrm{mm}^{2}\right)$ em relação aos grupos Canabidiol $10 \mathrm{mg}\left(0,34 / 0,052 \mathrm{~mm}^{2}\right)$, Pré-tratamento $(0,2$ / $\left.0,052 \mathrm{~mm}^{2}\right)$ e SHAM $\left(0,07 / 0,052 \mathrm{~mm}^{2}\right)$, porém sem diferença estatisticamente significativa (Figura 10).

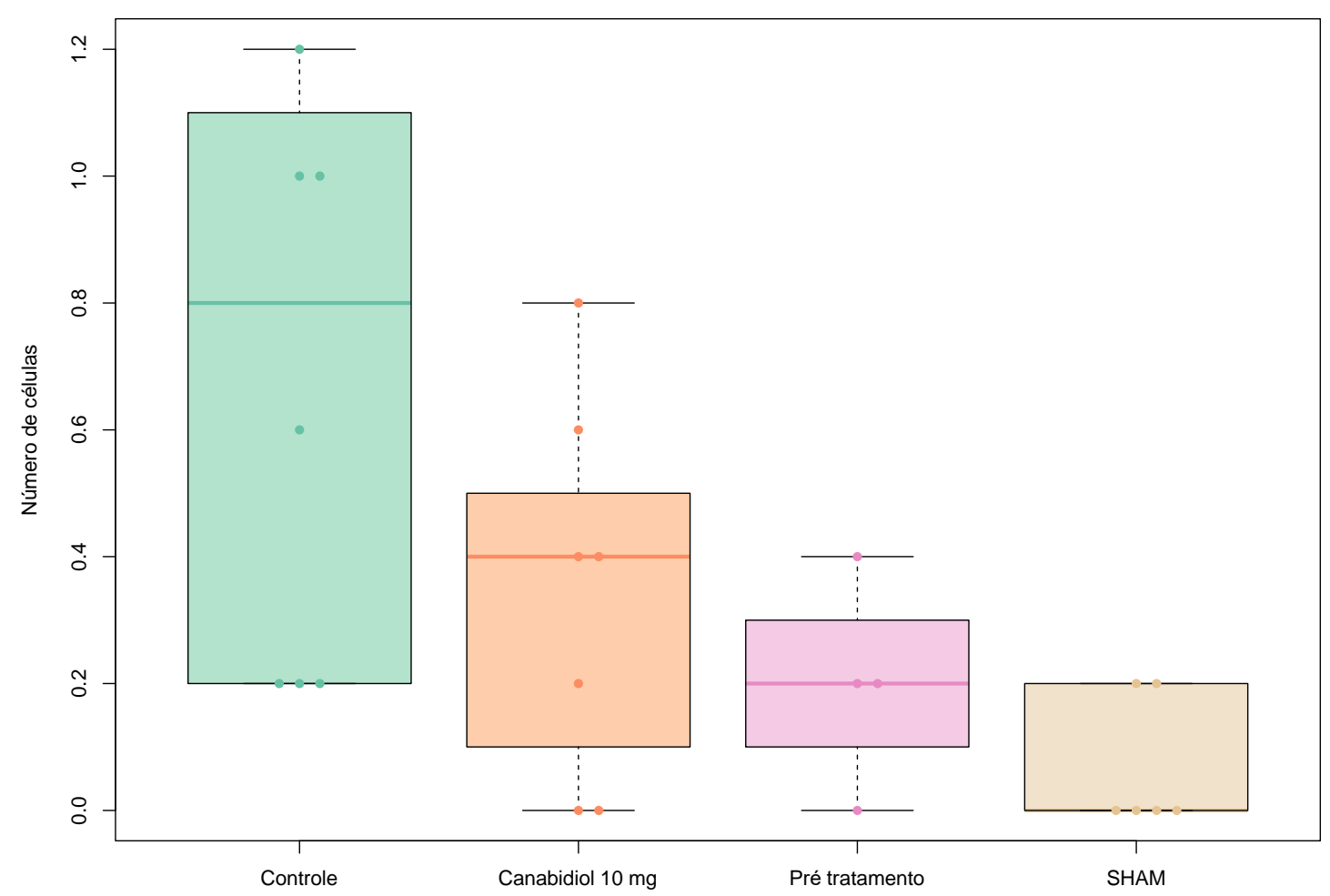

Figura 10 - Boxplot da quantidade de células Caspase 3 positivas (por campo de 0,052 $\mathrm{mm}^{2}$ ) em topografia dos núcleos da base 14 dias após hemorragia 


\subsubsection{Análise quantitativa de astrócitos GFAP+ no Stratum oriens da região de CA1 do hipocampo direito 14 dias após hemorragia}

Observou-se um aumento na concentração de astrócitos reativos marcados com GFAP no Stratum oriens (Figuras 11 e 12) no grupo Controle $\left(17,7 / 0,052 \mathrm{~mm}^{2}\right)$ em relação aos grupos Canabidiol $10 \mathrm{mg}(5,9$ / 0,052 mm²; $<$ 0,001), Pré-tratamento (8,4 / $\left.0,052 \mathrm{~mm}^{2} ; \mathrm{p}<0,05\right)$ e $\left.\operatorname{SHAM}\left(9,7 / 0,052 \mathrm{~mm}^{2}\right) ; \mathrm{p}<0.05\right)$.

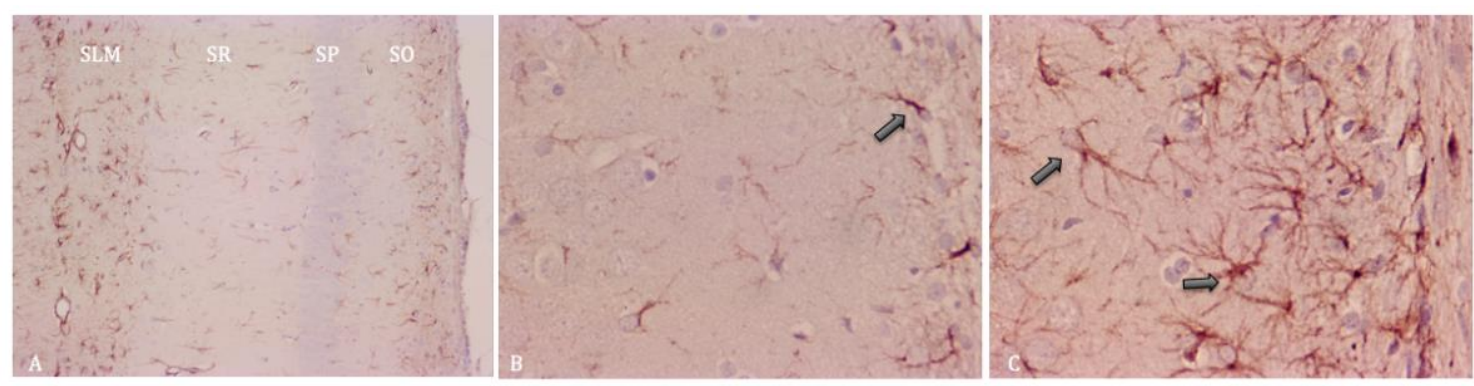

Figura 11 - Fotografia da região CA1 do hipocampo ipsilateral (A, 100x) e do Stratum oriens de aminal do grupo Canabidiol $10 \mathrm{mg}(\mathrm{B}, 400 \mathrm{x})$ e de animal do grupo Controle (C, 400x) 14 dias após hemorragia. Setas: élulas GFAP positivas. $\mathrm{SLM}=$ Stratum lacunosummoleculare $; \mathrm{SO}=$ Stratum oriens $; \mathrm{SP}=$ Stratum pyramidale $; \mathrm{SR}=$ Stratum radiatum .

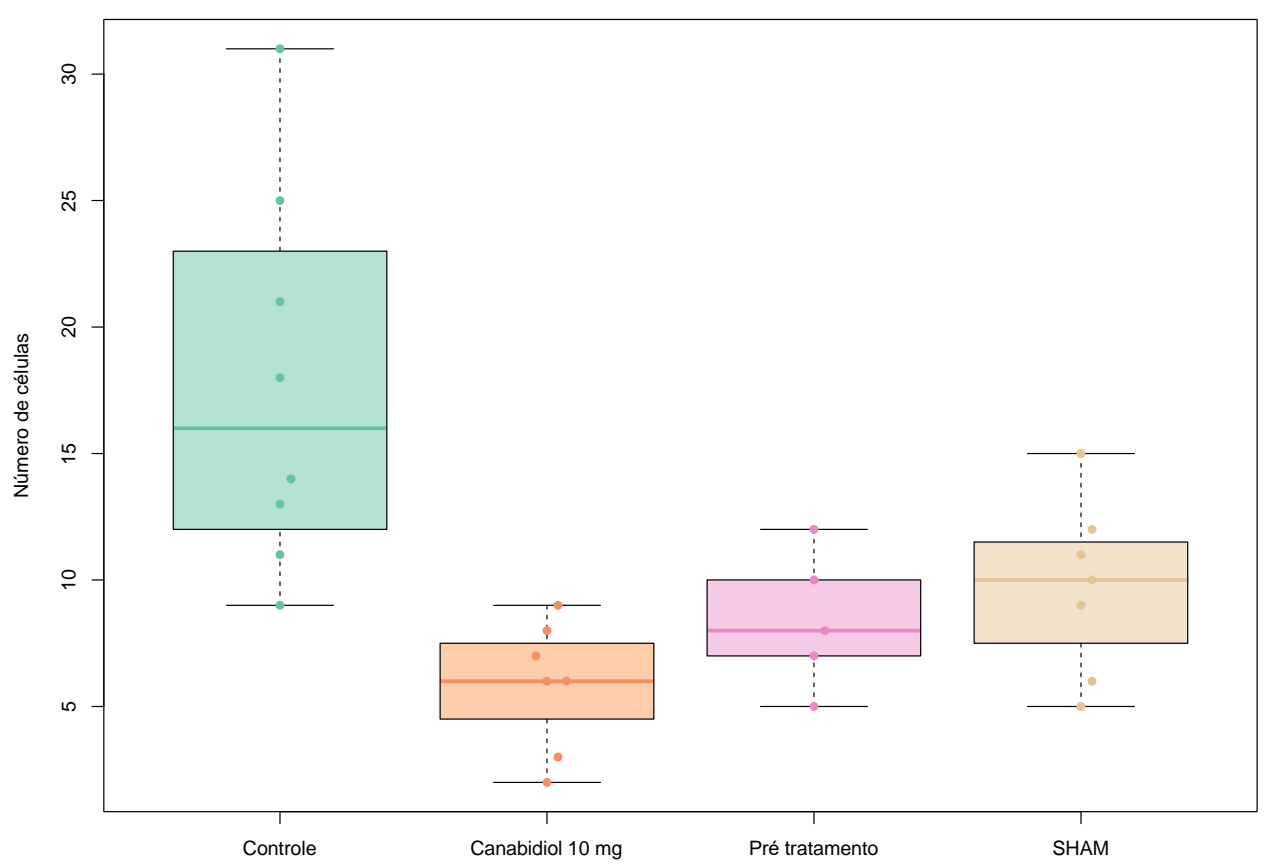

Figura 12 - Boxplot da quantidade de células GFAP positivas (por campo de 0,052 $\mathrm{mm}^{2}$ ) no Stratum oriens da região de CA1 14 dias após hemorragia 


\subsubsection{Análise quantitativa de astrócitos caspase 3+ no Stratum oriens da região de} CA1 do hipocampo direito 14 dias após hemorragia

Observou-se um aumento discreto no número de astrócitos marcados com Caspase 3 no Stratum oriens no grupo Controle $\left(3,6 / 0,052 \mathrm{~mm}^{2}\right)$ em relação aos grupos Canabidiol $10 \mathrm{mg}\left(0,29 / 0,052 \mathrm{~mm}^{2}\right)$, Pré-tratamento $\left(1,0 / 0,052 \mathrm{~mm}^{2}\right)$ e $\operatorname{SHAM}\left(0,38 / 0,052 \mathrm{~mm}^{2}\right)$, porém sem significância estatística (Figura 13).

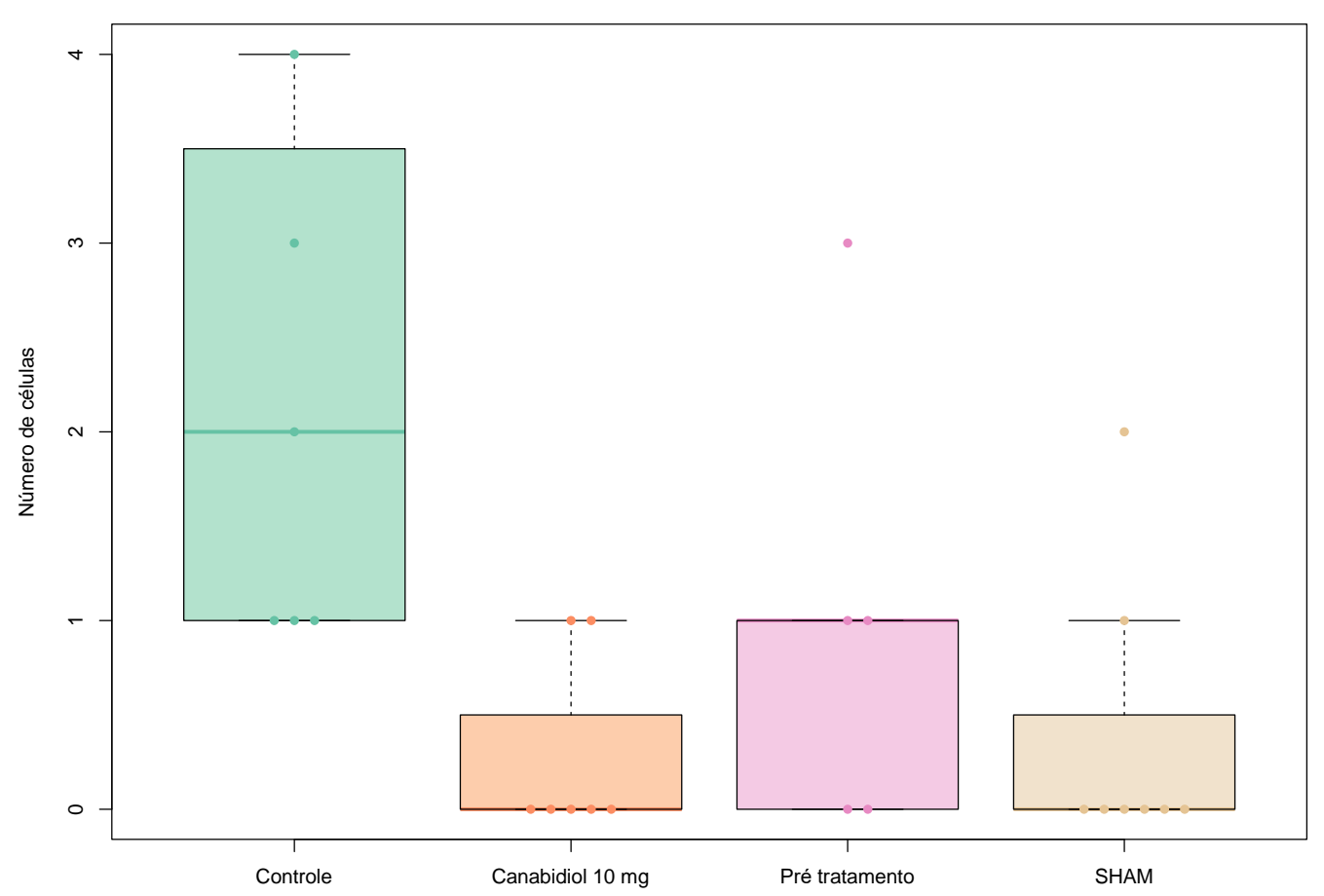

Figura 13 - Boxplot da quantidade de células Caspase 3 positivas (por campo de 0,052 $\mathrm{mm}^{2}$ ) no Stratum oriens da região de CA1 do hipocampo direito 14 dias após hemorragia

\subsubsection{Análise da espessura do corpo caloso na linha média 14 dias após hemorragia}

Não foi observada diferença significativa na espessura do corpo caloso 14 dias após hemorragia entre os grupos (Figuras 14 e 15). 

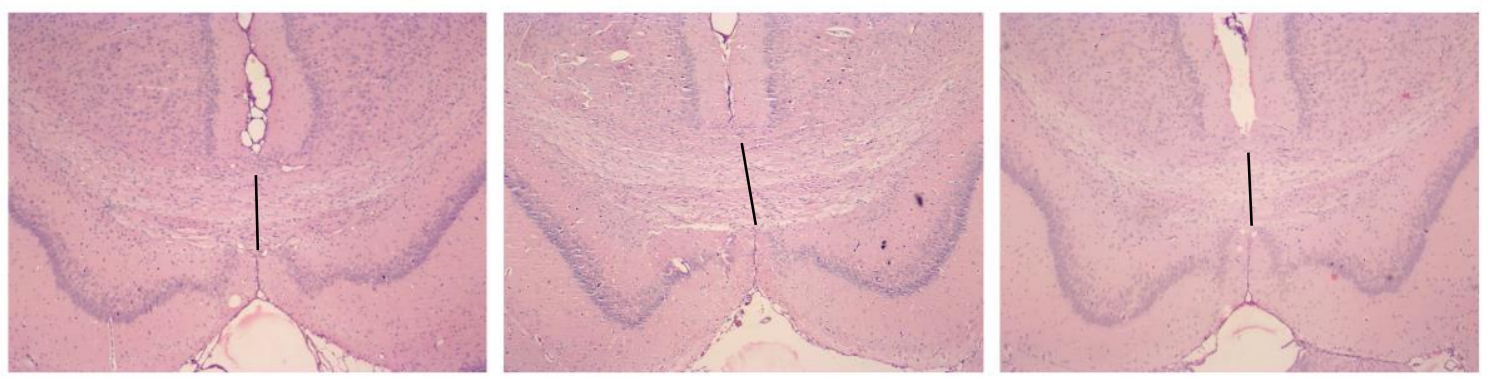

Figura 14 - Fotografia da região de corpo caloso na linha média 14 dias após hemorragia em três espécimes diferentes demonstrando o local de mensuração da espessura do corpo caloso

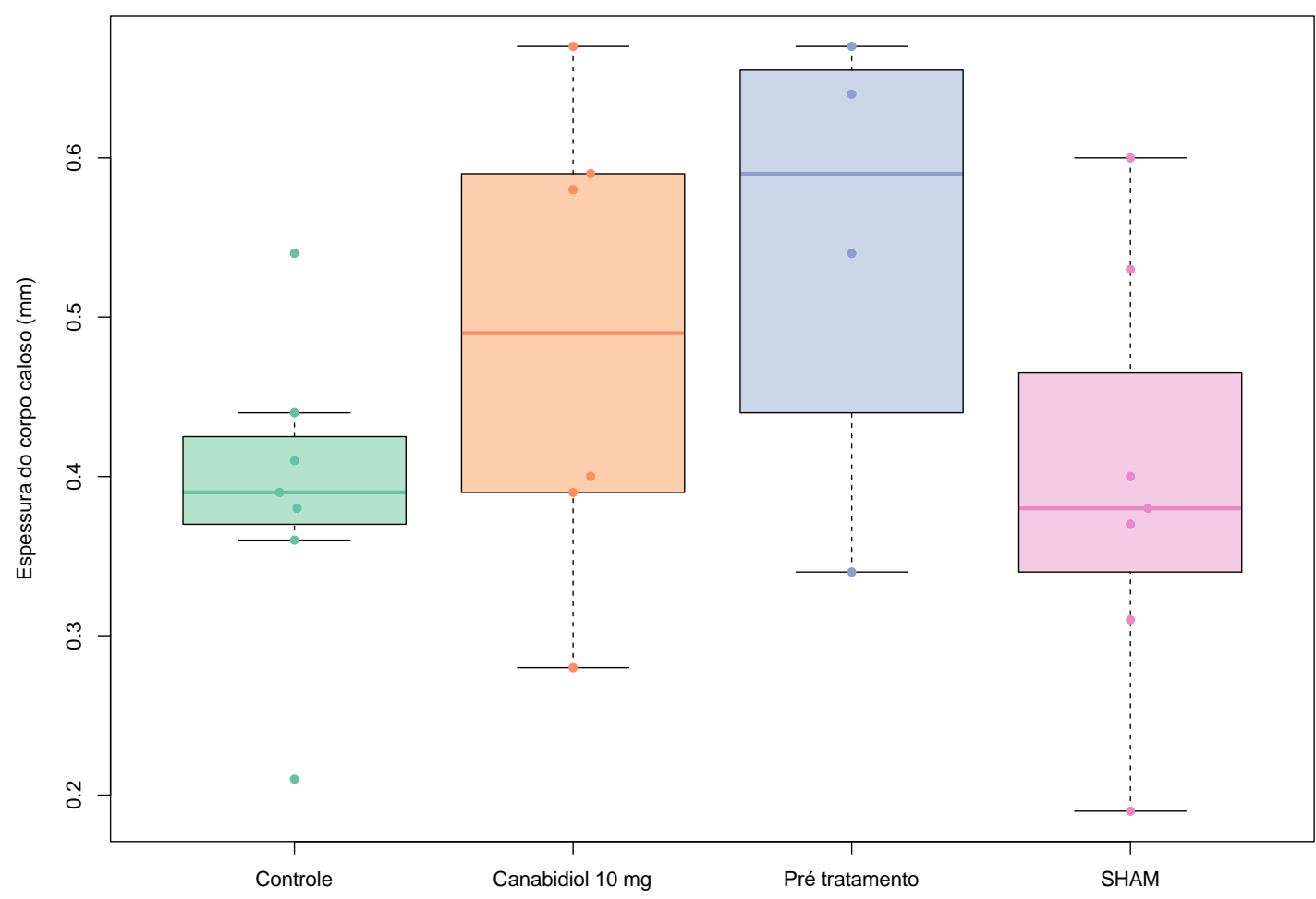

Figura 15 - Boxplot da espessura do corpo caloso (em mm) 14 dias após hemorragia 


\subsection{ANÁLISE DA PORCENTAGEM DE ÁGUA LIVRE CEREBRAL}

A coeficiente de água livre no hemisfério cerebral direito (Figura 16) foi menor no grupo SHAM $(0,864586456)$ em relação ao grupo Controle $(0,875537701 ; p<0.001)$. Não observou-se diferença significativa entre o grupo Controle e os grupos Canabidiol $10 \mathrm{mg}$ (0,873086916), Canabidiol $1 \mathrm{mg}(0,870564851)$ e Pré-tratamento $(0,873995030)$.

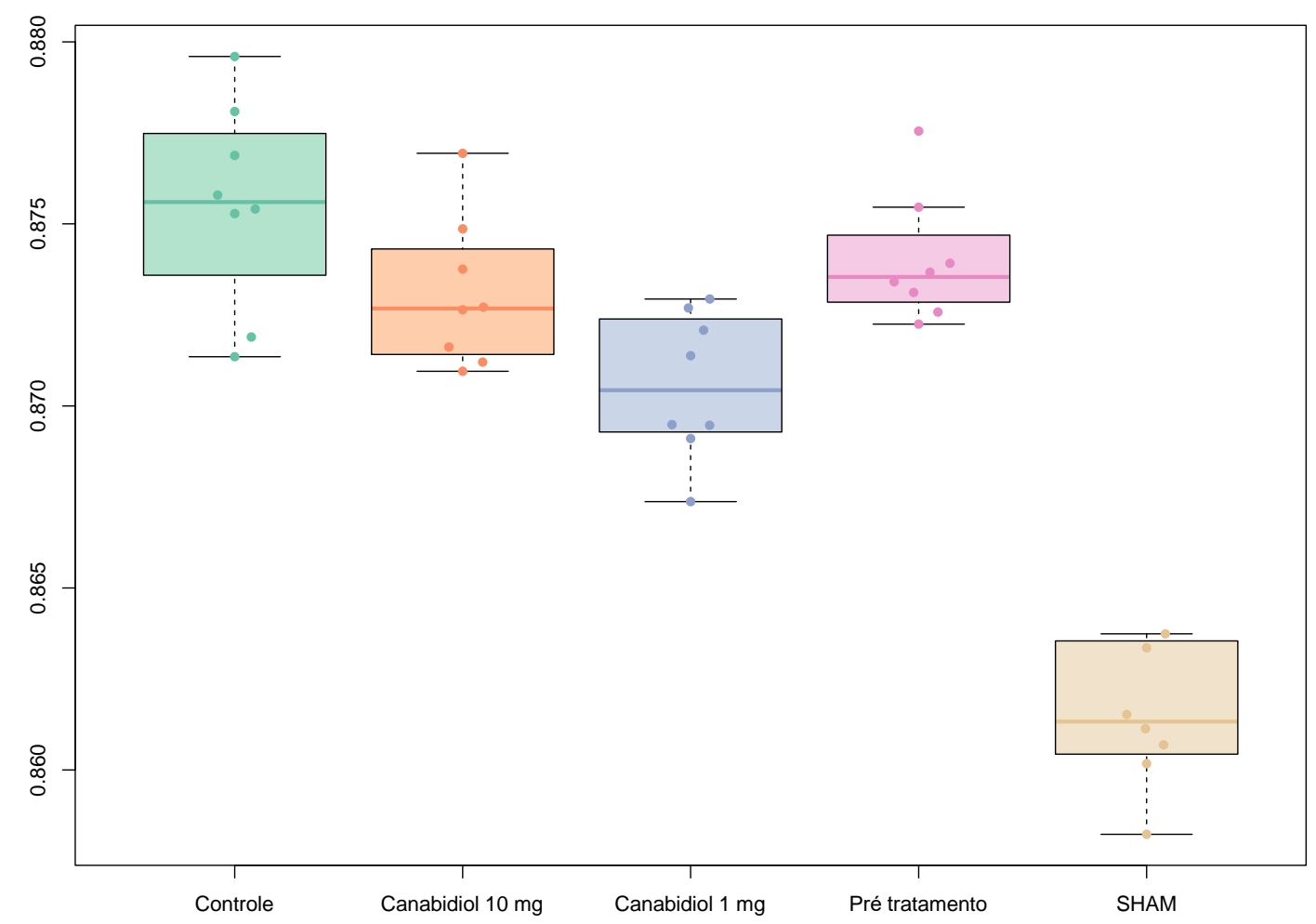

Figura 16 - Boxplot da porcentagem de água livre no hemisfério cerebral ipsilateral 24 horas após hemorragia 


\subsection{ANÁLISE DE ESTRESSE OXIDATIVO POR EXPRESSÃO DE MDA}

Não foi observado diferença estatisticamente significante na concentração de MDA (Figura 17) entre os grupos Controle $(9,7 \mu \mathrm{M} / \mathrm{mg}$ de proteína), SHAM $(9,45 \mu \mathrm{M} / \mathrm{mg}$ de proteína ) e Canabidiol $10 \mathrm{mg}(8,49 \mu \mathrm{M} / \mathrm{mg}$ de proteína). A dosagem de MDA foi significativamente maior nos grupos Canabidiol $1 \mathrm{mg}(24,0 \mu \mathrm{M} / \mathrm{mg}$ de proteína; $\mathrm{p}<0,001)$ e Pré-tratamento $(20,6 \mu \mathrm{M} / \mathrm{mg}$ de proteína; $\mathrm{p}<0,001)$.

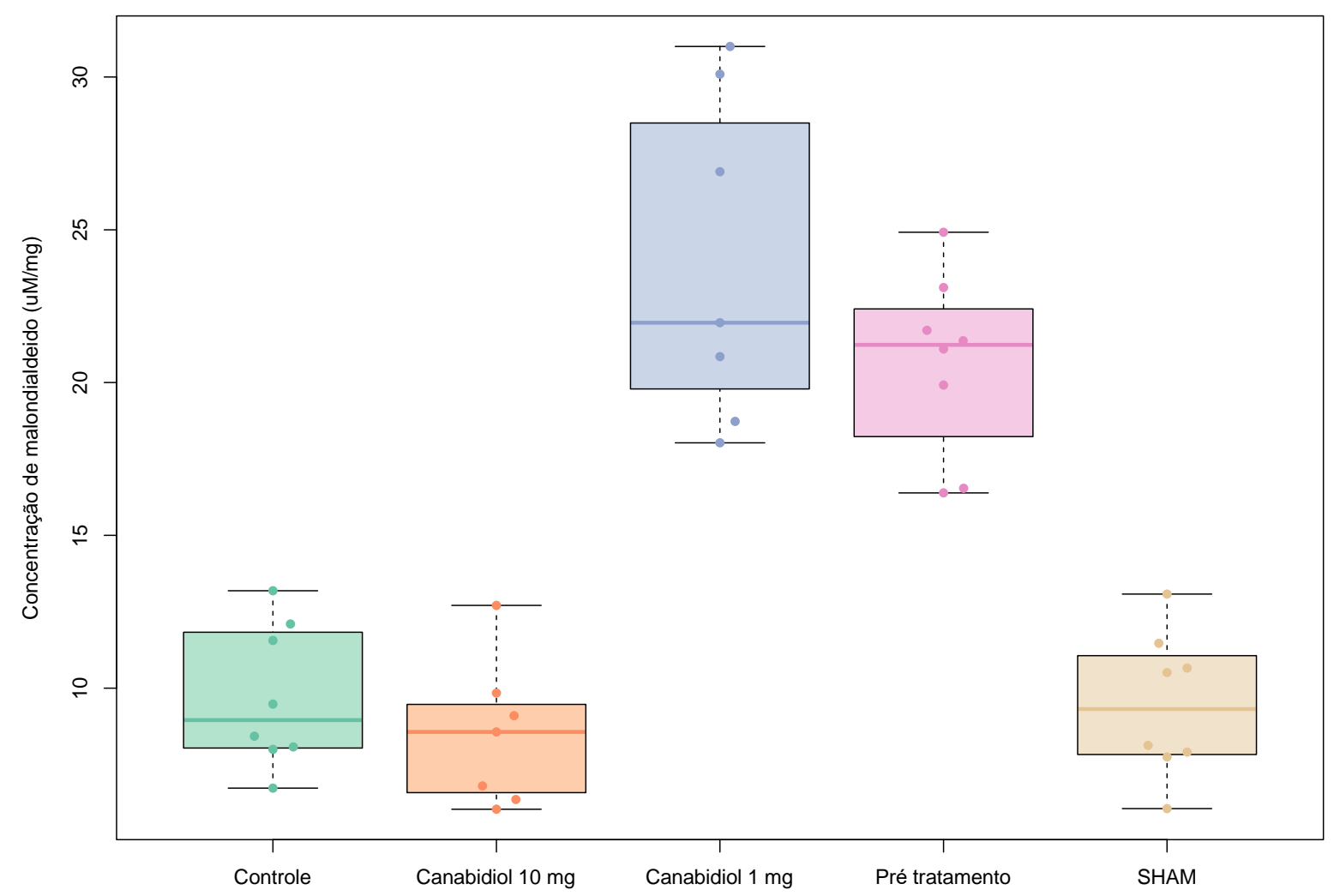

Figura 17 - Boxplot da dosagem de MDA (em $\mu \mathrm{M} / \mathrm{mg}$ de proteína) no hemisfério cerebral ipsilateral 24 horas após hemorragia 


\subsection{AVALIAÇÃO NEUROFUNCIONAL}

\subsubsection{Ganho ponderal}

Observou-se um diferença significativa no aumento de peso nos grupos tratados com canabidiol (Canabidiol 10 mg e Pré-tratado) em relação aos grupos Controle e SHAM $(p<0.05$; Figura 18).

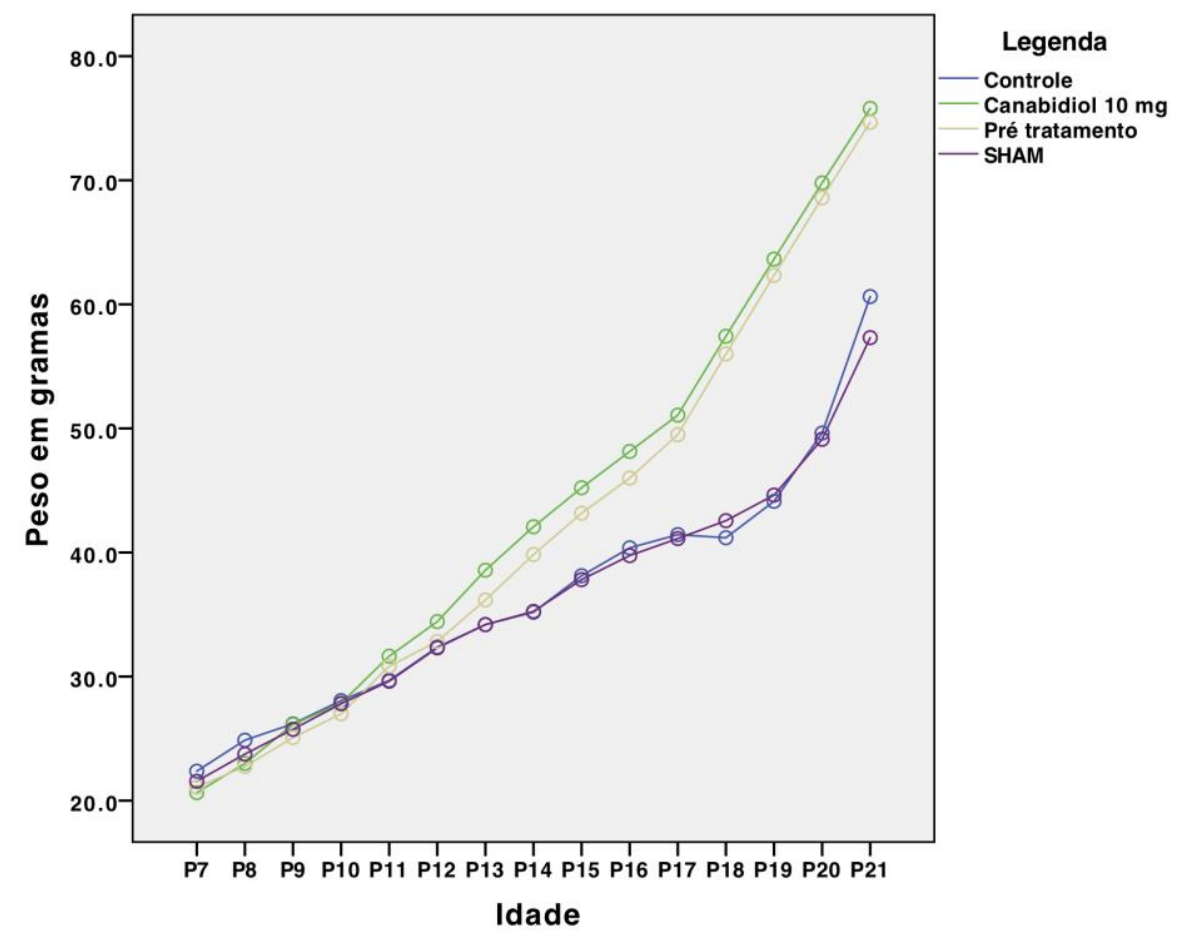

Figura 18 - Curvas de ganho ponderal (em gramas) após indução da hemorragia, por grupos de tratamento 


\subsubsection{Desenvolvimento neuropsicomotor}

Foi observado maior tempo para realização das tarefas nos testes de endireitamento (Figura 19), testados no $8^{0}, 9^{0}$ e $11^{0}$ dia de vida, entre o grupo controle $(1,23 \mathrm{~s})$ e os grupos Canabidiol $10 \mathrm{mg}(0,82 \mathrm{~s}, p=0.008)$ e Pré-tratamento $(0,84 \mathrm{~s}, p=0.018)$, e de geotaxia (Figura 20) entre o grupo Controle (22,2 s) e o grupo Canabidiol $10 \mathrm{mg}(9,55 \mathrm{~s}, p=0.002)$. Não observou-se, entretanto, diferença significativa nos testes de endireitamento e geotaxia entre os grupos Controle e SHAM (0,97 s e 14,94 s, respectivamente). Também não encontramos diferença significativa no tempo para desenvolvimento da abertura ocular.

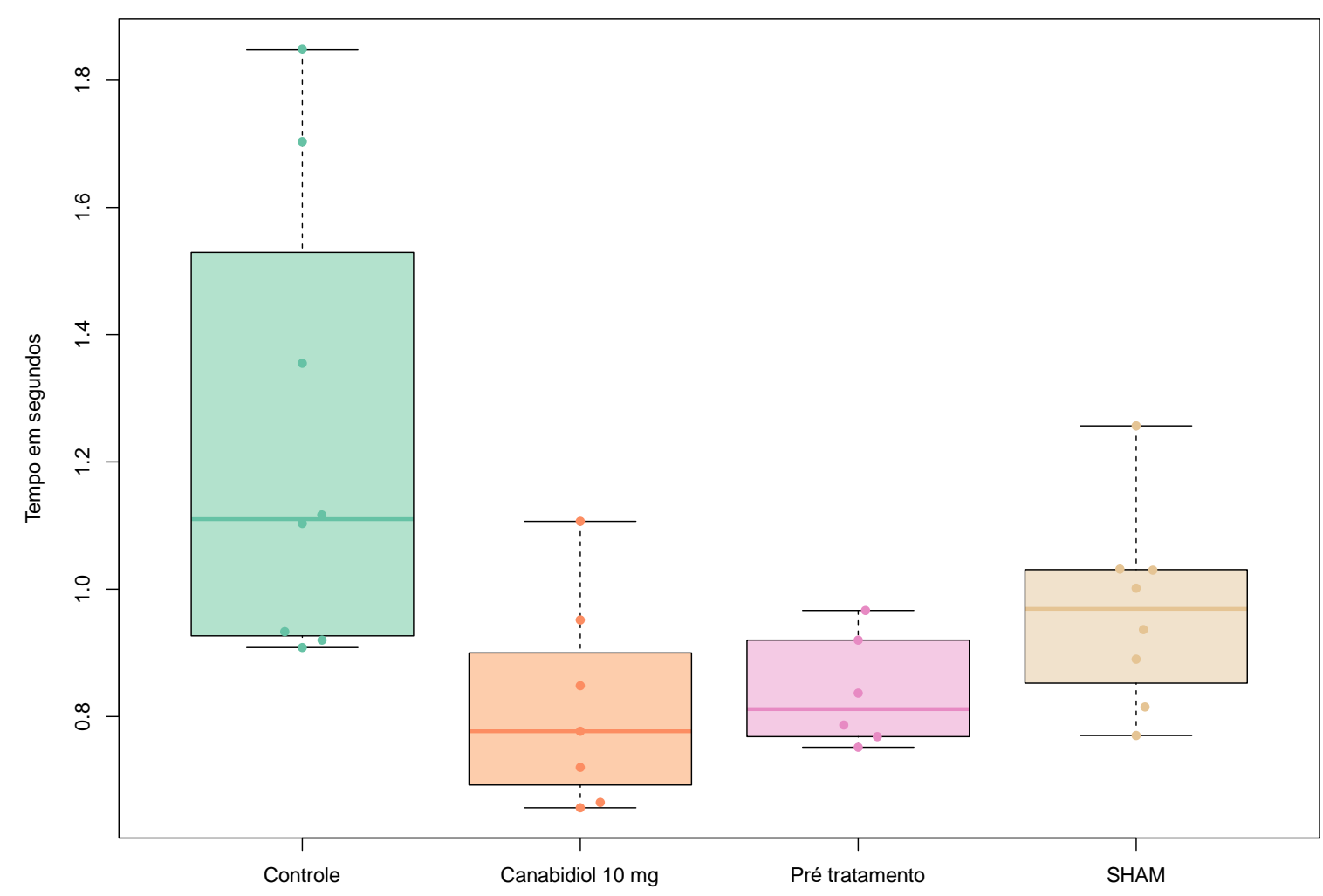

Figura 19 - Boxplot do tempo (em segundos) para realização de teste de endireitamento entre grupos 


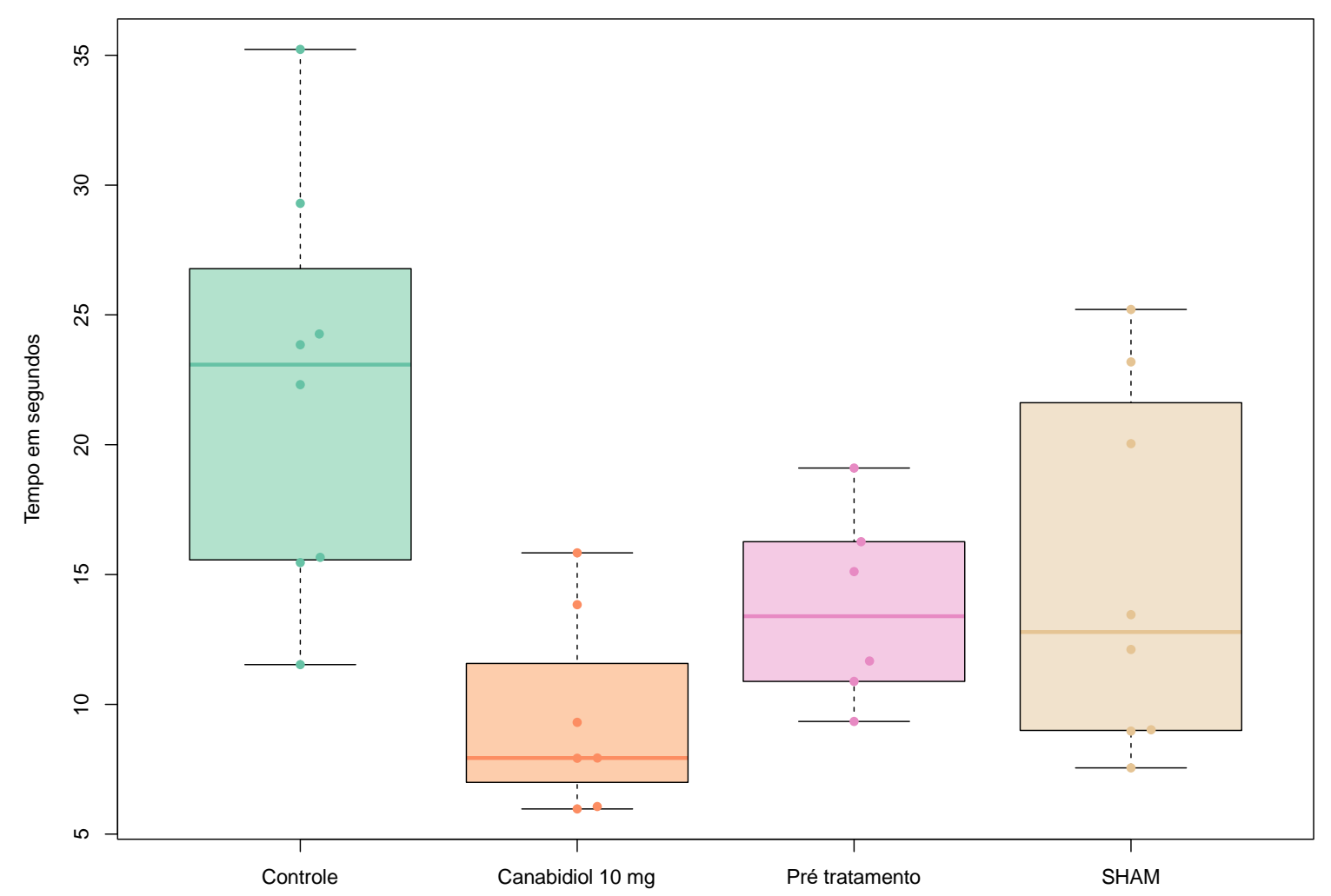

Figura 20 - Boxplot do tempo (em segundos) para realização de teste de geotaxia negativa entre grupos 


\subsubsection{Open field}

Não encontrou-se diferença estatisticamente significante no teste open field entre os grupos em nenhuma das variáveis estudadas (Figuras 21 a 24).

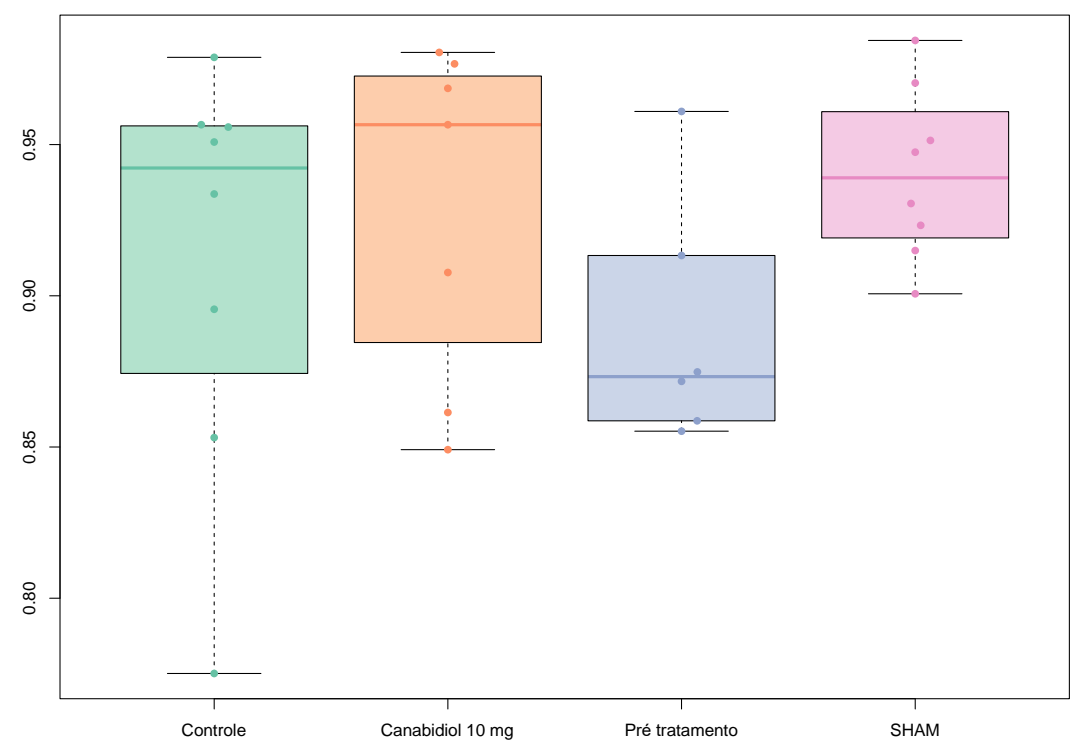

Figura 21 - Porcentagem de tempo gasto na região periférica durante o teste open field

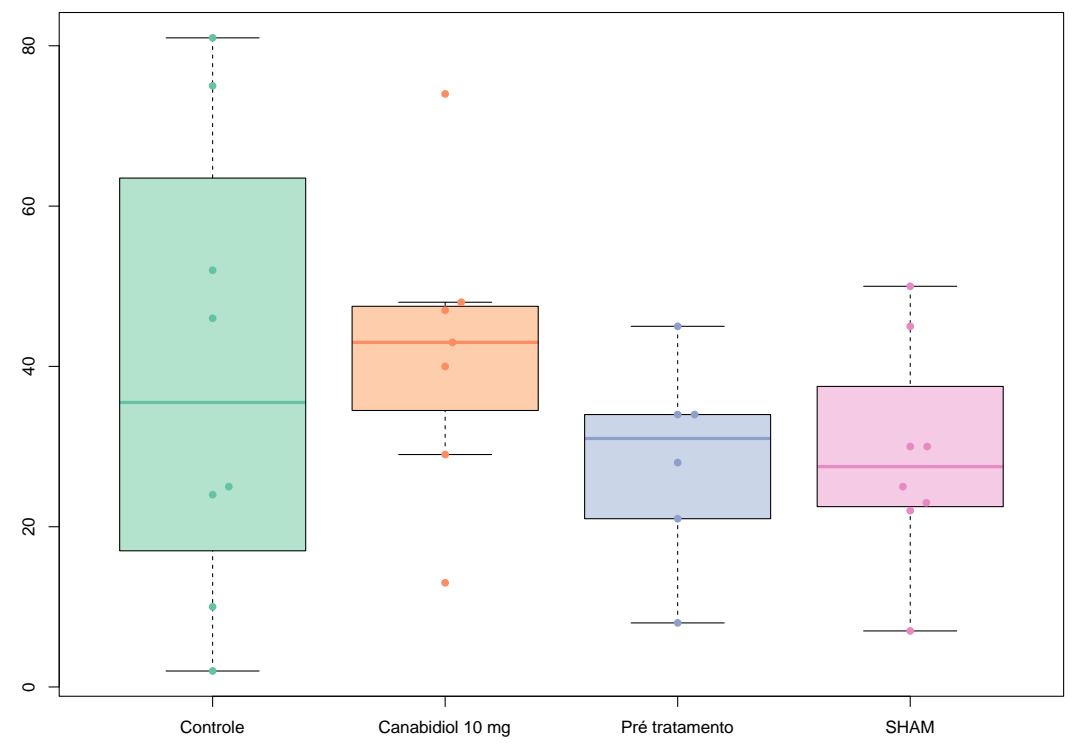

Figura 22 - Frequência de cruzamentos durante o teste open field 
Resultados $\mid 58$

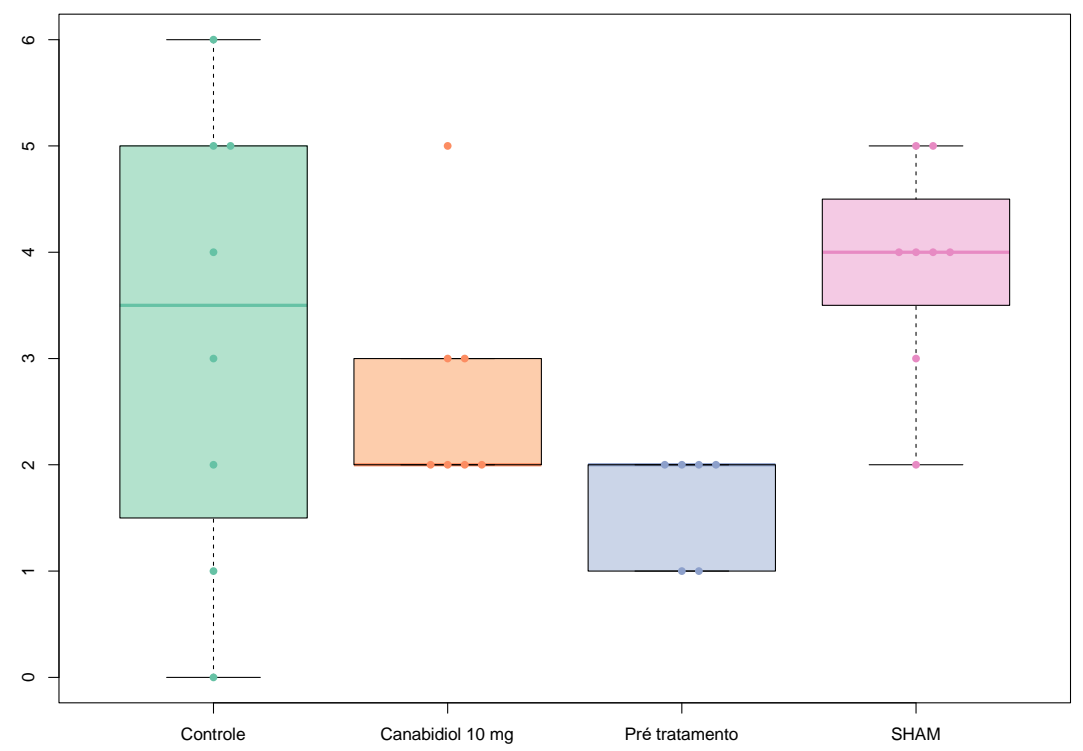

Figura 23 - Frequência de asseio durante o teste open field

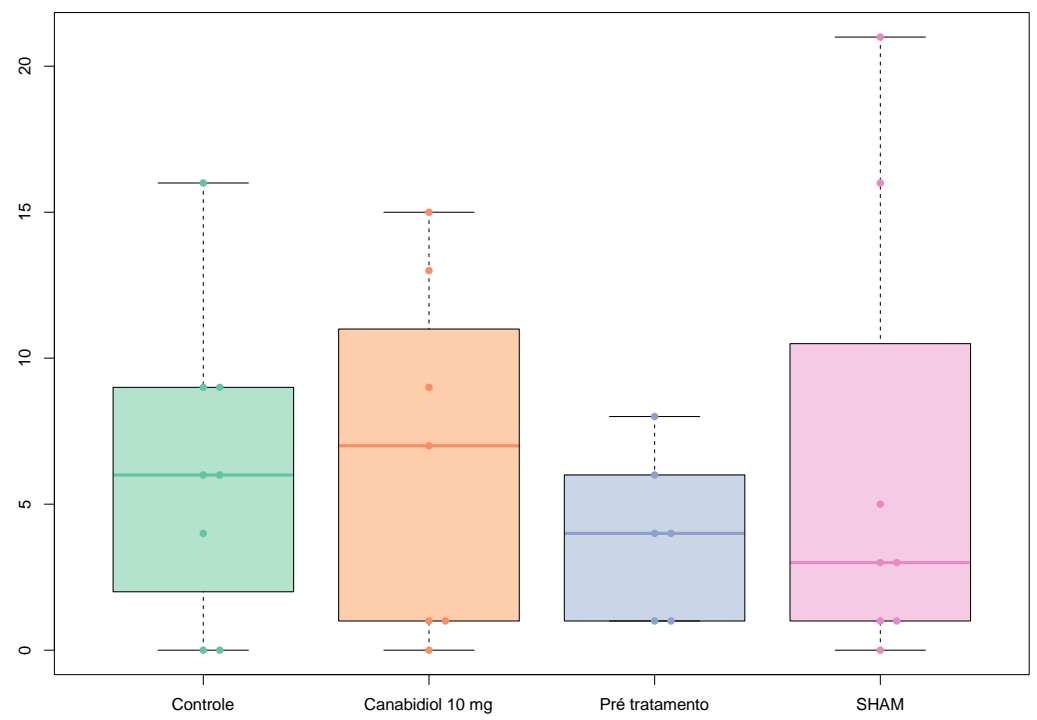

Figura 24 - Frequência de soerguimento durante teste open field 


\subsubsection{Labirinto em Y}

Não encontrou-se diferença estatisticamente significante no teste de memória espacial utilizando o labirinto em Y entre os grupos (Figura 25).

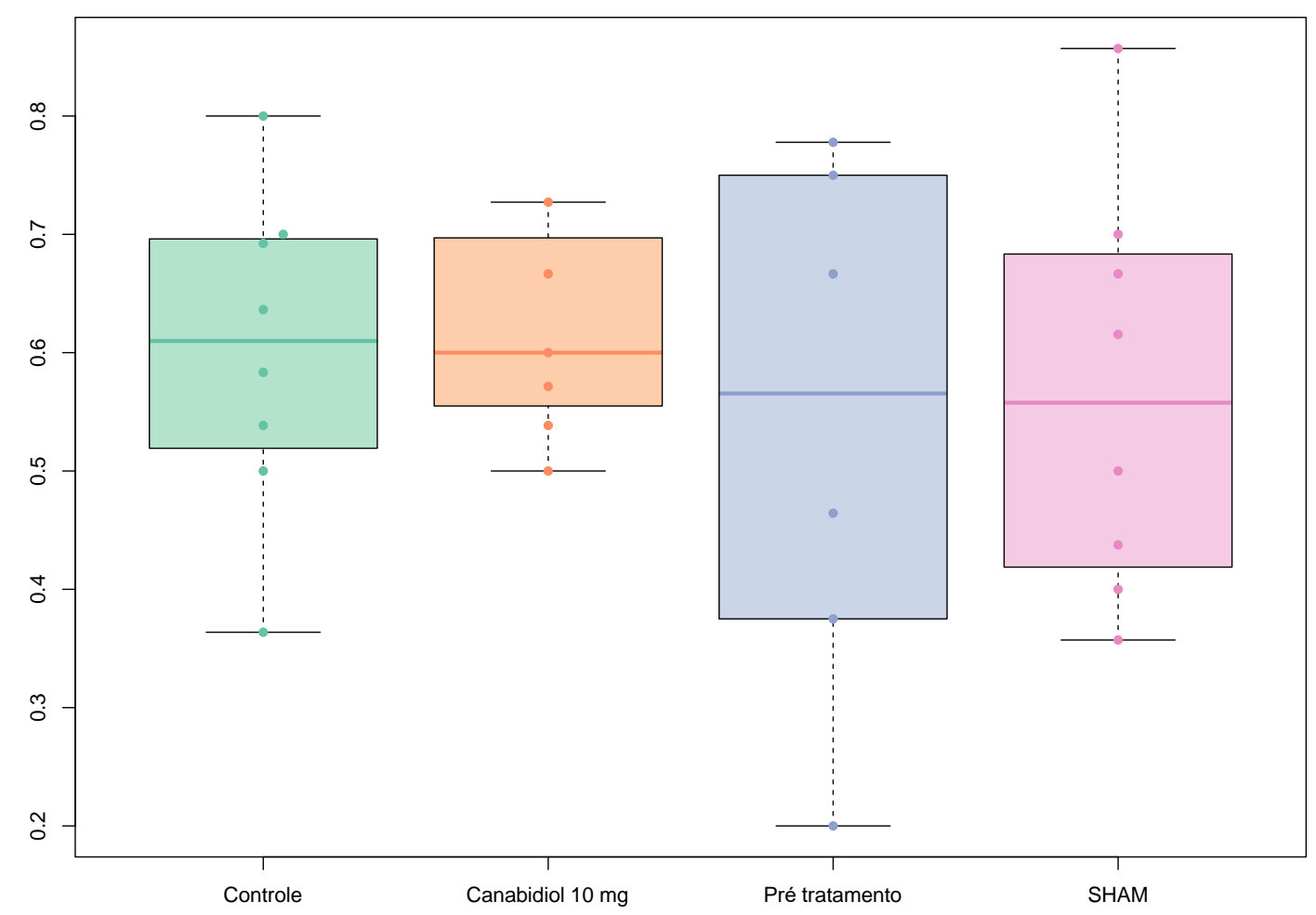

Figura 25 - Boxplot do coeficiente de sequências lógicas durante teste em labirinto em Y 


\subsubsection{Teste de reconhecimento de objetos}

Não foi observado diferença estatisticamente significante no percentual de tempo gasto na exploração do objeto novo entre os grupos (Figura 26).

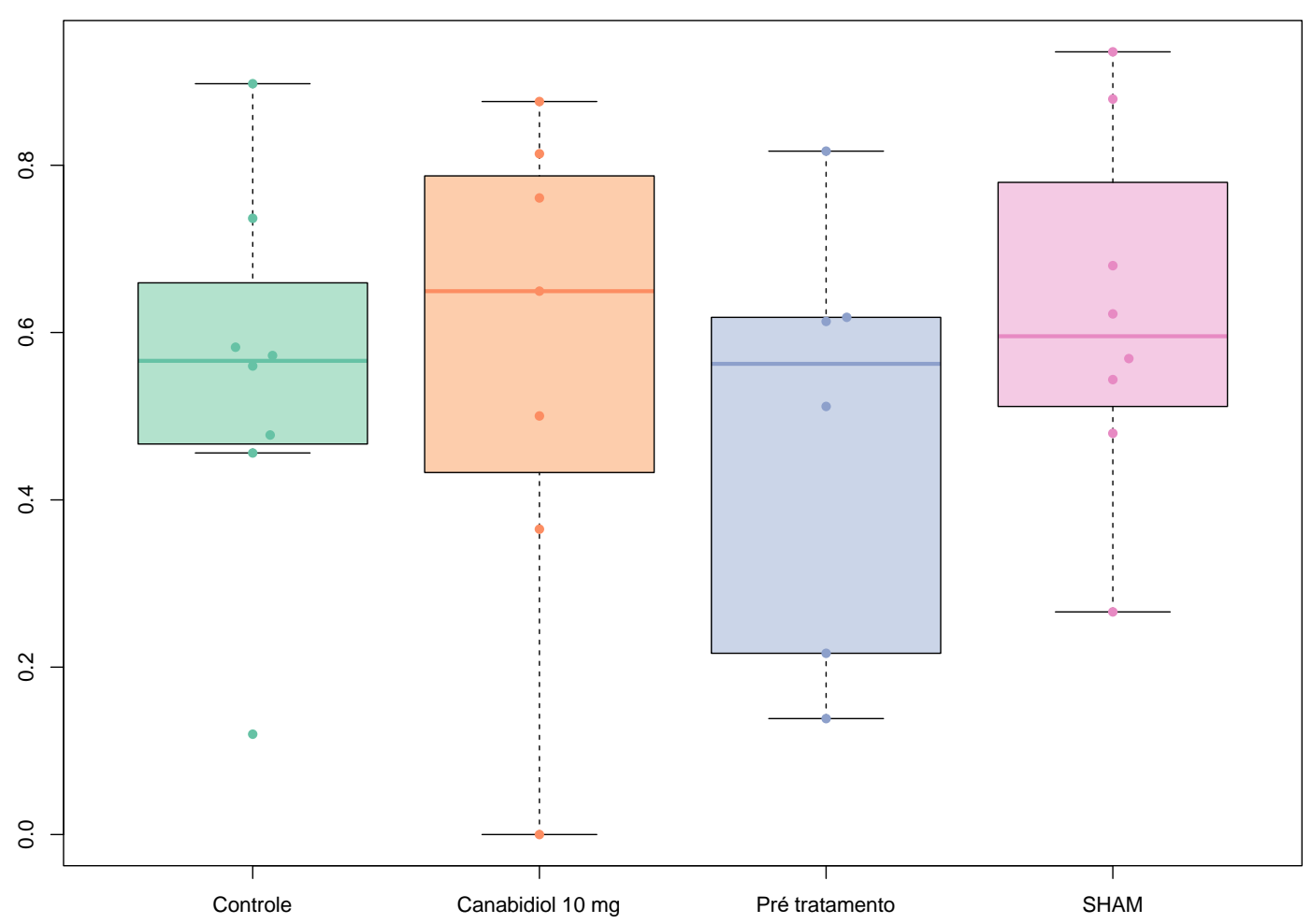

Figura 26 - Boxplot da porcentagem de tempo gasto na exploração do objeto novo entre os grupos Controle, Canabidiol $10 \mathrm{mg}$, Pré-tratamento e SHAM 
5. DISCUSSÃO 


\section{DISCUSSÃO}

Descrevemos pela primeira vez as propriedades neuroprotetoras do canabidiol em modelo experimental de HMG. Observamos, no presente trabalho, uma redução do número de astrócitos $\mathrm{GFAP}^{+}$na região perilesional ao nível dos núcleos da base 24 horas após a injúria hemorrágica com o uso do canabidiol. Essa diferença foi significativa em todos os grupos tratados com canabidiol (1 mg, $10 \mathrm{mg}$ e pré-tratamento com $10 \mathrm{mg}$ ), se assemelhando ao grupo SHAM. A redução da quantidade de astrócitos reativos também foi demonstrada na região dos núcleos da base 14 dias após a hemorragia. O grupo pré-tratado, entretanto, apesar de ter apresentado um número menor de astrócitos reativos em relação ao grupo controle, essa diferença não foi estatisticamente significativa $(p=0.22)$. De forma interessante, encontramos uma redução no número de astrócitos reativos no stratum oriens da região de CA1 do hipocampo ipsilateral 14 dias após a hemorragia, em todos os grupos tratados com canabidiol.

Astrócitos são usualmente alvos de estudo em pesquisas de neuroproteção, não apenas por serem as células mais abundantes do sistema nervoso central, mas também por sua atividade na organização de circuitos neuronais e na neuroplasticidade (BARRETO et al., 2011). Além disso, astrócitos demonstram-se mais resistentes que neurônios a períodos de privação de glicose e oxigênio, principalmente astrócitos fibrosos, comumente encontrados no striatum (GIFFARD; SWANSON, 2005; LUKASZEVICZ et al., 2002; XU; SAPOLSKY; GIFFARD, 2001). A redução do número de astrócitos reativos por campo tem sido amplamente utilizado como marcador de neuroproteção em estudos experimentais, embora ainda seja controverso o real impacto dos efeitos benéficos e deletérios dos astrócitos reativos em patologias isquêmicas ou hemorrágicas cerebrais. Algumas evidências sugerem que a redução da concentração dessas células nas fase aguda favoreceria a regeneração axonal (DAVIES; FIELD; RAISMAN, 1996) e a recuperação cognitiva e motora em modelo de isquemia cerebral (DI GIOVANNI et al., 2005). Outros estudos, entretanto, demonstraram efeitos benéficos da presença de astrócitos reativos através da preservação de neurônios corticais e da redução do processo inflamatório (MYER, 2006). Por fim, alguns autores demonstraram que a atividade astrocitária está relacionada ao período após a lesão, sendo que a presença dessas células na fase aguda e tardia estaria relacionada à piora da injúria neuronal, enquanto sua presença na fase subaguda, após a estabilização do processo inflamatório, se correlacionaria ao 
restabelecimento da hemostasia local com efeitos benéficos (HOLLAND et al., 2008; SOFRONIEW, 2005).

Baseado nos estudos in vitro e in vivo de neuroproteção, especialmente em modelos de isquemia cerebral, acreditamos que a redução da concentração dos astrócitos GFAP $^{+}$ encontrados nas fases aguda (24 horas) e tardia (14 dias) após a indução hemorrágica no presente estudo esteja relacionado à redução do processo inflamatório pelo canabidiol e que apresente potencial efeito benéfico como neuroprotetor.

Utilizamos técnica imuno-histoquímica para caspase 3 para análise da capacidade do canabidiol na prevenção da indução de apoptose após lesão hemorrágica. Observamos uma redução significativa na quantidade de astrócitos em processo de apoptose em todos os grupos tratados com canabidiol em relação ao grupo controle na fase aguda. O mesmo não foi observado tardiamente, onde a diferença entre os grupos controle e tratados não foi estatisticamente significativa.

A capacidade neuroprotetora do canabidiol foi descrita anteriormente através da redução da morte por apoptose induzida por beta-amilóide em cultura de células PC12 de ratos (IUVONE et al., 2004). Esse estudo demonstrou menor número de células caspase 3 positivas, bem como redução da produção de radicais livres e peroxidação lipídica, com consequente aumento na sobrevida celular, nas células tratadas com canabidiol. Resultado semelhante também foi demonstrado em modelo de toxicidade por ferro (DA SILVA et al., 2014). Animais tratados com canabidiol apresentaram redução do nível de sinaptofisina e caspase 3 em células hipocampais.

Entendemos a diminuição na quantidade de astrócitos marcados com caspase 3 na fase aguda como evidência de ação neuroprotetora pelo canabidiol através da redução de morte neuronal por apoptose, com consequente condensação nuclear e picnólise. Esse resultado está de acordo com dados da literatura que demonstram atividade neuroprotetora em modelo de lesão hipóxico-isquêmica em ratos neonatais tratados com inibidor reversível da caspase 3 (HAN et al., 2002). Análise quantitativa de astrócitos positivos para caspase 3 em modelo de isquemia cerebral por oclusão da artéria cerebral média em ratos demonstrou aumento da sua expressão 24 horas e 7 dias após a lesão isquêmica, mas não após 14 dias (MCLAUGHLIN et al., 2003). Esses resultados estão de acordo com a ausência de diferença significativa de astrócitos marcados para caspase 3 no striatum e no hipocampo entre controle e grupos tratados 14 dias após injúria hemorrágica. 
Estudos prévios com hemorragia intraventricular demonstraram a correlação entre a espessura do corpo caloso e a dilatação ventricular (AHN et al., 2013). Os autores demonstraram que, conforme a dilatação ventricular progride, a espessura do corpo caloso reduz significativamente. A espessura do corpo caloso pode, assim, ser utilizada como uma medida indireta da incidência de hidrocefalia em modelo de hemorragia ventricular. Não encontramos diferença entre os grupos na análise da espessura do corpo caloso 14 dias após a injúria hemorrágica. Essa observação pode estar relacionada ao fato da hemorragia ser localizada mais periventricular (na região da matriz germinativa) do que intraventricular, ou devido ao tempo transcorrido desde à HMG não ter sido suficiente para o surgimento de hidrocefalia.

Para análise do efeito do canabidiol na formação do edema cerebral após indução de HMG realizamos a desidratação do hemisfério cerebral ipsilateral através da técnica de liofilização por 12 horas. Conforme esperado, observamos uma diferença significativa entre o grupo controle e o grupo SHAM. Embora o valor da água livre no hemisfério ipsilateral dos animais tratados com canabidiol tenham sido menores do que aquele do grupo controle, essa diferença não apresentou significância estatística.

Estudos de neuroproteção em modelo de HMG tratados com minociclina ou JWH133 (agonista seletivo do receptor CB2) demonstraram redução significativa do edema perilesional nos grupos tratados (TANG et al., 2016; TAO et al., 2015). De forma semelhante, o mesmo grupo de pesquisadores demonstrou redução da quebra da barreira hematoencefálica induzida por trombina nos grupos tratados com JWH133 (LI et al., 2015).

Uma explicação para o resultado encontrado pode estar relacionado à técnica utilizada para análise tecidual. No presente estudo, utilizamos o hemisfério ipsilateral (sem o tronco cerebral e o cerebelo) para o cálculo da quantidade de água livre no tecido. Uma vez que o edema tecidual 24 horas após à lesão hemorrágica localiza-se predominantemente na zona perilesional, a técnica utilizada pode ter atenuado a diferença entre a quantidade de água livre tecidual entre os grupos controle e tratados. Nós questionamos se a restrição da análise tecidual ao lobo frontal imediatamente relacionado à área hemorrágica alteraria a diferença observada em nosso estudo. Por exemplo, a utilização de um corte coronal entre $1 \mathrm{~mm}$ anterior e $1 \mathrm{~mm}$ posterior à sutura coronal restringiria a análise tecidual à área de maior interesse. 
No estudo de estresse oxidativo com dosagem de MDA no parênquima cerebral ipsilateral, não observamos diferença estatisticamente significativa entre os grupos controle, SHAM e canabidiol 10mg. Observamos, entretanto, aumento significativo de MDA nos grupos tratados com canabidiol $1 \mathrm{mg}$ e pré-tratamento. Esse resultado nos faz suspeitar que o canabidiol possa aumentar a peroxidação lipídica quando utilizado em menores doses ou como profilático. Nós sugerimos que novos estudos sejam realizados com canabidiol em diferentes doses e com diferentes técnicas de avaliação do estresse oxidativo (por exemplo, atividade da superóxido dismutase).

Estudo in vitro demonstrou a capacidade do canabidiol de reduzir a excitotoxicidade glutamatérgica e morte celular induzida por estresse oxidativo em cultura de neurônios de ratos (HAMPSON et al., 1998b). Posteriormente, estudos animais em modelo de encefalopatia hipóxico-isquêmica adulto e neonatal demonstraram a capacidade do canabidiol de atuar como antioxidante através da redução da expressão da COX-2 e da atividade da mieloperoxidase, e do aumento da razão glutationa:creatinina em relação ao grupo controle (CASTILLO et al., 2010; HAYAKAWA et al., 2007; PAZOS et al., 2013). De forma semelhante, estudos com modelos de doenças neurodegenerativas demonstraram a capacidade antioxidante do canabidiol (ESPOSITO et al., 2011; GARCÍA-ARENCIBIA et al., 2007a).

Observamos no presente trabalho que os grupos tratados com canabidiol 10mg/Kg apresentaram aumento significativo do peso corporal ao longo de 14 dias após a indução da HMG. Resultados da literatura são conflitantes nesse aspecto com estudos demonstrando aumento e redução do ganho ponderal em animais tratados com canabidiol (IGNATOWSKA-JANKOWSKA; JANKOWSKI; SWIERGIEL, 2011; TAKEDA et al., 2015). Nosso trabalho favorece o achado que o canabidiol estimula o aumento do ganho ponderal.

Acompanhamos o desenvolvimento neuropsicomotor por 14 dias após indução da HMG. Foi observado, nos animais tratados com canabidiol, melhora do tempo necessário nas tarefas de endireitamento (canabidiol $10 \mathrm{mg}$ e pré-tratamento) e de geotaxia negativa (canabidiol $10 \mathrm{mg}$ ) em relação ao grupo controle. Esse resultado pode ser interpretado como potencial neuroprotetor ou neuroestimulante; devemos, entretanto, considerar que não houve diferença entre os grupos controle e SHAM.

Por fim, não observamos diferença significativa nos testes open field, labirinto em Y ou no teste de reconhecimento de objeto. Estudos anteriores com canabidiol em modelo 
de isquemia cerebral demonstraram melhora da coordenação motora testado com auxílio de um rota-rod e da memória de reconhecimento de curto prazo (HAYAKAWA et al., 2007; PAZOS et al., 2012). Melhora da memória espacial e de reconhecimento de objetos também foi demonstrada em modelo de doença de Alzheimer (CHENG et al., 2014; MARTIN-MORENO et al., 2011). Entretanto, em teste clínico com pacientes portadores de doença de Parkinson, não foram observadas mudanças na resposta motora ou nos testes de memória (ZUARDI et al., 2009). 
6. CONCLUSÃO 


\section{CONCLUSÃO}

O uso do canabidiol como neuroprotetor em modelo de HMG demonstrou resultados promissores. Os animais tratados com canabidiol apresentaram menor quantidade de astrócitos reativos e em apoptose na fase aguda da hemorragia. Encontramos ainda uma menor quantidade de astrócitos reativos na fase tardia à hemorragia, tanto para a zona parenquimatosa perilesional como no Stratum oriens de CA1. Não houve diferença entre a dose de $1 \mathrm{mg} / \mathrm{Kg}$ e $10 \mathrm{mg} / \mathrm{Kg}$ na resposta tecidual estudada.

Não encontramos diferença significativa na formação do edema cerebral ou na resposta de estresse oxidativo entre os grupos.

Os animais tratados com canabidiol na dose de $10 \mathrm{mg} / \mathrm{Kg}$ apresentaram melhor resposta nos testes de endireitamento e de geotaxia negativa durante desenvolvimento. Não encontramos, entretanto, diferença significativa na data de abertura ocular ou testes de memória entre os grupos.

O canabidiol apresentou propriedades neuroprotetoras anti-inflamatórias no modelo estudado. Entretanto, testes clínicos e pré-clínicos são necessários para demonstrar o real benefício terapêutico do canabidiol para o tratamento da $\mathrm{HMG}$ em prematuros extremos. 
REFERÊNCIAS 


\section{REFERÊNCIAS}

ACARIN, L.; GONZÁLEZ, B.; CASTELLANO, B. Neuronal, astroglial and microglial cytokine expression after an excitotoxic lesion in the immature rat brain. The European Journal of Neuroscience, v. 12, n. 10, p. 3505-20, out. 2000.

ADAMS-CHAPMAN, I. et al. Neurodevelopmental outcome of extremely low birth weight infants with posthemorrhagic hydrocephalus requiring shunt insertion. Pediatrics, v. 121, n. 5, p. e116777, maio 2008.

ADCOCK, K. et al. The TNF-alpha -308, MCP-1 -2518 and TGF-beta1 +915 polymorphisms are not associated with the development of chronic lung disease in very low birth weight infants. Genes and Immunity, v. 4, n. 6, p. 420-6, set. 2003.

AHN, S. Y. et al. Mesenchymal Stem Cells Prevent Hydrocephalus After Severe Intraventricular Hemorrhage. Stroke, v. 44, n. 2, p. 497-504, 1 fev. 2013.

ALLES, Y. C. J.; COSTA, J. C. Desenvolvimento de um modelo experimental de hemorragia subependimária-intraventricular em ratos recém-nascidos. [s.1.] Pontifícia Universidade Catoólica do Rio Grande do Sul, 2009 [dissertação de mestrado].

APPENDINO, G.; CHIANESE, G.; TAGLIALATELA-SCAFATI, O. Cannabinoids: occurrence and medicinal chemistry. Current Medicinal Chemistry, v. 18, p. 1085-1099, 2011.

BAIER, R. J. Genetics of perinatal brain injury in the preterm infant. Frontiers in Bioscience, v. 11, p. 1371-87, jan. 2006.

BALLABH, P. Intraventricular Hemorrhage in Premature Infants: Mechanism of Disease. Pediatric Research, v. 67, n. 1, p. 1-8, jan. 2010.

BARRETO, G. et al. Astrocytes: targets for neuroprotection in stroke. Central Nervous System Agents in Medicinal Chemistry, v. 11, n. 2, p. 164-73, 1 jun. 2011.

BRAIDA, D. et al. Post-ischemic treatment with cannabidiol prevents electroencephalographic flattening, hyperlocomotion and neuronal injury in gerbils. Neuroscience Letters, v. 346, n. 1-2, p. 61-4, 31 jul. 2003.

BRAIDA, D. et al. Cognitive function in young and adult IL (interleukin)-6 deficient mice. Behavioural Brain Research, v. 153, n. 2, p. 423-9, 31 ago. 2004. 
BROUWER, A. J. et al. Early and late complications of germinal matrix-intraventricular haemorrhage in the preterm infant: what is new? Neonatology, v. 106, n. 4, p. 296-303, jan. 2014.

CAI, Z. et al. Brain injury induced by intracerebral injection of interleukin-1beta and tumor necrosis factor-alpha in the neonatal rat. Pediatric Research, v. 56, n. 3, p. 377-84, set. 2004.

CARRIER, E. J.; AUCHAMPACH, J. A; HILLARD, C. J. Inhibition of an equilibrative nucleoside transporter by cannabidiol: a mechanism of cannabinoid immunosuppression. PNAS, v. 103, n. 20, p. 7895-7900, 2006.

CASTILLO, A. et al. The neuroprotective effect of cannabidiol in an in vitro model of newborn hypoxic-ischemic brain damage in mice is mediated by CB2 and adenosine receptors. Neurobiology of Disease, v. 37, n. 2, p. 434-440, fev. 2010.

CHENG, D. et al. Chronic cannabidiol treatment improves social and object recognition in double transgenic APPswe/PS1 $\triangle$ E9 mice. Psychopharmacology, v. 231, n. 15, p. 3009-3017, 1 ago. 2014.

COSTA, B. et al. Oral anti-inflammatory activity of cannabidiol, a non-psychoactive constituent of cannabis, in acute carrageenan-induced inflammation in the rat paw. Naunyn-Schmiedeberg's Archives of Pharmacology, v. 369, n. 3, p. 294-9, mar. 2004.

COSTA, B. et al. The non-psychoactive cannabis constituent cannabidiol is an orally effective therapeutic agent in rat chronic inflammatory and neuropathic pain. European Journal of Pharmacology, v. 556, n. 1-3, p. 75-83, 5 fev. 2007.

DA SILVA, V. K. et al. Cannabidiol Normalizes Caspase 3, Synaptophysin, and Mitochondrial Fission Protein DNM1L Expression Levels in Rats with Brain Iron Overload: Implications for Neuroprotection. Molecular Neurobiology, v. 49, n. 1, p. 222-233, 28 fev. 2014.

DAVIES, S. J. A.; FIELD, P. M.; RAISMAN, G. Regeneration of Cut Adult Axons Fails Even in the Presence of Continuous Aligned Glial Pathways. Experimental Neurology, v. 142, n. 2, p. 203-216, dez. 1996.

DEL BIGIO, M. R. Cell proliferation in human ganglionic eminence and suppression after prematurity-associated haemorrhage. Brain : A Journal of Neurology, v. 134, n. Pt 5, p. 1344-61, maio 2011.

DI GIOVANNI, S. et al. Cell cycle inhibition provides neuroprotection and reduces glial proliferation and scar formation after traumatic brain injury. Proceedings of the National Academy of Sciences, v. 102, n. 23, p. 8333-8338, 7 jun. 2005.

DOUGLAS-ESCOBAR, M.; WEISS, M. D. Biomarkers of brain injury in the premature infant. Frontiers in Neurology, v. 3, p. 185, jan. 2012. 
DUGGAN, P. J. et al. Intrauterine T-cell activation and increased proinflammatory cytokine concentrations in preterm infants with cerebral lesions. Lancet, v. 358, n. 9294, p. 1699-700, 17 nov. 2001.

EL-REMESSY, A. B. et al. Neuroprotective effect of (-)Delta9-tetrahydrocannabinol and cannabidiol in N-methyl-d-aspartate-induced retinal neurotoxicity: involvement of peroxynitrite. American Journal of Pathology, v. 163, p. 1997-2008, 2003.

ESPOSITO, G. et al. Cannabidiol Reduces A $\beta$-Induced Neuroinflammation and Promotes Hippocampal Neurogenesis through PPAR $\gamma$ Involvement. PLoS ONE, v. 6, n. 12, p. e28668, 5 dez. 2011.

FOWLIE, P. W.; DAVIS, P. G. Prophylactic indomethacin for preterm infants: a systematic review and meta-analysis. Archives of Disease in Childhood. Fetal and Neonatal edition, v. 88, n. 6, p. F464-6, nov. 2003.

GALASSO, J. M. et al. Inhibition of TNF-alpha can attenuate or exacerbate excitotoxic injury in neonatal rat brain. Neuroreport, v. 11, n. 2, p. 231-5, 7 fev. 2000.

GARCÍA-ARENCIBIA, M. et al. Evaluation of the neuroprotective effect of cannabinoids in a rat model of Parkinson's disease: Importance of antioxidant and cannabinoid receptor-independent properties. Brain Research, v. 1134, p. 162-170, fev. 2007a.

GARCÍA-ARENCIBIA, M. et al. Evaluation of the neuroprotective effect of cannabinoids in a rat model of Parkinson's disease: importance of antioxidant and cannabinoid receptor-independent properties. Brain research, v. 1134, n. 1, p. 162-70, 23 fev. 2007b.

GIFFARD, R. G.; SWANSON, R. A. Ischemia-induced programmed cell death in astrocytes. Glia, v. 50, n. 4, p. 299-306, jun. 2005.

GONG, C.; HOFF, J. T.; KEEP, R. F. Acute inflammatory reaction following experimental intracerebral hemorrhage in rat. Brain Research, v. 871, n. 1, p. 57-65, 14 jul. 2000.

GRILLI, M. et al. Interleukin-10 modulates neuronal threshold of vulnerability to ischaemic damage. The European Journal of Neuroscience, v. 12, n. 7, p. 2265-72, jul. 2000.

HALLIWELL, B. Reactive oxygen species and the central nervous system. Journal of Neurochemistry, v. 59, n. 5, p. 1609-23, nov. 1992.

HALLIWELL, B. Free radicals, proteins and DNA: oxidative damage versus redox regulation. Biochemical Society Transactions, v. 24, n. 4, p. 1023-7, nov. 1996. 
HAMPSON, A. J. et al. Cannabidiol and (-)Delta9-tetrahydrocannabinol are neuroprotective antioxidants. Proceedings of the National Academy of Sciences of the United States of America, v. 95, n. 14, p. 8268-73, 7 jul. 1998a.

HAMPSON, A. J. et al. Cannabidiol and (-)Delta9-tetrahydrocannabinol are neuroprotective antioxidants. Proceedings of the National Academy of Sciences of the United States of America, v. 95, n. 14, p. 8268-73, 7 jul. 1998b.

HAN, B. H. et al. Selective, Reversible Caspase-3 Inhibitor Is Neuroprotective and Reveals Distinct Pathways of Cell Death after Neonatal Hypoxic-ischemic Brain Injury. Journal of Biological Chemistry, v. 277, n. 33, p. 30128-30136, 16 ago. 2002.

HAYAKAWA, K. et al. Cannabidiol prevents infarction via the non-CB1 cannabinoid receptor mechanism. Neuroreport, v. 15, n. 15, p. 2381-5, 25 out. 2004.

HAYAKAWA, K. et al. Delayed treatment with cannabidiol has a cerebroprotective action via a cannabinoid receptor-independent myeloperoxidase-inhibiting mechanism. Journal of Neurochemistry, v. 102, n. 5, p. 1488-1496, set. 2007.

HEEP, A. et al. Increased serum levels of interleukin 6 are associated with severe intraventricular haemorrhage in extremely premature infants. Archives of Disease in Childhood. Fetal and Neonatal edition, v. 88, n. 6, p. F501-4, nov. 2003.

HICKENBOTTOM, S. L. et al. Nuclear factor-kappaB and cell death after experimental intracerebral hemorrhage in rats. Stroke, v. 30, n. 11, p. 2472-7; discussion 2477-8, nov. 1999.

HOLLAND, M. A. et al. Nicotinamide Treatment Provides Acute Neuroprotection and GFAP Regulation following Fluid Percussion Injury. Journal of Neurotrauma, v. 25, n. 2, p. 140-152, fev. 2008.

HOLMIN, S.; MATHIESEN, T. Intracerebral administration of interleukin-1beta and induction of inflammation, apoptosis, and vasogenic edema. Journal of Neurosurgery, v. 92, n. 1, p. 108-20, jan. 2000.

IGNATOWSKA-JANKOWSKA, B.; JANKOWSKI, M. M.; SWIERGIEL, A. H. Cannabidiol decreases body weight gain in rats: Involvement of CB2 receptors. Neuroscience Letters, v. 490, n. 1, p. 82-84, fev. 2011.

IUVONE, T. et al. Neuroprotective effect of cannabidiol, a non-psychoactive component from Cannabis sativa, on beta-amyloid-induced toxicity in PC12 cells. Journal of Neurochemistry, v. 89 , n. 1, p. 134-41, abr. 2004.

JAIN, N. J. et al. Impact of mode of delivery on neonatal complications: trends between 1997 and 2005. The Journal of Maternal-Fetal \& Neonatal Medicine, v. 22, n. 6, p. 491-500, jun. 2009. 
JENKINS, A.; MAXWELL, W.; GRAHAN, D. Experimental intracerebral hematoma in the rat: sequential light microscopic changes. Neuropathol Appl Neurobiol, v. 15, p. 477-86, 1989.

JUKNAT, A. et al. Differential transcriptional profiles mediated by exposure to the cannabinoids cannabidiol and $\Delta$-tetrahydrocannabinol in BV-2 microglial cells. British Journal of Pharmacology, v. 165, p. 2512-2528, 2012.

KUTTY, R. K.; MAINES, M. D. Purification and characterization of biliverdin reductase from rat liver. The Journal of Biological Chemistry, v. 256, n. 8, p. 3956-62, 25 abr. 1981.

LANGHOFF-ROOS, J. et al. Spontaneous preterm delivery in primiparous women at low risk in Denmark: population based study. BMJ (Clinical research ed.), v. 332, n. 7547, p. 937-9, 22 abr. 2006.

LEE, K. R. et al. Edema from intracerebral hemorrhage: the role of thrombin. Journal of Neurosurgery, v. 84, n. 1, p. 91-6, jan. 1996.

LEE, K. R. et al. Mechanisms of edema formation after intracerebral hemorrhage: effects of thrombin on cerebral blood flow, blood-brain barrier permeability, and cell survival in a rat model. Journal of Neurosurgery, v. 86, n. 2, p. 272-8, fev. 1997.

LEE, Y. B.; NAGAI, A.; KIM, S. U. Cytokines, chemokines, and cytokine receptors in human microglia. Journal of Neuroscience Research, v. 69, n. 1, p. 94-103, 1 jul. 2002.

LEKIC, T. et al. A Novel Preclinical Model of Germinal Matrix Hemorrhage Using Neonatal Rats. In: Acta neurochirurgica. Supplement. [s.l: s.n.]. v. 111p. 55-60.

LEKIC, T. et al. Rodent neonatal germinal matrix hemorrhage mimics the human brain injury, neurological consequences, and post-hemorrhagic hydrocephalus. Experimental Neurology, v. 236, n. 1, p. 69-78, 2012.

LI, H.; SWIERCZ, R.; ENGLANDER, E. W. Elevated metals compromise repair of oxidative DNA damage via the base excision repair pathway: implications of pathologic iron overload in the brain on integrity of neuronal DNA. Journal of Neurochemistry, v. 110, n. 6, p. 1774-83, set. 2009.

LI, L. et al. A Cannabinoid Receptor 2 Agonist Prevents Thrombin-Induced Blood-Brain Barrier Damage via the Inhibition of Microglial Activation and Matrix Metalloproteinase Expression in Rats. Translational Stroke Research, v. 6, n. 6, p. 467-477, 2015.

LUKASZEVICZ, A.-C. et al. High Sensitivity of Protoplasmic Cortical Astroglia to Focal Ischemia. Journal of Cerebral Blood Flow \& Metabolism, v. 22, n. 3, p. 289-298, 31 mar. 2002. 
LUNN, C. A. et al. A Novel Cannabinoid Peripheral Cannabinoid Receptor-Selective Inverse Agonist Blocks Leukocyte Recruitment in Vivo. Pharmacology, v. 316, n. 2, p. 780-788, 2006.

MAITRE, N. L. et al. Neurodevelopmental outcome of infants with unilateral or bilateral periventricular hemorrhagic infarction. Pediatrics, v. 124, n. 6, p. e1153-60, dez. 2009.

MALFAIT, A. M. et al. The nonpsychoactive cannabis constituent cannabidiol is an oral antiarthritic therapeutic in murine collagen-induced arthritis. Proceedings of the National Academy of Sciences of the United States of America, v. 97, n. 17, p. 9561-6, 15 ago. 2000.

MARLET, J. M.; BARRETO FONSECA, J. DE P. Experimental determination of time of intracranial hemorrhage by spectrophotometric analysis of cerebrospinal fluid. Journal of Forensic Sciences, v. 27, n. 4, p. 880-8, out. 1982.

MARTIN-MORENO, A. M. et al. Cannabidiol and Other Cannabinoids Reduce Microglial Activation In Vitro and In Vivo: Relevance to Alzheimer's Disease. Molecular Pharmacology, v. 79, n. 6, p. 964-973, 1 jun. 2011.

MARTINEZ, E. et al. Elevated Amniotic Fluid Interleukin-6 as a Predictor of Neonatal Periventricular Leukomalacia and Intraventricular Hemorrhage. Journal of Maternal-Fetal Investigation, v. 8, n. 3, p. 101-107, set. 1998.

MATTSON, M. P.; MEFFERT, M. K. Roles for NF-kappaB in nerve cell survival, plasticity, and disease. Cell Death and Differentiation, v. 13, n. 5, p. 852-60, maio 2006.

MCLAUGHLIN, B. et al. Caspase 3 activation is essential for neuroprotection in preconditioning. Proceedings of the National Academy of Sciences, v. 100, n. 2, p. 715-720, 21 jan. 2003.

MECHA, M. et al. Cannabidiol provides long-lasting protection against the deleterious effects of inflammation in a viral model of multiple sclerosis: a role for A2A receptors. Neurobiology of Disease, v. 59, p. 141-50, nov. 2013.

MISHIMA, K. et al. Cannabidiol prevents cerebral infarction via a serotonergic 5hydroxytryptamine1A receptor-dependent mechanism. Stroke; a journal of cerebral Circulation, v. 36, n. 5, p. 1077-82, maio 2005.

MURPHY, B. P. et al. Posthaemorrhagic ventricular dilatation in the premature infant: natural history and predictors of outcome. Archives of Disease in Childhood. Fetal and Neonatal edition, v. 87, n. 1, p. F37-41, jul. 2002.

MYER, D. J. Essential protective roles of reactive astrocytes in traumatic brain injury. Brain, v. 129, n. 10, p. 2761-2772, 15 jul. 2006. 
PAPILE, L. A. et al. Incidence and evolution of subependymal and intraventricular hemorrhage: a study of infants with birth weights less than 1,500 gm. The Journal of Pediatrics, v. 92, n. 4, p. 529-34, abr. 1978.

PAZOS, M. R. et al. Cannabidiol administration after hypoxia-ischemia to newborn rats reduces long-term brain injury and restores neurobehavioral function. Neuropharmacology, v. 63, n. 5, p. 776-783, out. 2012.

PAZOS, M. R. et al. Mechanisms of cannabidiol neuroprotection in hypoxic-ischemic newborn pigs: Role of 5HT1A and CB2 receptors. Neuropharmacology, v. 71, p. 282-291, ago. 2013.

PINTO-MARTIN, J. A. et al. Relation of cranial ultrasound abnormalities in low-birthweight infants to motor or cognitive performance at ages 2, 6, and 9 years. Developmental Medicine and Child Neurology, v. 41, n. 12, p. 826-33, dez. 1999.

RIBEIRO, A. et al. Cannabidiol, a non-psychotropic plant-derived cannabinoid, decreases inflammation in a murine model of acute lung injury: role for the adenosine $\mathrm{A}(2 \mathrm{~A})$ receptor. European Journal of Pharmacology, v. 678, n. 1-3, p. 78-85, 5 mar. 2012.

RODRÍGUEZ FANJUL, J.; FERNÁNDEZ-FEIJOO, C.; CAMPRUBÍ, M. A New Technique for Collection of Cerebrospinal Fluid in Rat Pups. Journal of Experimental Neuroscience, v. 9, p. 37-41, maio 2015.

RUSSO, E. B. et al. Agonistic properties of cannabidiol at 5-HT1a receptors. Neurochemical Research, v. 30, n. 8, p. 1037-1043, 2005.

SAGREDO, O. et al. Cannabidiol reduced the striatal atrophy caused 3-nitropropionic acid in vivo by mechanisms independent of the activation of cannabinoid, vanilloid TRPV1 and adenosine A2A receptors. The European Journal of Neuroscience, v. 26, n. 4, p. 843-51, ago. 2007.

SALVADOR, G. A. Iron in neuronal function and dysfunction. BioFactors (Oxford, England), v. 36, n. 2, p. 103-10, jan. 2010.

SHENNAN, A. H.; BEWLEY, S. Why should preterm births be rising? BMJ (Clinical Research edition), v. 332, n. 7547, p. 924-5, 22 abr. 2006.

SLATTERY, M. M.; MORRISON, J. J. Preterm delivery. Lancet (London, England), v. 360, n. 9344, p. 1489-97, 9 dez. 2002.

SOFRONIEW, M. V. Reactive Astrocytes in Neural Repair and Protection. The Neuroscientist, v. 11, n. 5, p. 400-407, 29 out. 2005. 
SRINIVASAKUMAR, P. et al. Posthemorrhagic ventricular dilatation-impact on early neurodevelopmental outcome. American Journal of Perinatology, v. 30, n. 3, p. 207-14, mar. 2013.

SUZUKI, J.; EBINA, T. Sequential changes in tissue surrounding ICH. In: PIA, W.; LONGMAID, C.; ZIERSKI, J. (Eds.). Spontaneous Intracerebral Hematomas. [s.l: s.n.]. p. 121-128.

TAKEDA, S. et al. Cannabidiol-2',6'-dimethyl ether stimulates body weight gain in apolipoprotein E-deficient BALB/c. KOR/Stm Slc-Apoeshl mice. The Journal of Toxicological Sciences, v. 40, n. 6, p. 739-743, 2015.

TANG, J. et al. Cannabinoid receptor 2 attenuates microglial accumulation and brain injury following germinal matrix hemorrhage via ERK dephosphorylation in vivo and in vitro. Neuropharmacology, v. 95, n. May, p. 424-433, ago. 2015.

TANG, J. et al. Minocycline Attenuates Neonatal Germinal-Matrix-Hemorrhage-Induced Neuroinflammation and Brain Edema by Activating Cannabinoid Receptor 2. Molecular Neurobiology, v. 53, n. 3, p. 1935-1948, 2 abr. 2016.

TANG, J. et al. A selective CB2R agonist (JWH133) restores neuronal circuit after Germinal Matrix Hemorrhage in the preterm via CX3CR1 + microglia. Neuropharmacology, v. 119, p. 157169, jun. 2017.

TAO, Y. et al. Cannabinoid CB2 receptor stimulation attenuates brain edema and neurological deficits in a germinal matrix hemorrhage rat model. Brain Research, v. 1602, n. C, p. 127-135, mar. 2015.

TAUSCHER, M. K. et al. Association of histologic chorioamnionitis, increased levels of cord blood cytokines, and intracerebral hemorrhage in preterm neonates. Biology of the Neonate, v. 83, n. 3, p. 166-70, jan. 2003.

THOMAS, A. et al. Cannabidiol displays unexpectedly high potency as an antagonist of CB1 and CB2 receptor agonists in vitro. British Journal of Pharmacology, v. 150, n. 5, p. 613-623, 29 jan. 2009.

TILG, H. et al. Interleukin-6 (IL-6) as an anti-inflammatory cytokine: induction of circulating IL-1 receptor antagonist and soluble tumor necrosis factor receptor p55. Blood, v. 83, n. 1, p. 113-8, 1 jan. 1994.

VALVASSORI, S. et al. Acute and chronic administration of cannabidiol increases mitochondrial complex and creatine kinase activity in the rat brain. Revista Brasileira de Psiquiatria, v. 35, p. 380-386, 2013. 
VOHR, B. R. et al. School-age outcomes of very low birth weight infants in the indomethacin intraventricular hemorrhage prevention trial. Pediatrics, v. 111, n. 4 Pt 1, p. e340-6, abr. 2003.

VORHEES, C. V; WILLIAMS, M. T. Morris water maze: procedures for assessing spatial and related forms of learning and memory. Nature Protocols, v. 1, n. 2, p. 848-58, jan. 2006.

WILSON-COSTELLO, D. et al. Improved survival rates with increased neurodevelopmental disability for extremely low birth weight infants in the 1990s. Pediatrics, v. 115, n. 4, p. 997-1003, abr. 2005.

WU, J. et al. Iron and iron-handling proteins in the brain after intracerebral hemorrhage. Stroke, v. 34, n. 12, p. 2964-9, dez. 2003.

XI, G.; KEEP, R. F.; HOFF, J. T. Mechanisms of brain injury after intracerebral haemorrhage. The Lancet. Neurology, v. 5, n. 1, p. 53-63, jan. 2006.

XU, L.; SAPOLSKY, R. M.; GIFFARD, R. G. Differential sensitivity of murine astrocytes and neurons from different brain regions to injury. Experimental Neurology, v. 169, n. 2, p. 416-24, jun. 2001.

YANG, G. Y. et al. Experimental intracerebral hemorrhage: relationship between brain edema, blood flow, and blood-brain barrier permeability in rats. Journal of Neurosurgery, v. 81, n. 1, p. 93-102, jul. 1994.

YANG, G. Y. et al. Inhibition of TNFalpha attenuates infarct volume and ICAM-1 expression in ischemic mouse brain. Neuroreport, v. 9, n. 9, p. 2131-4, 22 jun. 1998.

ZUARDI, A. et al. Cannabidiol for the treatment of psychosis in Parkinson's disease. Journal of Psychopharmacology, v. 23, n. 8, p. 979-983, 18 nov. 2009.

ZUARDI, A. W. Cannabidiol: from an inactive cannabinoid to a drug with wide spectrum of action. Revista Brasileira de Psiquiatria, v. 30, n. 3, p. 271-280, set. 2008. 
ANEXOS 
Anexo A. Certificado de aprovação da Comissão de Ética no Uso de Animais 


\section{UNIVERSIDADE DE SÃO PAULO FACULDADE DE MEDICINA DE RIBEIRÃO PRETO COMISSÃO DE ÉTICA NO USO DE ANIMAIS}

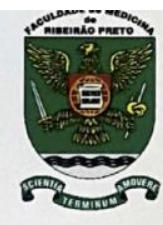

\section{CERTIFICADO}

Certificamos que o Protocolo intitulado "Efeitos clínicos, citológicos e imunohistoquímicos do canabidiol na zona perihemorrágica em modelo experimental de hemorragia da matriz germinativa em ratos", registrado com o número 149/2016, sob a responsabilidade da Profa. Dra. Luiza da Silva Lopes, envolvendo a produção, manutenção ou utilização de animais pertencentes ao filo Chordata, subfilo Vertebrata (exceto humanos) para fins de pesquisa científica, encontra-se de acordo com os preceitos da Lei $\mathrm{n}^{\circ} 11.794$ de 8 de outubro de 2008, do Decreto $n^{\circ} 6.899$ de 15 de julho de 2009 e com as normas editadas pelo Conselho Nacional de Controle de Experimentação Animal (CONCEA), e foi APROVADO pela Comissão de Ética no Uso de Animais da Faculdade de Medicina de Ribeirão Preto da Universidade de São Paulo em reunião de 26 de setembro de 2016.

Este Protocolo prevê a utilização de 128 ratos Wistar machos pesando $18 \mathrm{~g}$ e 16 ratos Wistar fêmeas pesando $350 \mathrm{~g}$, oriundos do Serviço de Biotério da Prefeitura do Campus de Ribeirão Preto da Universidade de São Paulo. Vigência da autorização: 26/09/2016 a 30/01/2018.

We certify that the Protocol $n^{\circ} 149 / 2016$, entitled "Clinical, cytologic and immunohistochemistry's effects of cannabidiol in a rat model of germinal matrix hemorrhage", is in accordance with the Ethical Principles in Animal Research adopted by the National Council for the Control of Animal Experimentation (CONCEA) and was approved by the Local Animal Ethical Committee from Ribeirão Preto Medical School of the University of São Paulo in 09/26/2016. This protocol involves the production, maintenance or use of animals from phylum Chordata, subphylum Vertebrata (except humans) for research purposes, and includes the use of 128 male Wistar rats weighing $18 \mathrm{~g}$ and 16 female Wistar rats weighing $350 \mathrm{~g}$ from the Central Animal House of Ribeirão Preto Medical School, University of São Paulo. This certificate is valid until 01/30/2018.

Ribeirão Preto, 26 de setembro de 2016

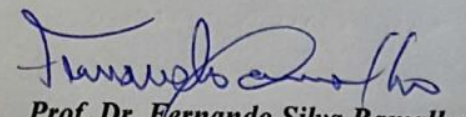

Prof. Dr. Fernando Silva Ramalho

Presidente da CEUA - FMRP - USP 
APÊNDICES 
Apêndice A. Resultados dos testes estatísticos realizados 
1. One-Way ANOVA para peso dos animais com sete dias de vida (dia da indução da hemorragia)

\begin{tabular}{|c|c|c|c|c|c|c|c|c|}
\hline \multicolumn{9}{|c|}{ Descriptives } \\
\hline Peso_animal & \multirow[b]{3}{*}{$\mathrm{N}$} & & \multirow{3}{*}{$\begin{array}{l}\text { Std. } \\
\text { Deviation }\end{array}$} & \multirow[b]{3}{*}{ Std. Error } & \multirow{2}{*}{\multicolumn{2}{|c|}{$\begin{array}{l}\text { 95\% Confidence Interval for } \\
\text { Mean }\end{array}$}} & \multirow[b]{3}{*}{ Minimum } & \multirow[b]{3}{*}{ Maximum } \\
\hline & & \multirow[b]{2}{*}{ Mean } & & & & & & \\
\hline & & & & & Lower Bound & Upper Bound & & \\
\hline Control & 32 & 20.969 & 4.1425 & .7323 & 19.475 & 22.462 & 13.5 & 31.0 \\
\hline Cannabidiol $10 \mathrm{mg}$ & 30 & 20.900 & 3.5414 & .6466 & 19.578 & 22.222 & 15.0 & 29.5 \\
\hline Cannabidiol $1 \mathrm{mg}$ & 23 & 22.348 & 2.6732 & .5574 & 21.192 & 23.504 & 18.5 & 27.5 \\
\hline Pre treatment & 30 & 21.683 & 2.4965 & .4558 & 20.751 & 22.616 & 17.0 & 27.0 \\
\hline SHAM & 32 & 20.297 & 2.4752 & .4376 & 19.404 & 21.189 & 14.5 & 25.5 \\
\hline Total & 147 & 21.170 & 3.1959 & .2636 & 20.649 & 21.691 & 13.5 & 31.0 \\
\hline
\end{tabular}

\section{ANOVA}

\begin{tabular}{|c|c|c|c|c|c|}
\hline \multicolumn{6}{|l|}{ Peso_animal } \\
\hline & $\begin{array}{l}\text { Sum of } \\
\text { Squares }\end{array}$ & df & Mean Square & $\mathrm{F}$ & Sig. \\
\hline Between Groups & 67.691 & 4 & 16.923 & 1.688 & .156 \\
\hline Within Groups & 1423.557 & 142 & 10.025 & & \\
\hline Total & 1491.248 & 146 & & & \\
\hline
\end{tabular}

2. Modelo de regrassão linear para análise do ganho ponderal entre o P7 e P21

\section{Multivariate Tests ${ }^{\mathrm{a}}$}

\begin{tabular}{|c|c|c|c|c|c|c|c|}
\hline Effect & & Value & $\mathrm{F}$ & $\begin{array}{c}\text { Hypothesis } \\
\text { df }\end{array}$ & Error df & Sig. & $\begin{array}{c}\text { Partial Eta } \\
\text { Squared }\end{array}$ \\
\hline \multirow[t]{4}{*}{ weight } & Pillai's Trace & .998 & $421.019^{b}$ & 14.000 & 12.000 & .000 & .998 \\
\hline & Wilks' Lambda & .002 & $421.019^{b}$ & 14.000 & 12.000 & .000 & .998 \\
\hline & Hotelling's Trace & 491.189 & $421.019^{b}$ & 14.000 & 12.000 & .000 & .998 \\
\hline & Roy's Largest Root & 491.189 & $421.019^{b}$ & 14.000 & 12.000 & .000 & .998 \\
\hline \multirow[t]{4}{*}{ weight * Grupo } & Pillai's Trace & 2.067 & 2.217 & 42.000 & 42.000 & .006 & .689 \\
\hline & Wilks' Lambda & .004 & 4.895 & 42.000 & 36.363 & .000 & .846 \\
\hline & Hotelling's Trace & 51.125 & 12.984 & 42.000 & 32.000 & .000 & .945 \\
\hline & Roy's Largest Root & 47.976 & $47.976^{c}$ & 14.000 & 14.000 & .000 & .980 \\
\hline
\end{tabular}

\footnotetext{
a. Design: Intercept + Grupo

Within Subjects Design: weight

b. Exact statistic

c. The statistic is an upper bound on $\mathrm{F}$ that yields a lower bound on the significance level.
}

\section{Mauchly's Test of Sphericity ${ }^{a}$}

Measure: MEASURE_1

\begin{tabular}{l|r|c|c|c|c|c|c|} 
& & & & \multicolumn{2}{c}{ Epsilon $^{\text {b }}$} \\
Within Subjects Effect & Mauchly's W & $\begin{array}{c}\text { Approx. Chi- } \\
\text { Square }\end{array}$ & df & Sig. & $\begin{array}{c}\text { Greenhouse- } \\
\text { Geisser }\end{array}$ & Huynh-Feldt & $\begin{array}{c}\text { Lower- } \\
\text { bound }\end{array}$ \\
\hline weight & .000 & 602.213 & 104 & .000 & .147 & .180 & .071 \\
\hline
\end{tabular}

Tests the null hypothesis that the error covariance matrix of the orthonormalized transformed dependent variables is proportional to an identity matrix.

a. Design: Intercept + Grupo

Within Subjects Design: weight

b. May be used to adjust the degrees of freedom for the averaged tests of significance. Corrected tests are displayed in the Tests of Within-Subjects Effects table. 
Tests of Between-Subjects Effects

Measure: MEASURE_1

Transformed Variable: Average

\begin{tabular}{l|r|r|r|r|r|r} 
Source & $\begin{array}{c}\text { Type III Sum } \\
\text { of Squares }\end{array}$ & df & Mean Square & \multicolumn{1}{c}{ F } & \multicolumn{1}{c}{ Sig. } & \multicolumn{1}{c}{$\begin{array}{c}\text { Partial Eta } \\
\text { Squared }\end{array}$} \\
\hline Intercept & 676190.681 & 1 & 676190.681 & 2859.803 & .000 & .991 \\
\hline Grupo & 4958.487 & 3 & 1652.829 & 6.990 & .001 & .456 \\
\hline Error & 5911.166 & 25 & 236.447 & & & \\
\hline
\end{tabular}

\section{Multiple Comparisons}

Measure: MEASURE_1

Tukey HSD

\begin{tabular}{|c|c|c|c|c|c|c|}
\hline \multirow[b]{2}{*}{ (I) Grupo } & \multirow[b]{2}{*}{ (J) Grupo } & \multirow{2}{*}{$\begin{array}{c}\text { Mean } \\
\text { Difference (I- } \\
J)\end{array}$} & \multirow[b]{2}{*}{ Std. Error } & \multirow[b]{2}{*}{ Sig. } & \multicolumn{2}{|c|}{ 95\% Confidence Interval } \\
\hline & & & & & Lower Bound & Upper Bound \\
\hline \multirow[t]{3}{*}{ Control } & Cannabidiol $10 \mathrm{mg}$ & $-7.133^{*}$ & 2.0548 & .010 & -12.785 & -1.481 \\
\hline & Pre treatment & -5.826 & 2.1442 & .054 & -11.724 & .072 \\
\hline & SHAM & .392 & 1.9851 & .997 & -5.069 & 5.852 \\
\hline \multirow[t]{3}{*}{ Cannabidiol $10 \mathrm{mg}$} & Control & $7.133^{*}$ & 2.0548 & .010 & 1.481 & 12.785 \\
\hline & Pre treatment & 1.306 & 2.2089 & .934 & -4.769 & 7.382 \\
\hline & SHAM & $7.524^{*}$ & 2.0548 & .006 & 1.872 & 13.176 \\
\hline \multirow[t]{3}{*}{ Pre treatment } & Control & 5.826 & 2.1442 & .054 & -.072 & 11.724 \\
\hline & Cannabidiol $10 \mathrm{mg}$ & -1.306 & 2.2089 & .934 & -7.382 & 4.769 \\
\hline & SHAM & $6.218^{*}$ & 2.1442 & .036 & .320 & 12.116 \\
\hline \multirow[t]{3}{*}{ SHAM } & Control & -.392 & 1.9851 & .997 & -5.852 & 5.069 \\
\hline & Cannabidiol $10 \mathrm{mg}$ & $-7.524^{*}$ & 2.0548 & .006 & -13.176 & -1.872 \\
\hline & Pre treatment & $-6.218^{*}$ & 2.1442 & .036 & -12.116 & -.320 \\
\hline
\end{tabular}

Based on observed means.

The error term is Mean Square(Error) $=15.763$.

*. The mean difference is significant at the .05 level. 
3. One-Way ANOVA para contagem de astrócitos reativos (GFAP positivos) na zona perihemorrágica 24 horas após a indução hemorrágica

\section{Oneway}

[DataSet1] /Users/timoteo/Desktop/Doutorado/Dados/CNB_spss.sav

\section{Descriptives}

media_PH_GFAP

\begin{tabular}{|c|c|c|c|c|c|c|c|c|}
\hline & \multirow[b]{2}{*}{$\mathrm{N}$} & \multirow[b]{2}{*}{ Mean } & \multirow{2}{*}{$\begin{array}{c}\text { Std. } \\
\text { Deviation }\end{array}$} & \multirow[b]{2}{*}{ Std. Error } & \multicolumn{2}{|c|}{$\begin{array}{c}\text { 95\% Confidence Interval for } \\
\text { Mean }\end{array}$} & \multirow[b]{2}{*}{ Minimum } & \multirow[b]{2}{*}{ Maximum } \\
\hline & & & & & Lower Bound & Upper Bound & & \\
\hline Control & 8 & 10.1563 & 5.57568 & 1.97130 & 5.4949 & 14.8176 & .75 & 19.50 \\
\hline Cannabidiol $10 \mathrm{mg}$ & 8 & 1.8125 & 1.71000 & .60458 & .3829 & 3.2421 & .00 & 4.25 \\
\hline Cannabidiol $1 \mathrm{mg}$ & 8 & 2.0625 & 1.73591 & .61374 & .6112 & 3.5138 & .25 & 5.00 \\
\hline Pre treatment & 7 & .8929 & .94491 & .35714 & .0190 & 1.7668 & .00 & 2.25 \\
\hline SHAM & 7 & .7143 & 1.00445 & .37965 & -.2147 & 1.6433 & .00 & 2.25 \\
\hline Total & 38 & 3.2500 & 4.54371 & .73709 & 1.7565 & 4.7435 & .00 & 19.50 \\
\hline
\end{tabular}

ANOVA

media_PH_GFAP

\begin{tabular}{lc|r|r|r|c} 
& $\begin{array}{l}\text { Sum of } \\
\text { Squares }\end{array}$ & df & Mean Square & \multicolumn{1}{c}{ F } & \multicolumn{1}{c}{ Sig. } \\
\hline Between Groups & 493.285 & 4 & 123.321 & 15.040 & .000 \\
\hline Within Groups & 270.590 & 33 & 8.200 & & \\
\hline Total & 763.875 & 37 & & & \\
\hline
\end{tabular}

\section{Multiple Comparisons}

Dependent Variable: media_PH_GFAP Tukey HSD

\begin{tabular}{|c|c|c|c|c|c|c|}
\hline \multirow[b]{2}{*}{ (I) Grupo } & \multirow[b]{2}{*}{ (J) Grupo } & \multirow{2}{*}{$\begin{array}{c}\text { Mean } \\
\text { Difference (I- } \\
\mathrm{J})\end{array}$} & \multirow[b]{2}{*}{ Std. Error } & \multirow[b]{2}{*}{ Sig. } & \multicolumn{2}{|c|}{ 95\% Confidence Interval } \\
\hline & & & & & Lower Bound & Upper Bound \\
\hline \multirow[t]{4}{*}{ Control } & Cannabidiol $10 \mathrm{mg}$ & $8.34375^{*}$ & 1.43176 & .000 & 4.2141 & 12.4734 \\
\hline & Cannabidiol $1 \mathrm{mg}$ & $8.09375^{*}$ & 1.43176 & .000 & 3.9641 & 12.2234 \\
\hline & Pre treatment & $9.26339^{*}$ & 1.48201 & .000 & 4.9888 & 13.5380 \\
\hline & SHAM & $9.44196^{*}$ & 1.48201 & .000 & 5.1674 & 13.7165 \\
\hline \multirow[t]{4}{*}{ Cannabidiol $10 \mathrm{mg}$} & Control & $-8.34375^{*}$ & 1.43176 & .000 & -12.4734 & -4.2141 \\
\hline & Cannabidiol $1 \mathrm{mg}$ & -.25000 & 1.43176 & 1.000 & -4.3796 & 3.8796 \\
\hline & Pre treatment & .91964 & 1.48201 & .971 & -3.3549 & 5.1942 \\
\hline & SHAM & 1.09821 & 1.48201 & .945 & -3.1764 & 5.3728 \\
\hline \multirow[t]{4}{*}{ Cannabidiol $1 \mathrm{mg}$} & Control & $-8.09375^{*}$ & 1.43176 & .000 & -12.2234 & -3.9641 \\
\hline & Cannabidiol $10 \mathrm{mg}$ & .25000 & 1.43176 & 1.000 & -3.8796 & 4.3796 \\
\hline & Pre treatment & 1.16964 & 1.48201 & .932 & -3.1049 & 5.4442 \\
\hline & SHAM & 1.34821 & 1.48201 & .891 & -2.9264 & 5.6228 \\
\hline \multirow[t]{4}{*}{ Pre treatment } & Control & $-9.26339^{*}$ & 1.48201 & .000 & -13.5380 & -4.9888 \\
\hline & Cannabidiol $10 \mathrm{mg}$ & -.91964 & 1.48201 & .971 & -5.1942 & 3.3549 \\
\hline & Cannabidiol $1 \mathrm{mg}$ & -1.16964 & 1.48201 & .932 & -5.4442 & 3.1049 \\
\hline & SHAM & .17857 & 1.53061 & 1.000 & -4.2362 & 4.5933 \\
\hline \multirow[t]{4}{*}{ SHAM } & Control & $-9.44196^{*}$ & 1.48201 & .000 & -13.7165 & -5.1674 \\
\hline & Cannabidiol $10 \mathrm{mg}$ & -1.09821 & 1.48201 & .945 & -5.3728 & 3.1764 \\
\hline & Cannabidiol $1 \mathrm{mg}$ & -1.34821 & 1.48201 & .891 & -5.6228 & 2.9264 \\
\hline & Pre treatment & -.17857 & 1.53061 & 1.000 & -4.5933 & 4.2362 \\
\hline
\end{tabular}

\footnotetext{
*. The mean difference is significant at the 0.05 level.
} 
4. One-Way ANOVA para contagem de astrócitos em apoptose (Caspase 3 positivos) na zona peri-hemorrágica 24 horas após a indução hemorrágica

\section{Oneway}

\section{Descriptives}

\begin{tabular}{|c|c|c|c|c|c|c|c|c|}
\hline & \multirow[b]{2}{*}{$\mathrm{N}$} & \multirow[b]{2}{*}{ Mean } & \multirow{2}{*}{$\begin{array}{l}\text { Std. } \\
\text { Deviation }\end{array}$} & \multirow[b]{2}{*}{ Std. Error } & \multicolumn{2}{|c|}{$\begin{array}{l}\text { 95\% Confidence Interval for } \\
\text { Mean }\end{array}$} & \multirow[b]{2}{*}{ Minimum } & \multirow[b]{2}{*}{ Maximum } \\
\hline & & & & & Lower Bound & Upper Bound & & \\
\hline Control & 8 & 11.3438 & 8.15578 & 2.88350 & 4.5253 & 18.1622 & .25 & 21.25 \\
\hline Cannabidiol $10 \mathrm{mg}$ & 8 & 1.4688 & 2.22581 & .78694 & -.3921 & 3.3296 & .00 & 6.50 \\
\hline Cannabidiol $1 \mathrm{mg}$ & 8 & 4.5625 & 6.02636 & 2.13064 & -.4757 & 9.6007 & .00 & 17.50 \\
\hline Pre treatment & 8 & .0625 & .11573 & .04092 & -.0343 & .1593 & .00 & .25 \\
\hline SHAM & 8 & .0313 & .08839 & .03125 & -.0426 & .1051 & .00 & .25 \\
\hline Total & 40 & 3.4938 & 6.15960 & .97392 & 1.5238 & 5.4637 & .00 & 21.25 \\
\hline
\end{tabular}

\section{ANOVA}

media_PH_casp

\begin{tabular}{l|r|r|r|r|r} 
& $\begin{array}{l}\text { Sum of } \\
\text { Squares }\end{array}$ & df & Mean Square & \multicolumn{1}{c}{ F } & \multicolumn{1}{c}{ Sig. } \\
\hline Between Groups & 725.022 & 4 & 181.255 & 8.406 & .000 \\
\hline Within Groups & 754.664 & 35 & 21.562 & & \\
\hline Total & 1479.686 & 39 & & & \\
\hline
\end{tabular}

\section{Multiple Comparisons}

Dependent Variable: media_PH_casp Tukey HSD

\begin{tabular}{|c|c|c|c|c|c|c|}
\hline \multirow[b]{2}{*}{ (I) Grupo } & \multirow[b]{2}{*}{ (J) Grupo } & \multirow{2}{*}{$\begin{array}{c}\text { Mean } \\
\text { Difference (I- } \\
\mathrm{J})\end{array}$} & \multirow[b]{2}{*}{ Std. Error } & \multirow[b]{2}{*}{ Sig. } & \multicolumn{2}{|c|}{ 95\% Confidence Interval } \\
\hline & & & & & Lower Bound & Upper Bound \\
\hline \multirow[t]{4}{*}{ Control } & Cannabidiol $10 \mathrm{mg}$ & $9.87500^{*}$ & 2.32174 & .001 & 3.1999 & 16.5501 \\
\hline & Cannabidiol $1 \mathrm{mg}$ & $6.78125^{*}$ & 2.32174 & .045 & .1061 & 13.4564 \\
\hline & Pre treatment & $11.28125^{*}$ & 2.32174 & .000 & 4.6061 & 17.9564 \\
\hline & SHAM & $11.31250^{*}$ & 2.32174 & .000 & 4.6374 & 17.9876 \\
\hline \multirow[t]{4}{*}{ Cannabidiol $10 \mathrm{mg}$} & Control & $-9.87500^{*}$ & 2.32174 & .001 & -16.5501 & -3.1999 \\
\hline & Cannabidiol $1 \mathrm{mg}$ & -3.09375 & 2.32174 & .673 & -9.7689 & 3.5814 \\
\hline & Pre treatment & 1.40625 & 2.32174 & .973 & -5.2689 & 8.0814 \\
\hline & SHAM & 1.43750 & 2.32174 & .971 & -5.2376 & 8.1126 \\
\hline \multirow[t]{4}{*}{ Cannabidiol $1 \mathrm{mg}$} & Control & $-6.78125^{*}$ & 2.32174 & .045 & -13.4564 & -.1061 \\
\hline & Cannabidiol $10 \mathrm{mg}$ & 3.09375 & 2.32174 & .673 & -3.5814 & 9.7689 \\
\hline & Pre treatment & 4.50000 & 2.32174 & .317 & -2.1751 & 11.1751 \\
\hline & SHAM & 4.53125 & 2.32174 & .310 & -2.1439 & 11.2064 \\
\hline \multirow[t]{4}{*}{ Pre treatment } & Control & $-11.28125^{*}$ & 2.32174 & .000 & -17.9564 & -4.6061 \\
\hline & Cannabidiol $10 \mathrm{mg}$ & -1.40625 & 2.32174 & .973 & -8.0814 & 5.2689 \\
\hline & Cannabidiol $1 \mathrm{mg}$ & -4.50000 & 2.32174 & .317 & -11.1751 & 2.1751 \\
\hline & SHAM & .03125 & 2.32174 & 1.000 & -6.6439 & 6.7064 \\
\hline \multirow[t]{4}{*}{ SHAM } & Control & $-11.31250^{*}$ & 2.32174 & .000 & -17.9876 & -4.6374 \\
\hline & Cannabidiol $10 \mathrm{mg}$ & -1.43750 & 2.32174 & .971 & -8.1126 & 5.2376 \\
\hline & Cannabidiol $1 \mathrm{mg}$ & -4.53125 & 2.32174 & .310 & -11.2064 & 2.1439 \\
\hline & Pre treatment & -.03125 & 2.32174 & 1.000 & -6.7064 & 6.6439 \\
\hline
\end{tabular}

\footnotetext{
*. The mean difference is significant at the 0.05 level.
} 
5. One-Way ANOVA para contagem de astrócitos reativos (GFAP positivos) na zona perihemorrágica 14 dias após a indução hemorrágica

\section{Oneway}

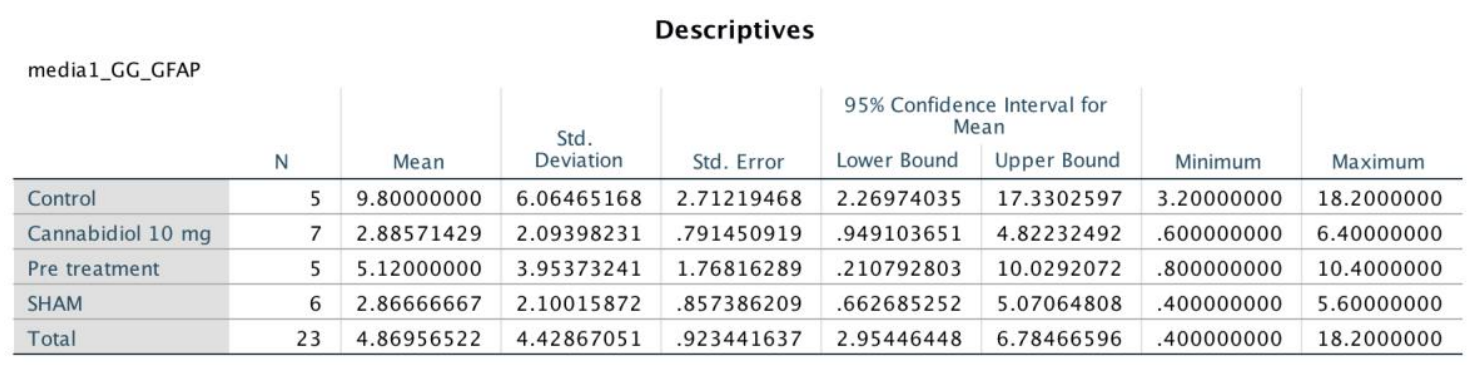

\begin{tabular}{|c|c|c|c|c|c|}
\hline \multicolumn{6}{|c|}{ VA } \\
\hline & $\begin{array}{l}\text { Sum of } \\
\text { Squares }\end{array}$ & df & Mean Square & $\mathrm{F}$ & Sig. \\
\hline Between Groups & 173.479 & 3 & 57.826 & 4.258 & .018 \\
\hline Within Groups & 258.010 & 19 & 13.579 & & \\
\hline Total & 431.489 & 22 & & & \\
\hline
\end{tabular}

\section{Post Hoc Tests}

\section{Multiple Comparisons}

Dependent Variable: media1_GG_GFAP Tukey HSD

\begin{tabular}{|c|c|c|c|c|c|c|}
\hline \multirow[b]{2}{*}{ (I) Grupo } & \multirow[b]{2}{*}{ (J) Grupo } & \multirow{2}{*}{$\begin{array}{c}\text { Mean } \\
\text { Difference (I- } \\
\mathrm{J})\end{array}$} & \multirow[b]{2}{*}{ Std. Error } & \multirow[b]{2}{*}{ Sig. } & \multicolumn{2}{|c|}{ 95\% Confidence Interval } \\
\hline & & & & & Lower Bound & Upper Bound \\
\hline \multirow[t]{3}{*}{ Control } & Cannabidiol $10 \mathrm{mg}$ & $6.9142857^{*}$ & 2.15773442 & .022 & .847068660 & 12.9815028 \\
\hline & Pre treatment & 4.68000000 & 2.33061955 & .220 & -1.8733434 & 11.2333434 \\
\hline & SHAM & $6.9333333^{*}$ & 2.23139833 & .027 & .658984701 & 13.2076820 \\
\hline \multirow[t]{3}{*}{ Cannabidiol $10 \mathrm{mg}$} & Control & $-6.914286^{*}$ & 2.15773442 & .022 & -12.981503 & -.84706866 \\
\hline & Pre treatment & -2.2342857 & 2.15773442 & .731 & -8.3015028 & 3.83293134 \\
\hline & SHAM & .019047619 & 2.05016313 & 1.000 & -5.7456955 & 5.78379077 \\
\hline \multirow[t]{3}{*}{ Pre treatment } & Control & -4.6800000 & 2.33061955 & .220 & -11.233343 & 1.87334341 \\
\hline & Cannabidiol $10 \mathrm{mg}$ & 2.23428571 & 2.15773442 & .731 & -3.8329313 & 8.30150277 \\
\hline & SHAM & 2.25333333 & 2.23139833 & .746 & -4.0210153 & 8.52768197 \\
\hline \multirow[t]{3}{*}{ SHAM } & Control & $-6.933333^{*}$ & 2.23139833 & .027 & -13.207682 & -.65898470 \\
\hline & Cannabidiol $10 \mathrm{mg}$ & -.01904762 & 2.05016313 & 1.000 & -5.7837908 & 5.74569553 \\
\hline & Pre treatment & -2.2533333 & 2.23139833 & .746 & -8.5276820 & 4.02101530 \\
\hline
\end{tabular}

*. The mean difference is significant at the 0.05 level. 
6. One-Way ANOVA para contagem de astrócitos em apoptose (Caspase 3 positivos) na zona peri-hemorrágica 14 dias após a indução hemorrágica

\section{Oneway}

\begin{tabular}{|c|c|c|c|c|c|c|c|c|}
\hline \multirow{3}{*}{\multicolumn{2}{|c|}{$\mathrm{N}$}} & \multicolumn{5}{|c|}{ Descriptives } & \multirow[b]{3}{*}{ Minimum } & \multirow[b]{3}{*}{ Maximum } \\
\hline & & \multirow[b]{2}{*}{ Mean } & \multirow{2}{*}{$\begin{array}{c}\text { Std. } \\
\text { Deviation }\end{array}$} & \multirow[b]{2}{*}{ Std. Error } & \multicolumn{2}{|c|}{$\begin{array}{c}\text { 95\% Confidence Interval for } \\
\text { Mean }\end{array}$} & & \\
\hline & & & & & Lower Bound & Upper Bound & & \\
\hline Control & 8 & .950 & .9957 & .3520 & .118 & 1.782 & .2 & 3.2 \\
\hline Cannabidiol $10 \mathrm{mg}$ & 7 & .343 & .2992 & .1131 & .066 & .620 & .0 & .8 \\
\hline Pre treatment & 4 & .200 & .1633 & .0816 & -.060 & .460 & .0 & .4 \\
\hline SHAM & 6 & .067 & .1033 & .0422 & -.042 & .175 & .0 & .2 \\
\hline Total & 25 & .448 & .6715 & .1343 & .171 & .725 & .0 & 3.2 \\
\hline
\end{tabular}

ANOVA

\begin{tabular}{|c|c|c|c|c|c|}
\hline & $\begin{array}{l}\text { Sum of } \\
\text { Squares }\end{array}$ & $d f$ & Mean Square & $\mathrm{F}$ & Sig. \\
\hline Between Groups & 3.212 & 3 & 1.071 & 2.954 & .056 \\
\hline Within Groups & 7.610 & 21 & .362 & & \\
\hline Total & 10.822 & 24 & & & \\
\hline
\end{tabular}

\section{Post Hoc Tests}

\section{Multiple Comparisons}

Dependent Variable: media_GG_casp Tukey HSD

\begin{tabular}{|c|c|c|c|c|c|c|}
\hline \multirow[b]{2}{*}{ (I) Grupo } & \multirow[b]{2}{*}{ (J) Grupo } & \multirow{2}{*}{$\begin{array}{c}\text { Mean } \\
\text { Difference (I- } \\
\mathrm{J})\end{array}$} & \multirow[b]{2}{*}{ Std. Error } & \multirow[b]{2}{*}{ Sig. } & \multicolumn{2}{|c|}{ 95\% Confidence Interval } \\
\hline & & & & & Lower Bound & Upper Bound \\
\hline \multirow[t]{3}{*}{ Control } & Cannabidiol $10 \mathrm{mg}$ & .6071 & .3116 & .239 & -.261 & 1.476 \\
\hline & Pre treatment & .7500 & .3686 & .207 & -.278 & 1.778 \\
\hline & SHAM & .8833 & .3251 & .058 & -.023 & 1.790 \\
\hline \multirow[t]{3}{*}{ Cannabidiol $10 \mathrm{mg}$} & Control & -.6071 & .3116 & .239 & -1.476 & .261 \\
\hline & Pre treatment & .1429 & .3773 & .981 & -.909 & 1.195 \\
\hline & SHAM & .2762 & .3349 & .842 & -.657 & 1.210 \\
\hline \multirow[t]{3}{*}{ Pre treatment } & Control & -.7500 & .3686 & .207 & -1.778 & .278 \\
\hline & Cannabidiol $10 \mathrm{mg}$ & -.1429 & .3773 & .981 & -1.195 & .909 \\
\hline & SHAM & .1333 & .3886 & .986 & -.950 & 1.216 \\
\hline \multirow[t]{3}{*}{ SHAM } & Control & -.8833 & .3251 & .058 & -1.790 & .023 \\
\hline & Cannabidiol $10 \mathrm{mg}$ & -.2762 & .3349 & .842 & -1.210 & .657 \\
\hline & Pre treatment & -.1333 & .3886 & .986 & -1.216 & .950 \\
\hline
\end{tabular}


7. One-Way ANOVA para contagem de astrócitos reativos (GFAP positivos) no Stratum oriens de CA1 do hipocampo direito 14 dias após a indução hemorrágica

\section{Oneway}

\begin{tabular}{|c|c|c|c|c|c|c|c|c|}
\hline \multicolumn{9}{|c|}{ Descriptives } \\
\hline HP_molecular_GFAP & & & & & & & & \\
\hline & \multirow[b]{2}{*}{$\mathrm{N}$} & \multirow[b]{2}{*}{ Mean } & \multirow{2}{*}{$\begin{array}{l}\text { Std. } \\
\text { Deviation }\end{array}$} & \multirow[b]{2}{*}{ Std. Error } & \multicolumn{2}{|c|}{$\begin{array}{c}\text { 95\% Confidence Interval for } \\
\text { Mean }\end{array}$} & \multirow[b]{2}{*}{ Minimum } & \multirow[b]{2}{*}{ Maximum } \\
\hline & & & & & Lower Bound & Upper Bound & & \\
\hline Control & 8 & 17.75 & 7.536 & 2.664 & 11.45 & 24.05 & 9 & 31 \\
\hline Cannabidiol $10 \mathrm{mg}$ & 7 & 5.86 & 2.545 & .962 & 3.50 & 8.21 & 2 & 9 \\
\hline Pre treatment & 5 & 8.40 & 2.702 & 1.208 & 5.05 & 11.75 & 5 & 12 \\
\hline SHAM & 7 & 9.71 & 3.450 & 1.304 & 6.52 & 12.91 & 5 & 15 \\
\hline Total & 27 & 10.85 & 6.597 & 1.270 & 8.24 & 13.46 & 2 & 31 \\
\hline
\end{tabular}

ANOVA

HP_molecular_GFAP

\begin{tabular}{l|r|r|r|r|r} 
& $\begin{array}{c}\text { Sum of } \\
\text { Squares }\end{array}$ & df & Mean Square & \multicolumn{1}{c}{ F } & \multicolumn{1}{c}{ Sig. } \\
\hline Between Groups & 594.422 & 3 & 198.141 & 8.487 & .001 \\
\hline Within Groups & 536.986 & 23 & 23.347 & & \\
\hline Total & 1131.407 & 26 & & & \\
\hline
\end{tabular}

\section{Post Hoc Tests}

\section{Multiple Comparisons}

Dependent Variable: HP_molecular_GFAP

Tukey HSD

\begin{tabular}{|c|c|c|c|c|c|c|}
\hline \multirow[b]{2}{*}{ (I) Grupo } & \multirow[b]{2}{*}{ (J) Grupo } & \multirow{2}{*}{$\begin{array}{c}\text { Mean } \\
\text { Difference (I- } \\
\mathrm{J})\end{array}$} & \multirow[b]{2}{*}{ Std. Error } & \multirow[b]{2}{*}{ Sig. } & \multicolumn{2}{|c|}{ 95\% Confidence Interval } \\
\hline & & & & & Lower Bound & Upper Bound \\
\hline \multirow[t]{3}{*}{ Control } & Cannabidiol 10 mg & $11.893^{*}$ & 2.501 & .000 & 4.97 & 18.81 \\
\hline & Pre treatment & $9.350^{*}$ & 2.755 & .012 & 1.73 & 16.97 \\
\hline & SHAM & $8.036^{*}$ & 2.501 & .019 & 1.12 & 14.96 \\
\hline \multirow[t]{3}{*}{ Cannabidiol $10 \mathrm{mg}$} & Control & $-11.893^{*}$ & 2.501 & .000 & -18.81 & -4.97 \\
\hline & Pre treatment & -2.543 & 2.829 & .806 & -10.37 & 5.29 \\
\hline & SHAM & -3.857 & 2.583 & .457 & -11.00 & 3.29 \\
\hline \multirow[t]{3}{*}{ Pre treatment } & Control & $-9.350^{*}$ & 2.755 & .012 & -16.97 & -1.73 \\
\hline & Cannabidiol $10 \mathrm{mg}$ & 2.543 & 2.829 & .806 & -5.29 & 10.37 \\
\hline & SHAM & -1.314 & 2.829 & .966 & -9.14 & 6.52 \\
\hline \multirow[t]{3}{*}{ SHAM } & Control & $-8.036^{*}$ & 2.501 & .019 & -14.96 & -1.12 \\
\hline & Cannabidiol $10 \mathrm{mg}$ & 3.857 & 2.583 & .457 & -3.29 & 11.00 \\
\hline & Pre treatment & 1.314 & 2.829 & .966 & -6.52 & 9.14 \\
\hline
\end{tabular}

*. The mean difference is significant at the 0.05 level. 
8. One-Way ANOVA para contagem de astrócitos em apoptose (Caspase 3 positivos) no Stratum oriens de CA1 do hipocampo direito 14 dias após a indução hemorrágica

\section{Oneway}

\begin{tabular}{|c|c|c|c|c|c|c|c|c|}
\hline \multirow{2}{*}{\multicolumn{9}{|c|}{ HP_molecular_casp }} \\
\hline & & & & & & & & \\
\hline & \multirow[b]{2}{*}{$\mathrm{N}$} & \multirow[b]{2}{*}{ Mean } & \multirow{2}{*}{$\begin{array}{c}\text { Std. } \\
\text { Deviation }\end{array}$} & \multirow[b]{2}{*}{ Std. Error } & \multicolumn{2}{|c|}{$\begin{array}{l}\text { 95\% Confidence Interval for } \\
\text { Mean }\end{array}$} & \multirow[b]{2}{*}{ Minimum } & \multirow[b]{2}{*}{ Maximum } \\
\hline & & & & & Lower Bound & Upper Bound & & \\
\hline Control & 7 & 3.57 & 4.315 & 1.631 & -.42 & 7.56 & 1 & 13 \\
\hline Cannabidiol $10 \mathrm{mg}$ & 7 & .29 & .488 & .184 & -.17 & .74 & 0 & 1 \\
\hline Pre treatment & 5 & 1.00 & 1.225 & .548 & -.52 & 2.52 & 0 & 3 \\
\hline SHAM & 8 & .38 & .744 & .263 & -.25 & 1.00 & 0 & 2 \\
\hline Total & 27 & 1.30 & 2.584 & .497 & .27 & 2.32 & 0 & 13 \\
\hline
\end{tabular}

ANOVA

HP_molecular_casp

\begin{tabular}{l|r|r|r|r|r} 
& $\begin{array}{l}\text { Sum of } \\
\text { Squares }\end{array}$ & df & Mean Square & \multicolumn{1}{c}{ F } & \multicolumn{1}{c}{ Sig. } \\
\hline Between Groups & 50.612 & 3 & 16.871 & 3.154 & .044 \\
\hline Within Groups & 123.018 & 23 & 5.349 & & \\
\hline Total & 173.630 & 26 & & & \\
\hline
\end{tabular}

\section{Post Hoc Tests}

\section{Multiple Comparisons}

Dependent Variable: HP_molecular_casp

Tukey HSD

\begin{tabular}{|c|c|c|c|c|c|c|}
\hline \multirow[b]{2}{*}{ (I) Grupo } & \multirow[b]{2}{*}{ (J) Grupo } & \multirow{2}{*}{$\begin{array}{c}\text { Mean } \\
\text { Difference (I- } \\
\mathrm{J})\end{array}$} & \multirow[b]{2}{*}{ Std. Error } & \multirow[b]{2}{*}{ Sig. } & \multicolumn{2}{|c|}{ 95\% Confidence Interval } \\
\hline & & & & & Lower Bound & Upper Bound \\
\hline \multirow[t]{3}{*}{ Control } & Cannabidiol $10 \mathrm{mg}$ & 3.286 & 1.236 & .063 & -.14 & 6.71 \\
\hline & Pre treatment & 2.571 & 1.354 & .256 & -1.18 & 6.32 \\
\hline & SHAM & 3.196 & 1.197 & .061 & -.12 & 6.51 \\
\hline \multirow[t]{3}{*}{ Cannabidiol $10 \mathrm{mg}$} & Control & -3.286 & 1.236 & .063 & -6.71 & .14 \\
\hline & Pre treatment & -.714 & 1.354 & .952 & -4.46 & 3.03 \\
\hline & SHAM & -.089 & 1.197 & 1.000 & -3.40 & 3.22 \\
\hline \multirow[t]{3}{*}{ Pre treatment } & Control & -2.571 & 1.354 & .256 & -6.32 & 1.18 \\
\hline & Cannabidiol $10 \mathrm{mg}$ & .714 & 1.354 & .952 & -3.03 & 4.46 \\
\hline & SHAM & .625 & 1.318 & .964 & -3.02 & 4.27 \\
\hline \multirow[t]{3}{*}{ SHAM } & Control & -3.196 & 1.197 & .061 & -6.51 & .12 \\
\hline & Cannabidiol $10 \mathrm{mg}$ & .089 & 1.197 & 1.000 & -3.22 & 3.40 \\
\hline & Pre treatment & -.625 & 1.318 & .964 & -4.27 & 3.02 \\
\hline
\end{tabular}


9. One-Way ANOVA para espessura do corpo caloso na linha média 14 dias após a indução hemorrágica

\section{Oneway}

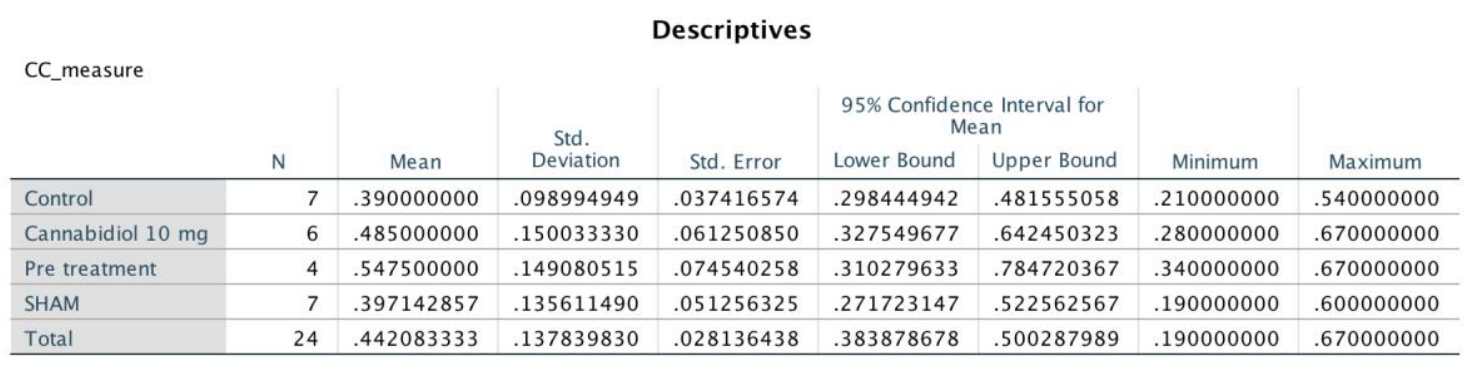

\begin{tabular}{|c|c|c|c|c|c|}
\hline & & ANOV & & & \\
\hline asure & & & & & \\
\hline & $\begin{array}{l}\text { Sum of } \\
\text { Squares }\end{array}$ & df & Mean Square & $\mathrm{F}$ & Sig. \\
\hline Between Groups & .089 & 3 & .030 & 1.696 & .200 \\
\hline Within Groups & .348 & 20 & .017 & & \\
\hline Total & .437 & 23 & & & \\
\hline
\end{tabular}

\section{Post Hoc Tests}

\section{Multiple Comparisons}

Dependent Variable: CC_measure Tukey HSD

\begin{tabular}{|c|c|c|c|c|c|c|}
\hline \multirow[b]{2}{*}{ (I) Grupo } & \multirow[b]{2}{*}{ (J) Grupo } & \multirow{2}{*}{$\begin{array}{c}\text { Mean } \\
\text { Difference (I- } \\
\mathrm{J})\end{array}$} & \multirow[b]{2}{*}{ Std. Error } & \multirow[b]{2}{*}{ Sig. } & \multicolumn{2}{|c|}{ 95\% Confidence Interval } \\
\hline & & & & & Lower Bound & Upper Bound \\
\hline \multirow[t]{3}{*}{ Control } & Cannabidiol $10 \mathrm{mg}$ & -.09500000 & .073426203 & .577 & -.30051526 & .110515259 \\
\hline & Pre treatment & -.15750000 & .082722065 & .258 & -.38903378 & .074033784 \\
\hline & SHAM & -.00714286 & .070545614 & 1.000 & -.20459553 & .190309817 \\
\hline \multirow[t]{3}{*}{ Cannabidiol $10 \mathrm{mg}$} & Control & .095000000 & .073426203 & .577 & -.11051526 & .300515259 \\
\hline & Pre treatment & -.06250000 & .085191923 & .882 & -.30094676 & .175946758 \\
\hline & SHAM & .087857143 & .073426203 & .636 & -.11765812 & .293372402 \\
\hline \multirow[t]{3}{*}{ Pre treatment } & Control & .157500000 & .082722065 & .258 & -.07403378 & .389033784 \\
\hline & Cannabidiol $10 \mathrm{mg}$ & .062500000 & .085191923 & .882 & -.17594676 & .300946758 \\
\hline & SHAM & .150357143 & .082722065 & .295 & -.08117664 & .381890927 \\
\hline \multirow[t]{3}{*}{ SHAM } & Control & .007142857 & .070545614 & 1.000 & -.19030982 & .204595532 \\
\hline & Cannabidiol $10 \mathrm{mg}$ & -.08785714 & .073426203 & .636 & -.29337240 & .117658117 \\
\hline & Pre treatment & -.15035714 & .082722065 & .295 & -.38189093 & .081176641 \\
\hline
\end{tabular}




\section{One-Way ANOVA para percentual de água livre cerebral}

\section{Descriptives}

\begin{tabular}{|c|c|c|c|c|c|c|c|c|}
\hline \multicolumn{9}{|l|}{ Edema_cerebro } \\
\hline & \multirow[b]{2}{*}{$\mathrm{N}$} & \multirow[b]{2}{*}{ Mean } & \multirow{2}{*}{$\begin{array}{c}\text { Std. } \\
\text { Deviation }\end{array}$} & \multirow[b]{2}{*}{ Std. Error } & \multicolumn{2}{|c|}{$\begin{array}{c}\text { 95\% Confidence Interval for } \\
\text { Mean }\end{array}$} & \multirow[b]{2}{*}{ Minimum } & \multirow[b]{2}{*}{ Maximum } \\
\hline & & & & & Lower Bound & Upper Bound & & \\
\hline Control & 8 & .875537701 & .002822371 & .000997859 & .873178140 & .877897262 & .871352449 & .879601690 \\
\hline Cannabidiol $10 \mathrm{mg}$ & 8 & .873086916 & .002037015 & .000720194 & .871383929 & .874789903 & .870950324 & .876939831 \\
\hline Cannabidiol $1 \mathrm{mg}$ & 8 & .870564851 & .001993943 & .000704965 & .868897873 & .872231829 & .867370892 & .872938632 \\
\hline Pre treatment & 8 & .873995030 & .001735033 & .000613427 & .872544507 & .875445554 & .872246696 & .877551020 \\
\hline SHAM & 8 & .864586456 & .009559079 & .003379645 & .856594866 & .872578046 & .858233370 & .887847097 \\
\hline Total & 40 & .871554191 & .005911676 & .000934718 & .869663545 & .873444837 & .858233370 & .887847097 \\
\hline
\end{tabular}

\section{ANOVA}

\begin{tabular}{|c|c|c|c|c|c|}
\hline & $\begin{array}{l}\text { Sum of } \\
\text { Squares }\end{array}$ & df & Mean Square & $\mathrm{F}$ & Sig. \\
\hline Between Groups & .001 & 4 & .000 & 6.671 & .000 \\
\hline Within Groups & .001 & 35 & .000 & & \\
\hline Total & .001 & 39 & & & \\
\hline
\end{tabular}

\section{Multiple Comparisons}

Dependent Variable: Edema_cerebro Tukey HSD

\begin{tabular}{|c|c|c|c|c|c|c|}
\hline \multirow[b]{2}{*}{ (I) Grupo } & \multirow[b]{2}{*}{ (J) Grupo } & \multirow{2}{*}{$\begin{array}{c}\text { Mean } \\
\text { Difference (I- } \\
\text { J) }\end{array}$} & \multirow[b]{2}{*}{ Std. Error } & \multirow[b]{2}{*}{ Sig. } & \multicolumn{2}{|c|}{ 95\% Confidence Interval } \\
\hline & & & & & Lower Bound & Upper Bound \\
\hline \multirow[t]{4}{*}{ Control } & Cannabidiol $10 \mathrm{mg}$ & .002450785 & .002350291 & .834 & -.00430644 & .009208012 \\
\hline & Cannabidiol $1 \mathrm{mg}$ & .004972850 & .002350291 & .236 & -.00178438 & .011730078 \\
\hline & Pre treatment & .001542670 & .002350291 & .964 & -.00521456 & .008299898 \\
\hline & SHAM & $.01095124^{*}$ & .002350291 & .000 & .004194017 & .017708473 \\
\hline \multirow[t]{4}{*}{ Cannabidiol $10 \mathrm{mg}$} & Control & -.00245078 & .002350291 & .834 & -.00920801 & .004306443 \\
\hline & Cannabidiol $1 \mathrm{mg}$ & .002522065 & .002350291 & .819 & -.00423516 & .009279293 \\
\hline & Pre treatment & -.00090811 & .002350291 & .995 & -.00766534 & .005849113 \\
\hline & SHAM & $.00850046^{*}$ & .002350291 & .008 & .001743232 & .015257688 \\
\hline \multirow[t]{4}{*}{ Cannabidiol $1 \mathrm{mg}$} & Control & -.00497285 & .002350291 & .236 & -.01173008 & .001784378 \\
\hline & Cannabidiol $10 \mathrm{mg}$ & -.00252207 & .002350291 & .819 & -.00927929 & .004235163 \\
\hline & Pre treatment & -.00343018 & .002350291 & .595 & -.01018741 & .003327048 \\
\hline & SHAM & .005978395 & .002350291 & .104 & -.00077883 & .012735623 \\
\hline \multirow[t]{4}{*}{ Pre treatment } & Control & -.00154267 & .002350291 & .964 & -.00829990 & .005214558 \\
\hline & Cannabidiol $10 \mathrm{mg}$ & .000908114 & .002350291 & .995 & -.00584911 & .007665342 \\
\hline & Cannabidiol $1 \mathrm{mg}$ & .003430180 & .002350291 & .595 & -.00332705 & .010187407 \\
\hline & SHAM & $.00940857^{*}$ & .002350291 & .003 & .002651347 & .016165802 \\
\hline \multirow[t]{4}{*}{ SHAM } & Control & $-.0109512^{*}$ & .002350291 & .000 & -.01770847 & -.00419402 \\
\hline & Cannabidiol $10 \mathrm{mg}$ & $-.0085005^{*}$ & .002350291 & .008 & -.01525769 & -.00174323 \\
\hline & Cannabidiol $1 \mathrm{mg}$ & -.00597839 & .002350291 & .104 & -.01273562 & .000778833 \\
\hline & Pre treatment & $-.0094086^{*}$ & .002350291 & .003 & -.01616580 & -.00265135 \\
\hline
\end{tabular}

*. The mean difference is significant at the 0.05 level. 
11. One-Way ANOVA para dosagem de MDA no tecido cerebral 24 horas após indução hemorrágica

\begin{tabular}{|c|c|c|c|c|c|c|c|c|}
\hline \multicolumn{9}{|c|}{ oscrintivo } \\
\hline & \multirow[b]{2}{*}{$\mathrm{N}$} & \multirow[b]{2}{*}{ Mean } & \multirow{2}{*}{$\begin{array}{c}\text { Std. } \\
\text { Deviation }\end{array}$} & \multirow[b]{2}{*}{ Std. Error } & \multicolumn{2}{|c|}{$\begin{array}{c}\text { 95\% Confidence Interval for } \\
\text { Mean }\end{array}$} & \multirow[b]{2}{*}{ Minimum } & \multirow[b]{2}{*}{ Maximum } \\
\hline & & & & & Lower Bound & Upper Bound & & \\
\hline Control & 8 & 9.69625000 & 2.31134431 & .817183616 & 7.76391780 & 11.6285822 & 6.73000000 & 13.1900000 \\
\hline Cannabidiol $10 \mathrm{mg}$ & 7 & 8.48857143 & 2.35955101 & .891826453 & 6.30635071 & 10.6707921 & 6.04000000 & 12.7100000 \\
\hline Cannabidiol $1 \mathrm{mg}$ & 7 & 23.9371429 & 5.35363339 & 2.02348322 & 18.9858578 & 28.8884279 & 18.0300000 & 31.0000000 \\
\hline Pre treatment & 8 & 20.6325000 & 2.96886582 & 1.04965258 & 18.1504661 & 23.1145339 & 16.3900000 & 24.9200000 \\
\hline SHAM & 8 & 9.44625000 & 2.34035979 & .827442138 & 7.48966025 & 11.4028397 & 6.06000000 & 13.0800000 \\
\hline Total & 38 & 14.3468421 & 7.18122255 & 1.16494813 & 11.9864330 & 16.7072512 & 6.04000000 & 31.0000000 \\
\hline
\end{tabular}

ANOVA

oxi_resultado_A

\begin{tabular}{|l|r|r|r|r|l} 
& $\begin{array}{l}\text { Sum of } \\
\text { Squares }\end{array}$ & \multicolumn{1}{c|}{ df } & Mean Square & \multicolumn{1}{c|}{ F } & \multicolumn{1}{c|}{ Sig. } \\
\hline Between Groups & 1565.279 & 4 & 391.320 & 37.670 & .000 \\
\hline Within Groups & 342.810 & 33 & 10.388 & & \\
\hline Total & 1908.088 & 37 & & & \\
\hline
\end{tabular}

\section{Multiple Comparisons}

Dependent Variable: oxi_resultado_A

Tukey HSD

\begin{tabular}{|c|c|c|c|c|c|c|}
\hline \multirow[b]{2}{*}{ (I) Grupo } & \multirow[b]{2}{*}{ (J) Grupo } & \multirow{2}{*}{$\begin{array}{c}\text { Mean } \\
\text { Difference (I- } \\
\mathrm{J})\end{array}$} & \multirow[b]{2}{*}{ Std. Error } & \multirow[b]{2}{*}{ Sig. } & \multicolumn{2}{|c|}{$95 \%$ Confidence Interval } \\
\hline & & & & & Lower Bound & Upper Bound \\
\hline \multirow[t]{4}{*}{ Control } & Cannabidiol $10 \mathrm{mg}$ & 1.20767857 & 1.66809624 & .949 & -3.6036389 & 6.01899599 \\
\hline & Cannabidiol $1 \mathrm{mg}$ & $-14.24089^{*}$ & 1.66809624 & .000 & -19.052210 & -9.4295754 \\
\hline & Pre treatment & $-10.93625^{*}$ & 1.61153407 & .000 & -15.584424 & -6.2880758 \\
\hline & SHAM & .250000000 & 1.61153407 & 1.000 & -4.3981742 & 4.89817423 \\
\hline \multirow[t]{4}{*}{ Cannabidiol $10 \mathrm{mg}$} & Control & -1.2076786 & 1.66809624 & .949 & -6.0189960 & 3.60363885 \\
\hline & Cannabidiol $1 \mathrm{mg}$ & $-15.44857^{*}$ & 1.72280239 & .000 & -20.417679 & -10.479464 \\
\hline & Pre treatment & $-12.14393^{*}$ & 1.66809624 & .000 & -16.955246 & -7.3326111 \\
\hline & SHAM & -.95767857 & 1.66809624 & .978 & -5.7689960 & 3.85363885 \\
\hline \multirow[t]{4}{*}{ Cannabidiol $1 \mathrm{mg}$} & Control & $14.240893^{*}$ & 1.66809624 & .000 & 9.42957543 & 19.0522103 \\
\hline & Cannabidiol $10 \mathrm{mg}$ & $15.448571^{*}$ & 1.72280239 & .000 & 10.4794642 & 20.4176787 \\
\hline & Pre treatment & 3.30464286 & 1.66809624 & .297 & -1.5066746 & 8.11596028 \\
\hline & SHAM & $14.490893^{*}$ & 1.66809624 & .000 & 9.67957543 & 19.3022103 \\
\hline \multirow[t]{4}{*}{ Pre treatment } & Control & $10.936250^{*}$ & 1.61153407 & .000 & 6.28807577 & 15.5844242 \\
\hline & Cannabidiol $10 \mathrm{mg}$ & $12.143929^{*}$ & 1.66809624 & .000 & 7.33261115 & 16.9552460 \\
\hline & Cannabidiol $1 \mathrm{mg}$ & -3.3046429 & 1.66809624 & .297 & -8.1159603 & 1.50667457 \\
\hline & SHAM & $11.186250^{*}$ & 1.61153407 & .000 & 6.53807577 & 15.8344242 \\
\hline \multirow[t]{4}{*}{ SHAM } & Control & -.25000000 & 1.61153407 & 1.000 & -4.8981742 & 4.39817423 \\
\hline & Cannabidiol $10 \mathrm{mg}$ & .957678571 & 1.66809624 & .978 & -3.8536389 & 5.76899599 \\
\hline & Cannabidiol $1 \mathrm{mg}$ & $-14.49089^{*}$ & 1.66809624 & .000 & -19.302210 & -9.6795754 \\
\hline & Pre treatment & $-11.18625^{*}$ & 1.61153407 & .000 & -15.834424 & -6.5380758 \\
\hline
\end{tabular}

*. The mean difference is significant at the 0.05 level. 
12. One-Way ANOVA para média em segundos do teste da geotaxia negativa 24, 48 e 96 horas após indução hemorrágica

\section{Oneway}

\begin{tabular}{|c|c|c|c|c|c|c|c|c|}
\hline \\
\hline & \multirow[b]{2}{*}{$\mathrm{N}$} & \multirow[b]{2}{*}{ Mean } & \multirow{2}{*}{$\begin{array}{c}\text { Std. } \\
\text { Deviation }\end{array}$} & \multirow[b]{2}{*}{ Std. Error } & \multicolumn{2}{|c|}{$\begin{array}{l}\text { 95\% Confidence Interval for } \\
\text { Mean }\end{array}$} & \multirow[b]{2}{*}{ Minimum } & \multirow[b]{2}{*}{ Maximum } \\
\hline & & & & & Lower Bound & Upper Bound & & \\
\hline Control & 8 & 22.2014583 & 7.82970612 & 2.76821915 & 15.6556602 & 28.7472565 & 11.5283333 & 35.2283333 \\
\hline Cannabidiol $10 \mathrm{mg}$ & 7 & 9.55333333 & 3.83259788 & 1.44858584 & 6.00877148 & 13.0978952 & 5.97333333 & 15.8333333 \\
\hline Pre treatment & 6 & 13.7294444 & 3.70929593 & 1.51431372 & 9.83677710 & 17.6221118 & 9.34166667 & 19.1000000 \\
\hline SHAM & 8 & 14.9443750 & 6.91677240 & 2.44544833 & 9.16180856 & 20.7269414 & 7.55500000 & 25.2083333 \\
\hline Total & 29 & 15.3936782 & 7.43715787 & 1.38104555 & 12.5647346 & 18.2226217 & 5.97333333 & 35.2283333 \\
\hline
\end{tabular}

\begin{tabular}{l|r|r|r|r|r}
\multicolumn{7}{c}{ ANOVA } & & \\
geo_media1 & $\begin{array}{l}\text { Sum of } \\
\text { Squares }\end{array}$ & df & Mean Square & \multicolumn{1}{c}{ F } & Sig. \\
\hline Between Groups & 627.767 & 3 & 209.256 & 5.680 & .004 \\
\hline Within Groups & 920.949 & 25 & 36.838 & & \\
\hline Total & 1548.717 & 28 & & & \\
\hline
\end{tabular}

\section{Post Hoc Tests}

\section{Multiple Comparisons}

Dependent Variable: geo_media 1 Tukey HSD

\begin{tabular}{|c|c|c|c|c|c|c|}
\hline \multirow[b]{2}{*}{ (I) Grupo } & \multirow[b]{2}{*}{ (J) Grupo } & \multirow{2}{*}{$\begin{array}{c}\text { Mean } \\
\text { Difference (I- } \\
\mathrm{J})\end{array}$} & \multirow[b]{2}{*}{ Std. Error } & \multirow[b]{2}{*}{ Sig. } & \multicolumn{2}{|c|}{ 95\% Confidence Interval } \\
\hline & & & & & Lower Bound & Upper Bound \\
\hline \multirow[t]{3}{*}{ Control } & Cannabidiol $10 \mathrm{mg}$ & $12.648125^{*}$ & 3.14122841 & .002 & 4.00772576 & 21.2885242 \\
\hline & Pre treatment & 8.47201389 & 3.27786679 & .071 & -.54422880 & 17.4882566 \\
\hline & SHAM & 7.25708333 & 3.03471496 & .105 & -1.0903354 & 15.6045020 \\
\hline \multirow[t]{3}{*}{ Cannabidiol $10 \mathrm{mg}$} & Control & $-12.64813^{*}$ & 3.14122841 & .002 & -21.288524 & -4.0077258 \\
\hline & Pre treatment & -4.1761111 & 3.37671908 & .610 & -13.464261 & 5.11203899 \\
\hline & SHAM & -5.3910417 & 3.14122841 & .337 & -14.031441 & 3.24935757 \\
\hline \multirow[t]{3}{*}{ Pre treatment } & Control & -8.4720139 & 3.27786679 & .071 & -17.488257 & .544228804 \\
\hline & Cannabidiol $10 \mathrm{mg}$ & 4.17611111 & 3.37671908 & .610 & -5.1120390 & 13.4642612 \\
\hline & SHAM & -1.2149306 & 3.27786679 & .982 & -10.231173 & 7.80131214 \\
\hline \multirow[t]{3}{*}{ SHAM } & Control & -7.2570833 & 3.03471496 & .105 & -15.604502 & 1.09033538 \\
\hline & Cannabidiol $10 \mathrm{mg}$ & 5.39104167 & 3.14122841 & .337 & -3.2493576 & 14.0314409 \\
\hline & Pre treatment & 1.21493056 & 3.27786679 & .982 & -7.8013121 & 10.2311732 \\
\hline
\end{tabular}

*. The mean difference is significant at the 0.05 level. 
13. One-Way ANOVA para média em segundos do teste de endireitamento 24, 48 e 96 horas após indução hemorrágica

\section{Oneway}

\begin{tabular}{|c|c|c|c|c|c|c|c|c|}
\hline \multicolumn{9}{|c|}{ escriptives } \\
\hline & \multirow[b]{2}{*}{$\mathrm{N}$} & \multirow[b]{2}{*}{ Mean } & \multirow{2}{*}{$\begin{array}{l}\text { Std. } \\
\text { Deviation }\end{array}$} & \multirow[b]{2}{*}{ Std. Error } & \multicolumn{2}{|c|}{$\begin{array}{l}\text { 95\% Confidence Interval for } \\
\text { Mean }\end{array}$} & \multirow[b]{2}{*}{ Minimum } & \multirow[b]{2}{*}{ Maximum } \\
\hline & & & & & Lower Bound & Upper Bound & & \\
\hline Control & 8 & 1.23604167 & .366095808 & .129434414 & .929977912 & 1.54210542 & .908333333 & 1.84833333 \\
\hline Cannabidiol $10 \mathrm{mg}$ & 7 & .817857143 & .164754909 & .062271502 & .665484266 & .970230020 & .656666667 & 1.10666667 \\
\hline Pre treatment & 6 & .838333333 & .087432514 & .035694174 & .746578537 & .930088129 & .751666667 & .966666667 \\
\hline SHAM & 8 & .966458333 & .152136732 & .053788458 & .839268842 & 1.09364782 & .770000000 & 1.25666667 \\
\hline Total & 29 & .978448276 & .275913681 & .051235884 & .873496325 & 1.08340023 & .656666667 & 1.84833333 \\
\hline
\end{tabular}

\begin{tabular}{|c|c|c|c|c|c|}
\hline \multirow{2}{*}{ end_media 1} & \multicolumn{4}{|c|}{ ANOVA } & \multirow[b]{2}{*}{ Sig. } \\
\hline & $\begin{array}{l}\text { Sum of } \\
\text { Squares }\end{array}$ & $\mathrm{df}$ & Mean Square & $\mathrm{F}$ & \\
\hline Between Groups & .830 & 3 & .277 & 5.317 & .006 \\
\hline Within Groups & 1.301 & 25 & .052 & & \\
\hline Total & 2.132 & 28 & & & \\
\hline
\end{tabular}

\section{Post Hoc Tests}

\section{Multiple Comparisons}

Dependent Variable: end_media1 Tukey HSD

\begin{tabular}{|c|c|c|c|c|c|c|}
\hline \multirow[b]{2}{*}{ (I) Grupo } & \multirow[b]{2}{*}{ (J) Grupo } & \multirow{2}{*}{$\begin{array}{c}\text { Mean } \\
\text { Difference (I- } \\
\mathrm{J})\end{array}$} & \multirow[b]{2}{*}{ Std. Error } & \multirow[b]{2}{*}{ Sig. } & \multicolumn{2}{|c|}{ 95\% Confidence Interval } \\
\hline & & & & & Lower Bound & Upper Bound \\
\hline \multirow[t]{3}{*}{ Control } & Cannabidiol $10 \mathrm{mg}$ & $.41818452^{*}$ & .118077882 & .008 & .093394375 & .742974672 \\
\hline & Pre treatment & $.39770833^{*}$ & .123214080 & .017 & .058790336 & .736626330 \\
\hline & SHAM & .269583333 & .114074072 & .111 & -.04419376 & .583360427 \\
\hline \multirow[t]{3}{*}{ Cannabidiol $10 \mathrm{mg}$} & Control & $-.4181845^{*}$ & .118077882 & .008 & -.74297467 & -.09339438 \\
\hline & Pre treatment & -.02047619 & .126929909 & .998 & -.36961511 & .328662729 \\
\hline & SHAM & -.14860119 & .118077882 & .597 & -.47339134 & .176188958 \\
\hline \multirow[t]{3}{*}{ Pre treatment } & Control & $-.3977083^{*}$ & .123214080 & .017 & -.73662633 & -.05879034 \\
\hline & Cannabidiol $10 \mathrm{mg}$ & .020476190 & .126929909 & .998 & -.32866273 & .369615109 \\
\hline & SHAM & -.12812500 & .123214080 & .728 & -.46704300 & .210792997 \\
\hline \multirow[t]{3}{*}{ SHAM } & Control & -.26958333 & .114074072 & .111 & -.58336043 & .044193761 \\
\hline & Cannabidiol $10 \mathrm{mg}$ & .148601190 & .118077882 & .597 & -.17618896 & .473391339 \\
\hline & Pre treatment & .128125000 & .123214080 & .728 & -.21079300 & .467042997 \\
\hline
\end{tabular}

*. The mean difference is significant at the 0.05 level. 
14. One-Way ANOVA para o tempo para abertura ocular nos ratos neonatais

\section{Oneway}

\begin{tabular}{|c|c|c|c|c|c|c|c|c|}
\hline \multicolumn{9}{|c|}{ Descriptives } \\
\hline bertura_ocular & \multirow[b]{3}{*}{$\mathrm{N}$} & & & & & & & \\
\hline & & \multirow[b]{2}{*}{ Mean } & \multirow{2}{*}{$\begin{array}{c}\text { Std. } \\
\text { Deviation }\end{array}$} & \multirow[b]{2}{*}{ Std. Error } & \multicolumn{2}{|c|}{$\begin{array}{c}\text { 95\% Confidence Interval for } \\
\text { Mean }\end{array}$} & \multirow[b]{2}{*}{ Minimum } & \multirow[b]{2}{*}{ Maximum } \\
\hline & & & & & Lower Bound & Upper Bound & & \\
\hline Control & 8 & 12.75 & .707 & .250 & 12.16 & 13.34 & 12 & 14 \\
\hline Cannabidiol $10 \mathrm{mg}$ & 7 & 12.86 & .900 & .340 & 12.03 & 13.69 & 12 & 14 \\
\hline Pre treatment & 6 & 12.83 & .753 & .307 & 12.04 & 13.62 & 12 & 14 \\
\hline SHAM & 8 & 12.75 & 1.282 & .453 & 11.68 & 13.82 & 11 & 15 \\
\hline Total & 29 & 12.79 & .902 & .167 & 12.45 & 13.14 & 11 & 15 \\
\hline
\end{tabular}

ANOVA

\begin{tabular}{|c|c|c|c|c|c|}
\hline & $\begin{array}{l}\text { Sum of } \\
\text { Squares }\end{array}$ & $d f$ & Mean Square & $\mathrm{F}$ & Sig. \\
\hline Between Groups & .068 & 3 & .023 & .025 & .995 \\
\hline Within Groups & 22.690 & 25 & .908 & & \\
\hline Total & 22.759 & 28 & & & \\
\hline
\end{tabular}

\section{Post Hoc Tests}

\section{Multiple Comparisons}

Dependent Variable: Abertura_ocular Tukey HSD

\begin{tabular}{|c|c|c|c|c|c|c|}
\hline \multirow[b]{2}{*}{ (I) Grupo } & \multirow[b]{2}{*}{ (J) Grupo } & \multirow{2}{*}{$\begin{array}{c}\text { Mean } \\
\text { Difference (I- } \\
\mathrm{J})\end{array}$} & \multirow[b]{2}{*}{ Std. Error } & \multirow[b]{2}{*}{ Sig. } & \multicolumn{2}{|c|}{ 95\% Confidence Interval } \\
\hline & & & & & Lower Bound & Upper Bound \\
\hline \multirow[t]{3}{*}{ Control } & Cannabidiol $10 \mathrm{mg}$ & -.107 & .493 & .996 & -1.46 & 1.25 \\
\hline & Pre treatment & -.083 & .515 & .998 & -1.50 & 1.33 \\
\hline & SHAM & .000 & .476 & 1.000 & -1.31 & 1.31 \\
\hline \multirow[t]{3}{*}{ Cannabidiol $10 \mathrm{mg}$} & Control & .107 & .493 & .996 & -1.25 & 1.46 \\
\hline & Pre treatment & .024 & .530 & 1.000 & -1.43 & 1.48 \\
\hline & SHAM & .107 & .493 & .996 & -1.25 & 1.46 \\
\hline \multirow[t]{3}{*}{ Pre treatment } & Control & .083 & .515 & .998 & -1.33 & 1.50 \\
\hline & Cannabidiol $10 \mathrm{mg}$ & -.024 & .530 & 1.000 & -1.48 & 1.43 \\
\hline & SHAM & .083 & .515 & .998 & -1.33 & 1.50 \\
\hline \multirow[t]{3}{*}{ SHAM } & Control & .000 & .476 & 1.000 & -1.31 & 1.31 \\
\hline & Cannabidiol $10 \mathrm{mg}$ & -.107 & .493 & .996 & -1.46 & 1.25 \\
\hline & Pre treatment & -.083 & .515 & .998 & -1.50 & 1.33 \\
\hline
\end{tabular}


15. One-Way ANOVA para percentual de movimentos corretos durante teste com labirinto em Y 10 dias após indução hemorrágica

\section{Oneway}

\begin{tabular}{|c|c|c|c|c|c|c|c|c|}
\hline & & & & escriptiv & & & & \\
\hline maze_perc & & & & & & & & \\
\hline & & & & & $95 \%$ Confider & $\begin{array}{l}\text { e Interval for } \\
\text { an }\end{array}$ & & \\
\hline & $\mathrm{N}$ & Mean & Deviation & Std. Error & Lower Bound & Upper Bound & Minimum & Maximum \\
\hline Control & 8 & .601762821 & .136146293 & .048134984 & .487941671 & .715583970 & .363636364 & .800000000 \\
\hline Cannabidiol $10 \mathrm{mg}$ & 7 & .657689929 & .169287332 & .063984597 & .501125260 & .814254598 & .500000000 & 1.00000000 \\
\hline Pre treatment & 6 & .538955026 & .230318830 & .094027269 & .297250238 & .780659815 & .200000000 & .777777778 \\
\hline SHAM & 8 & .566729625 & .172102162 & .060847303 & .422848617 & .710610632 & .357142857 & .857142857 \\
\hline Total & 29 & .592603421 & .171882150 & .031917714 & .527222948 & .657983895 & .200000000 & 1.00000000 \\
\hline
\end{tabular}

ANOVA

\begin{tabular}{|c|c|c|c|c|c|}
\hline & $\begin{array}{l}\text { Sum of } \\
\text { Squares }\end{array}$ & df & Mean Square & $\mathrm{F}$ & Sig. \\
\hline Between Groups & .053 & 3 & .018 & .570 & .640 \\
\hline Within Groups & .774 & 25 & .031 & & \\
\hline Total & .827 & 28 & & & \\
\hline
\end{tabular}

\section{Post Hoc Tests}

\section{Multiple Comparisons}

Dependent Variable: Y_maze_perc Tukey HSD

\begin{tabular}{|c|c|c|c|c|c|c|}
\hline \multirow[b]{2}{*}{ (I) Grupo } & \multirow[b]{2}{*}{ (J) Grupo } & \multirow{2}{*}{$\begin{array}{c}\text { Mean } \\
\text { Difference (I- } \\
\mathrm{J})\end{array}$} & \multirow[b]{2}{*}{ Std. Error } & \multirow[b]{2}{*}{ Sig. } & \multicolumn{2}{|c|}{ 95\% Confidence Interval } \\
\hline & & & & & Lower Bound & Upper Bound \\
\hline \multirow[t]{3}{*}{ Control } & Cannabidiol $10 \mathrm{mg}$ & -.05592711 & .091080878 & .927 & -.30645813 & .194603909 \\
\hline & Pre treatment & .062807794 & .095042750 & .911 & -.19862092 & .324236507 \\
\hline & SHAM & .035033196 & .087992488 & .978 & -.20700276 & .277069153 \\
\hline \multirow[t]{3}{*}{ Cannabidiol $10 \mathrm{mg}$} & Control & .055927109 & .091080878 & .927 & -.19460391 & .306458126 \\
\hline & Pre treatment & .118734903 & .097909002 & .625 & -.15057785 & .388047654 \\
\hline & SHAM & .090960305 & .091080878 & .752 & -.15957071 & .341491322 \\
\hline \multirow[t]{3}{*}{ Pre treatment } & Control & -.06280779 & .095042750 & .911 & -.32423651 & .198620919 \\
\hline & Cannabidiol $10 \mathrm{mg}$ & -.11873490 & .097909002 & .625 & -.38804765 & .150577849 \\
\hline & SHAM & -.02777460 & .095042750 & .991 & -.28920331 & .233654115 \\
\hline \multirow[t]{3}{*}{ SHAM } & Control & -.03503320 & .087992488 & .978 & -.27706915 & .207002761 \\
\hline & Cannabidiol 10 mg & -.09096030 & .091080878 & .752 & -.34149132 & .159570713 \\
\hline & Pre treatment & .027774598 & .095042750 & .991 & -.23365411 & .289203311 \\
\hline
\end{tabular}


16. One-Way ANOVA para percentual do tempo de exploração do objeto novo no teste de reconhecimento de objetos 12 dias após indução hemorrágica

\section{Oneway}

\section{Warnings}

Post hoc tests are not performed for explora_novo

because there are fewer than three groups.

\section{Descriptives}

\begin{tabular}{|c|c|c|c|c|c|c|c|c|}
\hline & \multirow[b]{2}{*}{ v } & \multirow[b]{2}{*}{ Mean } & \multirow{2}{*}{$\begin{array}{l}\text { Std. } \\
\text { Deviation }\end{array}$} & \multirow[b]{2}{*}{ Std. Error } & \multicolumn{2}{|c|}{$\begin{array}{c}\text { 95\% Confidence Interval for } \\
\text { Mean }\end{array}$} & \multirow[b]{2}{*}{ Minimum } & \multirow[b]{2}{*}{ Maximum } \\
\hline & & & & & Lower Bound & Upper Bound & & \\
\hline Control & 8 & .578274283 & .154370650 & .054578267 & .449217190 & .707331376 & .411840000 & .818713450 \\
\hline SHAM & 7 & .508989052 & .175256299 & .066240655 & .346904008 & .671074095 & .141843972 & .646482636 \\
\hline Total & 15 & .545941175 & .162353750 & .041919558 & .456032665 & .635849685 & .141843972 & .818713450 \\
\hline
\end{tabular}

ANOVA

\begin{tabular}{|c|c|c|c|c|c|}
\hline & $\begin{array}{l}\text { Sum of } \\
\text { Squares }\end{array}$ & $\mathrm{df}$ & Mean Square & $\mathrm{F}$ & Sig. \\
\hline Between Groups & .018 & 1 & .018 & .664 & .430 \\
\hline Within Groups & .351 & 13 & .027 & & \\
\hline Total & .369 & 14 & & & \\
\hline
\end{tabular}


Apêndice B. Artigo publicado na revista Neurological Research 


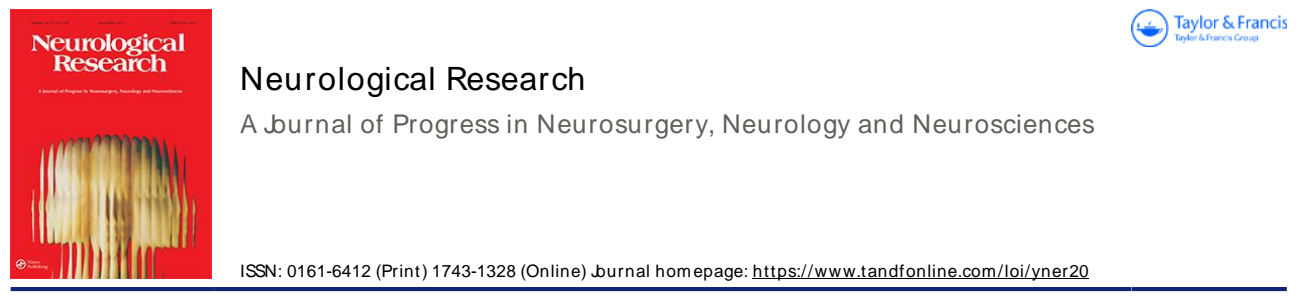

\section{Intraperitoneal cannabidiol attenuates neonatal germinal matrix hemorrhage-induced neuroinflamtion and perilesional apoptosis}

Timóteo Abrantes De Lacerda Alm eida, Marcelo Volpon Santos, Luiza Da Silva Lopes, Gunjan Goel, Renato Leonardo De Freitas, Priscila De Medeiros, bsé Alexandre Crippa \& Hélio Rubens Machado

To cite this article: Timóteo Abrantes De Lacerda Almeida, Marcelo Volpon Santos, Luiza Da Silva Lopes, Gunjan Goel, Renato Leonardo De Freitas, Priscila De Medeiros, José Alexandre Crippa \& Hélio Rubens Machado (2019): Intraperitoneal cannabidiol attenuates neonatal germinal matrix hemorrhage-induced neuroinflamtion and perilesional apoptosis, Neurological Research, DOI: 10.1080/01616412.2019.1651487

To link to this article: https://doi.org/10.1080/01616412.2019.1651487

Published online: 05 Aug 2019

Submit your article to this journal $\square$

Q View Crossmark data $\smile$ 


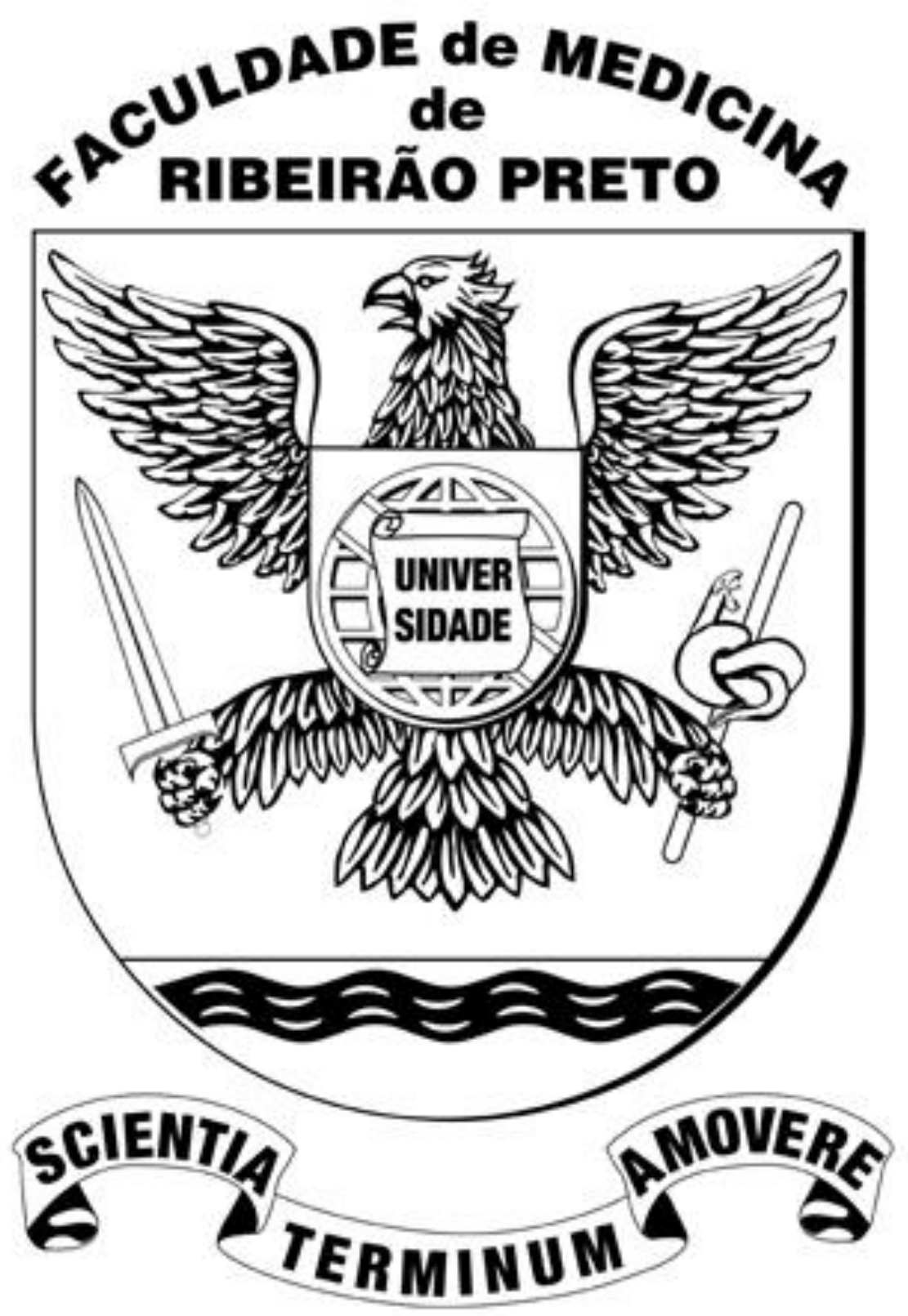

